\title{
6
}

\section{Gastrointestinal Infections}

\section{Gastroenteritis}

Gastrointestinal infections are second only to respiratory infectious diseases in frequency and morbidity. A conservative estimate places the annual worldwide mortality from gastroenteritis-related infections at six million children. Although stomatitis and esophagitis are occasionally seen as distinct entities, the vast majority of gastrointestinal infections manifest as vomiting and/or diarrhea syndromes, commonly referred to as gastroenteritis. In many cases the term "enterocolitis" describes the pathologic and clinical features more accurately.

\section{Epidemiology}

Diarrhea is most pronounced in communities where undernutrition, poor hygiene, and poorly developed community facilities for sewage and drinking water exist. In such communities, as recently described for Bangladesh, the peak incidence of diarrhea syndromes occurs between 2 and 11 months of age, and most infants in their first year of life can be expected to have seven episodes of gastroenteritis. ${ }^{38}$ Expression and frequency of infection are related to decreased host resistance secondary to nutritional deficiencies, and increased spread referable to crowded living quarters, contaminated water and food, inadequate washing and toilet facilities, abundant flies, and inadequate refrigeration and cooking technology.

Young infants are most prone to the dehydrating and debilitating effects of acute gastroenteritis and have the highest attack rates. Some organisms, such as Shigella, predominate in the summer and fall months, whereas others, such as rotavirus, are frequent in the winter months in temperate climates ${ }^{53}$ and year-round in the tropics. ${ }^{38}$ Campylobacter and enterotoxigenic $E$. coli are also very prevalent in such areas. ${ }^{94}$ 
In developed countries, diarrhea outbreaks occur in day-care centers ${ }^{297}$ and other institutions, as well as in the community. ${ }^{261}$ Here the same problems of hygiene, crowding, frequent direct contact, and inappropriate disposal of waste contribute to the scope of the problem. In North America, such outbreaks are most frequently seen in infants under 2 years of age, and in large day-care centers or in those that place less emphasis on space, hygiene, and adequate numbers of staff. The most virulent organisms (i.e., those that can cause disease with the smallest inoculum) are frequently responsible. These include Shigella, Giardia, ${ }^{347}$ and rotavirus, and are also among the most frequent gastrointestinal pathogens worldwide. Rarely, $C$. difficile may be causative. ${ }^{197}$

Many mechanisms of spread may be involved. For example, Norwalk virus may be foodborne, waterborne, or spread from person to person. ${ }^{186}$ In fact, two of these mechanisms were involved in an outbreak after exposure occurring in a swimming pool. ${ }^{187}$

\section{Pathogenesis}

Host factors important in the pathogenesis of gastroenteritis include young age, wasting (i.e., low weight in relation to height), and poor hygiene. In addition to frequency, the duration of illness is also increased in malnourished children. ${ }^{385}$ The interplay of nutrition and infection is a remarkably constant feature in the pathogenesis of gastroenteritis and its complications. Patients with reduced stomach acid secretion are also at increased risk for salmonellosis and toxigenic diarrheas. ${ }^{268}$

Acquired immunity to gastrointestinal infections is often very specific for the individual serotype of bacteria or strain of virus, and can be quite short-lived. For example, gastrointestinal immunity provided by breast milk is often effective, probably due to its content of secretory $\operatorname{IgA}$, but is not expected to last beyond the breast-feeding period. ${ }^{61}$ Both humoral and secretory immune mechanisms are usually involved in recovery from enteric infections but their respective roles in prevention are not completely understood.

Characteristics of the infecting organism also play important roles in the pathogenesis of infectious diarrhea. The major pathogenic mechanisms described include adherence (i.e., the ability of the pathogens to attach to the gastrointestinal epithelial cell), invasion (i.e., the ability of the organism to enter the cell and thereby bring about its destruction), toxin production (many different toxins are produced), and stimulation of inflammatory responses. ${ }^{105}$ It is likely that other mechanisms remain to be described.

Adherence seems particularly significant for $E$. coli and has recently been described in strains of these bacteria associated with chronic diarrhea syndromes of infancy. ${ }^{75}$ One of the modes of action of breast milk 
and locally produced secretory immunoglobulins may be to prevent attachment of bacteria to the intestinal epithelial cells. At least three accessory virulence structures have been identified on the surface of human isolates of enterotoxic $E$. coli. ${ }^{110}$ The complex interaction of these components, fimbriae (pili), colonization factor antigens, and the gastrointestinal surface involves chemotaxis, penetration of mucus, adhesion to mucus and cell receptors, and bacterial multiplication. Insight into host defenses includes descriptions of natural inhibition, secretory IgA, competition for attachment sites and nutrients, and alterations in epithelial cell receptors associated with rapid cell turnover. Unravelling these mysteries may provide the basis for future preventive measures and treatments.

Invasive organisms include Salmonella and Shigella, although in the strictest sense, viruses, Entamoeba histolytica, and Giardia lamblia should be considered invasive as well. That is because these organisms have in common the ability to cause considerable cell destruction and ulceration of the intestinal mucosa. Cellular invasion cannot always be correlated with invasion of the bacteria beyond the gastrointestinal tract. Hence, bacteremia is frequently seen with Salmonella but is uncommon with Shigella infections, despite the fact that both organisms have the capacity to invade cells. There is no satisfactory explanation for this difference, although it may relate to the ability of some strains of Salmonella to resist phagocytosis and/or intracellular killing.

Enterotoxins are important in the pathogenesis of diarrhea due to $E$. coli, Staphylococcus aureus, Clostridium perfringens, Vibrio cholerae, and possibily even Pseudomonas aeruginosa, Aeromonas hydrophila, and Campylobacter. ${ }^{326}$ These toxins can act in several ways. ${ }^{63}$ The actions of cholera and E. coli toxins are similar, with their net effect being a hypersecretion of fluid and electrolytes into the lumen of the bowel. Despite this similarity, the stool content of sodium is more concentrated with cholera than it is with enterotoxigenic E. coli. ${ }^{260}$ The most active enterotoxins (those elaborated by Vibrio cholerae, E. coli, and Staphylococcous aureus) are heat-labile. The functions of heat-stable enterotoxins (E. coli, Yersinia enterocolitica) are not well understood. ${ }^{286}$ It is also interesting that enterotoxigenic $E$. coli plays only a minor role in the pathogenesis of diarrhea in North America, yet is extremely important in the pathogenesis of diarrhea in developing countries. This may be one of the reasons why traveler's diarrhea (commonly caused by enterotoxigenic $E$. coli) is such a severe illness in visitors from developed countries. Another enigma concerns the role of $C$. difficile toxins ${ }^{101}$ in the pathogenesis of pediatric gastroenteritis. Although these substances are either enterotoxic or cytotoxic, or both, by laboratory analysis, they are often found in the stools of asymptomatic subjects, particularly in newborns and infants. ${ }^{236}$

The pathogenesis and etiology of diarrhea syndromes are dynamic 
features. This is related to community spread of these organisms, the effects of travel, the effects of antibiotic therapy in humans and in animal feeds, and the fact that many of the pathogenic mechanisms are under plasmid control. ${ }^{105}$ For example, the control of adherence (colonization factor antigens) and enterotoxins is related to genes contained in plasmids that can be transferred between diverse bacteria. Thus classic bacterial enteropathogens may develop new clinical features (indicative of the acquisition of a new mechanism of pathogenesis), or organisms that are not usually enteropathogenic are associated with outbreaks of diarrhea.

\section{Etiology}

As in respiratory infections, the most common causes of gastroenteritis are viruses ${ }^{336}$ Another parallel also exists-that is the fact that as many as $45 \%$ of cases of gastroenteritis have no defined etiology. The common causes of diarrhea are outlined in Table 6-1. This list is remarkably consistent around the world, with some exceptions. Parasitic causes of diarrhea and cholera are more common in tropical climates, where amebiasis and hookworm infestations abound. Shigella is also more frequently seen in warmer climates whereas Salmonella, Campylobacter, and Yersinia are more characteristic of temperate and colder climates.

Worldwide, cholera and rotavirus are the commonest causes of gastroenteritis in all populations ${ }^{38}$ Much information about Norwalk agent, a small 27-nm parvovirus-like particle, and its subtypes, is derived from North American studies, and its global impact has not been well examined. ${ }^{204}$ Similarly, new information about noncultivatable adenoviruses has reawakened earlier speculation that these agents play an important role in the pathogenesis of gastroenteritis. ${ }^{415}$ Older studies, employing classic tissue culture techniques, suggested that the frequencies of adenovirus isolation in children with diarrhea and well children were similar, but recent surveys, using electron microscopy, ${ }^{46}$ dispute these findings, based on the frequency of noncultivatable adenoviruses in the stools of the symptomatic patients. ${ }^{313}$ Undoubtedly, ECHO and coxsackie viruses can also cause outbreaks of gastroenteritis, although considerable numbers of patients acquire and transiently excrete these agents without symptoms. ${ }^{40}$ These may be immune subjects, and the situation may be somewhat analogous to other carrier states, such as described with Haemophilus influenzae, Neisseria meningitidis, and even rotavirus. ${ }^{72}$

Newer candidates as causes for diarrhea include Aeromonas hydrophila, ${ }^{58}$ Aeromonas sobria, ${ }^{66}$ Bacillus cereus, ${ }^{165}$ Plesiomonas shigelloides, ${ }^{328}$ Cryptosporidium, ${ }^{179}$ and newer, incompletely characterized viral agents (e.g., calicivirus, ${ }^{88}$ Snow Mountain agent, ${ }^{100}$ coronavirus, and minirotavirus $\left.{ }^{366}\right)$. Some of these viruses, such as calicivirus, may be responsible for clinical outbreaks previously characterized as winter vomiting disease. ${ }^{89}$ The roles 
TABLE 6-1. Common Causes of Acute Infectious Diarrhea

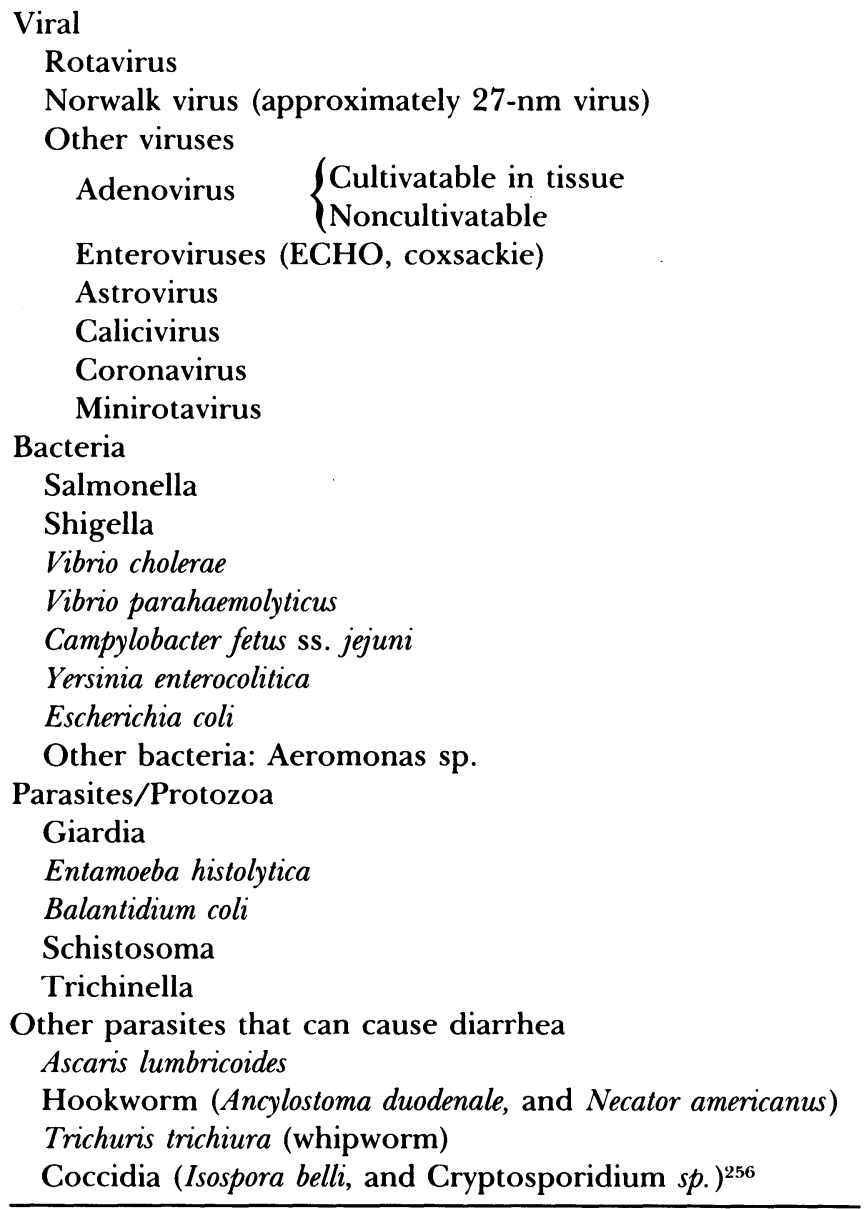

of yeasts, Pseudomonas, and other stool flora, present in high concentrations in the gastrointestinal tract, remain controversial. Even Streptococcus pyogenes has been associated with dysentery. ${ }^{307}$

Although Clostridium difficile is clearly identified as a cause of pseudomembranous colitis, ${ }^{394}$ even in infants, ${ }^{4}$ its role in the pathogenesis of antibiotic-associated colitis, ${ }^{116}$ necrotizing enterocolitis, chronic diarrhea, and other gastroenteritis syndromes in children is unclear. ${ }^{402}$ Part of the confusion derives from the frequent cultivation of this organism and/or detection of its toxin in the stools of normal newborns, infants, ${ }^{82}$ and children. ${ }^{382}$ Moreover, pseudomembranous colitis can clearly occur in the absence of $C$. difficile. ${ }^{295}$ 
Gastroenteritis can be grouped according to several different criteria. Table 6-2 describes the etiologies encountered in outbreaks of common source. Some cases are due predominantly to preformed toxins, as seen with staphylococcal infections. Others are associated with ingestion of large numbers of bacteria that have multiplied in the food product; this is seen with Clostridium perfringens, ${ }^{355}$ Bacillus cereus, ${ }^{165}$ Salmonella, and $E$. coli. ${ }^{381}$ Vibrio parahaemolyticus, V. fluvialis, ${ }^{377}$ and $V$. vulnificus ${ }^{177}$ should be kept in mind when travelers or others report ingestion of raw shellfish, and Edwardsiella in association with ornamental fish. ${ }^{387}$ Occasionally, the cause is not directly infectious, but secondary to the capacity of certain bacteria (e.g., Morganella) to convert histidine in tuna or other fish (called scombroid fish poisoning). The released histamine-like substance can cause afebrile gastroenteritis. ${ }^{14}$

Ascaris lumbricoides is one of the most prevalent parasites worldwide, and children have high rates of infection. Most are asymptomatic, however, and acute and chronic diarrhea are rare features of ascariasis, although vomiting may accompany intestinal obstruction. ${ }^{398}$ Sometimes adult worms are seen in the vomitus; enough, in some cases, to look like spaghetti. Biliary obstruction, malnutrition, and hypersensitivity pneumonitis may also result. The diagnosis is usually made by visualization of ascaris eggs in the stool. Treatment with piperazine is highly effective (Chapter 2).

Occasionally larvae (e.g., myiasis) and worms, such as Dipylidium caninum (dog tapeworms), are seen in the stools of asymptomatic infants or children. ${ }^{237}$ Irritability, restlessness, anorexia, poor weight gain, pruritus, and abdominal pain may occur. ${ }^{154}$ A single dose of niclosamide (see Chapter 2) is curative.

The diagnosis and management of other intestinal nematodes (hookworms, tapeworms, pinworms, Strongyloides, Trichuris, and Capillaria) have been recently summarized ${ }^{77}$ and are also considered in Chapter 2. Eosinophilia in association with peptic ulcer symptoms suggests the possibility of strongyloidiasis. ${ }^{196}$ Some of these children may have asthma as well. $^{18}$

As detailed above, epidemiologic history can be important in suggesting the etiology. Thus, information about travel, attendance at day-care centers, common food or water exposure, diarrhea in other family and community members, and the season of the year is useful. ${ }^{147}$

Chronic diarrhea (variably defined as lasting more than 2 weeks, or more than a month) has many causes, most of which are noninfectious. ${ }^{126}$ Giardia is probably the most common direct infectious cause of chronic diarrhea but still is less frequently responsible than postinfectious intolerances due to mucosal damage and acquired disaccharidase deficiency. Occasionally, Campylobacter, Mycobacterium tuberculosis, ${ }^{140.303}$ Salmonella, adherent enteropathogenic E. coli, ${ }^{75} C$. difficile, ${ }^{224}$ Yersiniae, or amoebae may be responsible. The role of some parasites, such as Dientamoeba fragilis, 


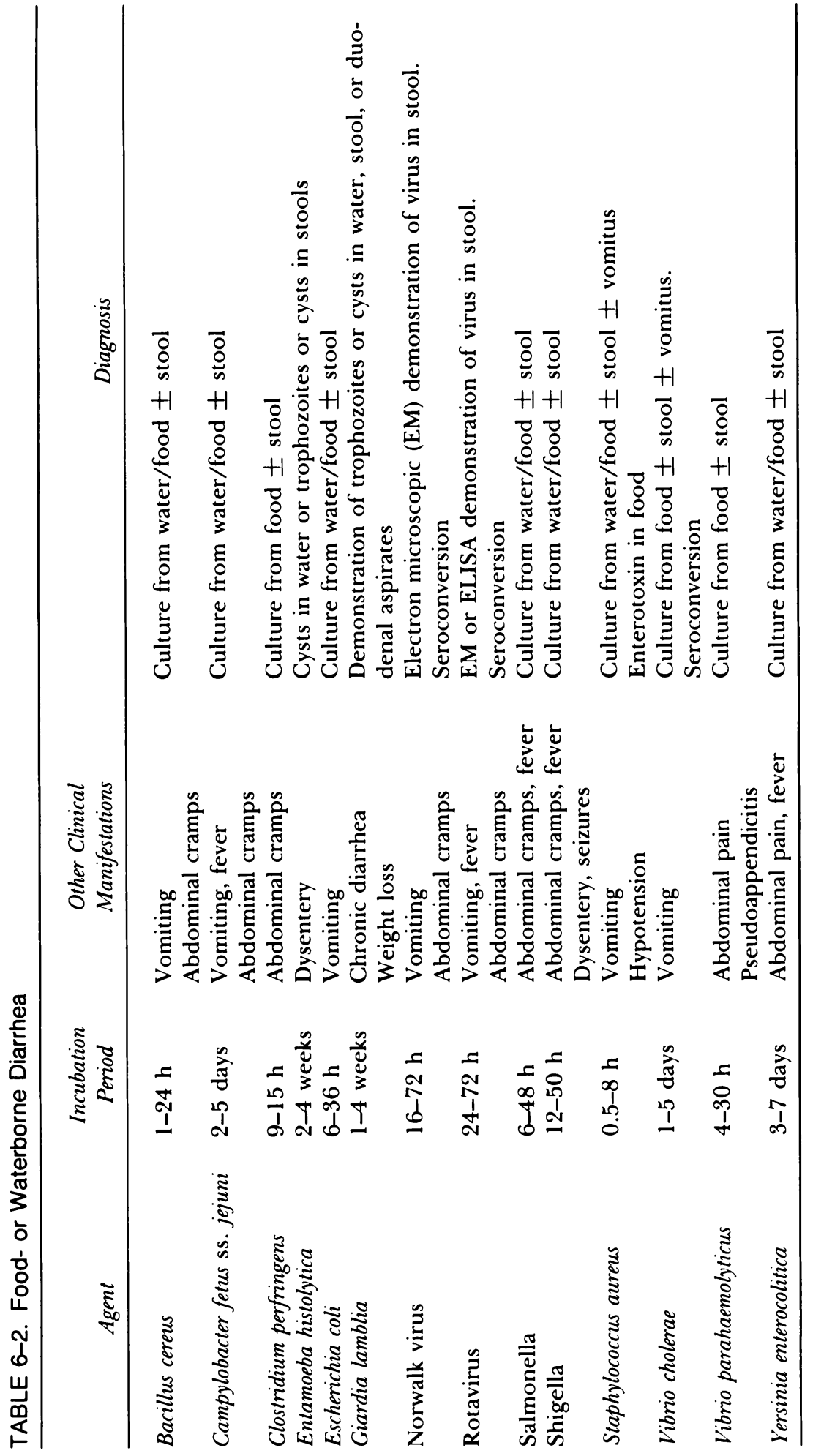


in the pathogenesis of diarrhea is unclear. A therapeutic trial of diiodohydroxyquin $40 \mathrm{mg} / \mathrm{kg} /$ day for 20 days has been suggested for selected cases, but only after exclusion of more conventional causes of diarrhea. ${ }^{191}$ In the strictest sense, contaminated small bowel syndromes (colonic flora in the small bowel) secondary to congenital or acquired obstructions, malrotations, etc. (often seen after gastrointestinal surgery) could be considered infectious. Gastrointestinal coccidiosis (Cryptosporidium or Isospora) suggests the presence of cellular immunodeficiency conditions, including AIDS, in which these infections may also be associated with salmonellosis and candidiasis. ${ }^{12}$ Causes of noninfectious diarrhea are listed in Table 6-3.

\section{Clinical Manifestations}

The predominant signs of gastrointestinal infection are vomiting and diarrhea. Vomiting is more frequently seen with rotavirus and Norwalk agent infections and less common with most bacterial and parasitic causes of diarrhea. Vomiting usually precedes diarrhea and is more short-lived, rarely lasting more than 1-2 days. It is useful to describe diarrhea as either "cholera-like" (watery) or "dysentery-like" (mucus and/or blood). The former is more characteristic of toxigenic causes of diarrhea (e.g., cholera, enterotoxigenic $E$. coli), and the latter more frequently seen with invasive infection (e.g., amebiasis, shigellosis, and Campylobacter gastroenteritis). Recently, a dysentery syndrome with severe cramping abdominal pain and grossly bloody stools has been described due to $E$. coli. ${ }^{318}$ Salmonella, Vibrio parahemolyticus, and Yersinia enterocolitica infections often result in production of greenish stool (sometimes described as "peasoup-like") without the above features. In this way, description of the stools allows more specific inquiry into cause and can guide the clinician in selecting diagnostic procedures and management.

Other signs of gastroenteritis include fever, which commonly precedes Shigella, Campylobacter, and Yersinia infections. It is also present in over $90 \%$ of infants with rotavirus diarrhea. ${ }^{336}$ Conversely, it is uncommon in school-age children with Norwalk agent gastroenteritis and may also be absent in parasitic gastroenteritis. Some of the characteristics of gastroenteritis associated with food or water-borne outbreaks of diarrhea are listed in Table 6-2. Perianal pruritus and worms in the stool may be the only signs of the presence of pinworms (Enterobius vermicularis) in the gastrointestinal tract, but, occasionally, appendicitis, and even salpingitis and peritonitis may occur. ${ }^{292}$

Selected features of diarrhea syndromes are summarized in Table 64. Other manifestations may reflect extragastrointestinal involvement. Hence, bacteremia is common and rose spots can occasionally be seen with Salmonella (and rarely, Shigella), ${ }^{139}$ visceromegaly with leishmaniasis, anemia with hookworm infection, and severe abdominal pain with 
TABLE 6-3. Noninfectious Causes of Diarrhea

Drugs and chemicals including antibiotics

Postinfectious

Secondary disaccharidase deficiency, intolerances, bile salt malabsorption

Inflammatory bowel disease

Ulcerative colitis

Regional enteritis

Psychogenic

Neoplastic

Carcinoid

Neuroblastoma

Zollinger-Ellison

Ganglioneuroma

Anatomic: congenital

Malrotation

Hirschsprung

Postsurgical

Blind loop syndrome

Short bowel syndrome

Malabsorption

Sprue syndromes, celiac disease

Pancreatic insufficiency

Cystic fibrosis

Shwachman syndrome

Carbohydrate intolerance

Lactose

Sucrose-isomaltose

Monosaccharide

Protein intolerance

Allergy

Enterokinase deficiency

Trypsinogen deficiency

Amino-acidopathies

Allergic

Cow's milk protein

Endocrine-metabolic

e.g., Hyperthyroid states, hypoadrenalism

Antibody deficiency syndromes

Acrodermatitis enteropathica

Benign lymphatic hyperplasia of the rectum

Diet

Candy containing hexitols

Idiopathic acute and persistent diarrheas 


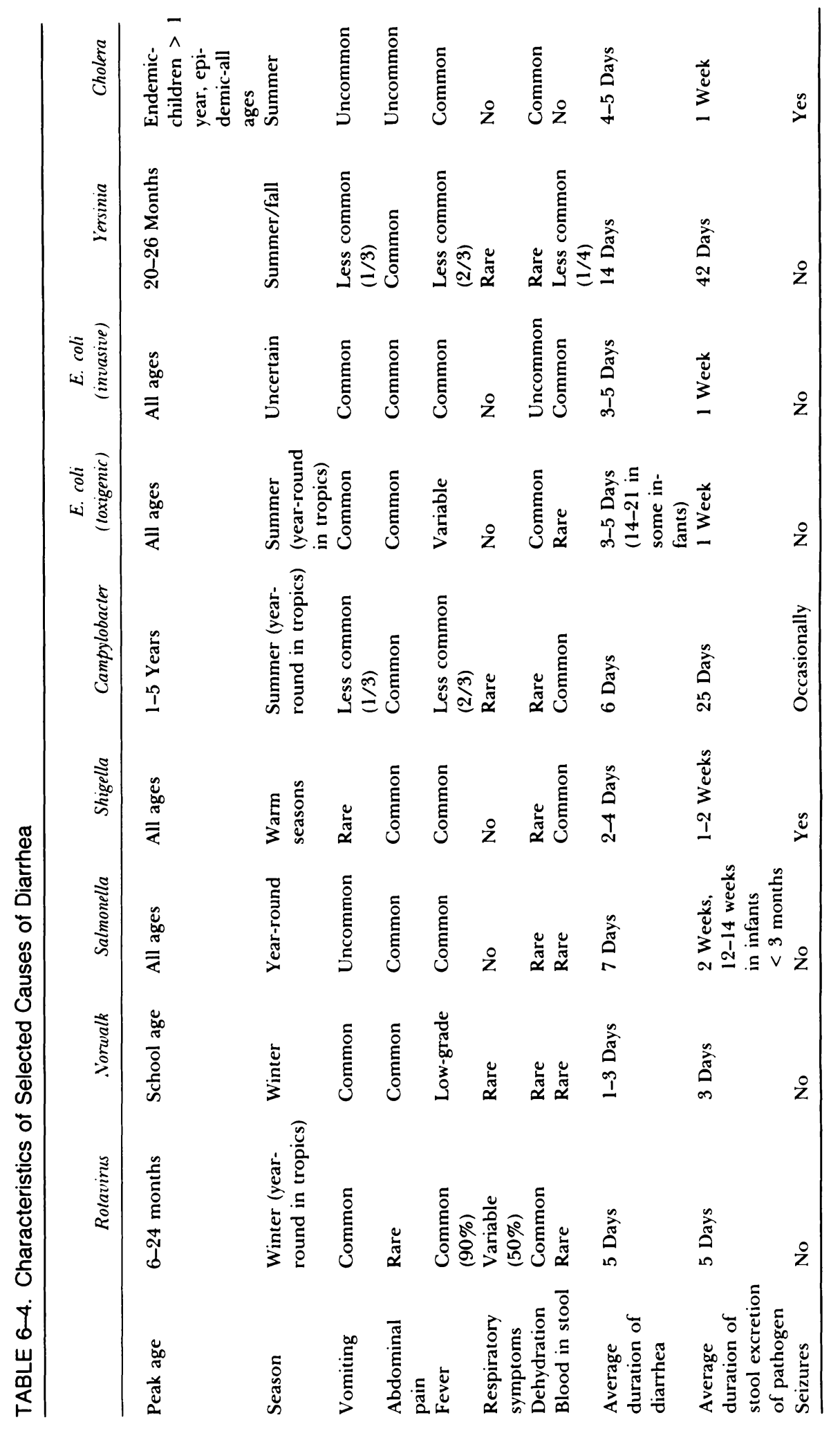


Yersinia ${ }^{241}$ and Campylobacter infection, ${ }^{102}$ both presumably due to mesenteric lympadenitis. In fact, the abdominal pain can be so severe in these infections that "pseudoappendicitis" syndromes are described, leading to exploratory laparotomy and appendectomy in many patients..$^{39}$ Other clinical manifestations, such as meningismus and seizures with shigellosis, are frequently observed, although their pathogenesis is not completely understood. ${ }^{24}$ The diagnostic possibility of gastroenteritis may be forgotten when the earliest clinical manifestations are fever or seizures. We see this situation often in nosocomial gastroenteritis and shigellosis, respectively. Long-term carrier states are common in adults (not in children) with Salmonella but rare with Shigella ${ }^{220}$ and other enteric pathogens (except Entamoeba histolytica, where asymptomatic patients who excrete cysts are encountered). Excretion of Salmonella in the stools of recovering young infants may be noted for a 2-3-month period. ${ }^{193}$

\section{Diagnosis}

As outlined in Table 6-2, outbreaks of common source, the duration of the incubation period, and the clinical manifestations may suggest the etiologic diagnosis. This is also clear (but too frequently forgotten) in a situation where one family member has a Shigella infection and another develops gastroenteritis. What is less easy to diagnose is the sporadic case of gastroenteritis in the community, or the traveler who returns from a trip to a tropical climate where several enteropathogens predominate. ${ }^{111}$

Before discussing specific diagnostic tests, it seems worthwhile to ask when to investigate the etiology of diarrhea. Since the vast majority of gastrointestinal infections are self-limited and benign, and due to viruses and other agents not responsive to specific therapy, most cases require little laboratory investigation in the first few days of illness. Exceptions include the newborn, the immunologically abnormal host, the severely ill individual, and the patient with a prolonged or atypical course of illness. For example, the child with sickle-cell anemia is particularly prone to invasion and extragastrointestinal infection by Salmonella. ${ }^{122}$ Yersinia, Campylobacter, Shigella, ${ }^{118}$ and Salmonella may also be problems for patients with leukemia and those receiving immunosuppressive drugs. If the patient does not have fever, or there is no clear history of travel or contact with infection, or the cause of illness seems atypical, noninfectious causes of diarrhea should also be considered (Table 6-3).

Laboratory procedures useful in the diagnosis of the specific cause of diarrhea include microbiologic techniques for culturing enteroviruses and bacteria, and examination of stool for ova and parasites (Table 6-5). Familiarity with the growth requirements and colonial morphology of the enteric bacilli is critical (Fig. 6-1). The gram or $1 \%$ aqueous basic fuchsinstained stool smear may be useful if large quantities of vibrio-shaped organisms are $\operatorname{seen}^{346}$ (Fig. 6-2). This can point to a diagnosis of cam- 
Rapid methods

Rotavirus antigen-ELISA method

Rotavirus

Norwalk virus

Adenovirus

Electron microscopy

Other viruses

Campylobacter/Vibrio: Gram stain

C. difficile toxins-ELISA or CIE

Parasites: smear

Selective/enrichment media helpful

C. difficile: Cycloserine, cefoxitin agar

Yersinia enterocolitica: Cold enrichment in phosphate-buffered saline

Campylobacter: Skirrow's medium, incubation at $42^{\circ} \mathrm{C}$

Salmonella: Selinite broth

Shigella: Hektoen enteric agar

Vibrio: Thiosulfate-citrate-bile salts

pylobacteriosis, Vibrio cholerae, or Vibrio parahemolyticus. Methylene blue stain of the stool can also be useful, since polymorphonuclear leukocytes are rarely seen with viral pathogens, amebiasis, or toxigenic bacteria. ${ }^{298}$ An exception to this is pseudomembranous colitis, thought to be due to toxigenic $C$. difficile, yet also associated wtih colonic ulceration, pseudomembrane formation, and polymorphonuclear leukocytes in tissue and stool. Stool leukocytes in normal children with diarrhea are seen with Shigella, early Salmonella, Yersinia, ${ }^{229}$ Campylobacter ${ }^{228}$ infections, and with amebiasis.

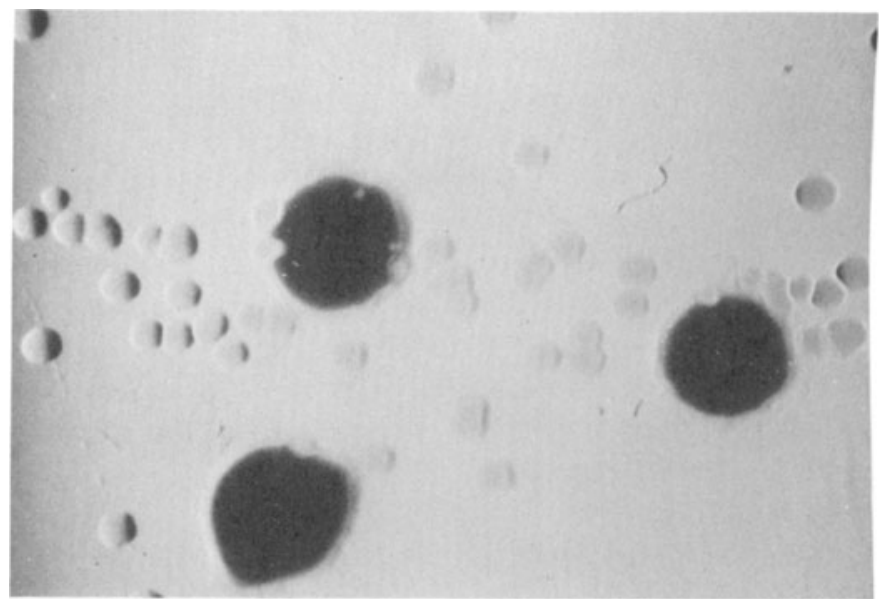

Figure 6-1. Small lactose-negative colonies of Yersinia enterocolitica adjacent to large lactose-positive E. coli. 


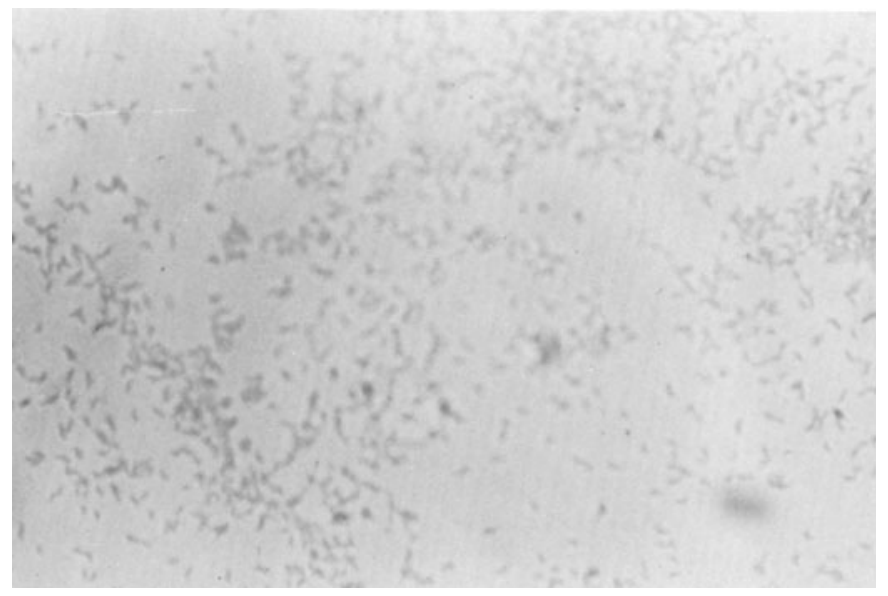

Figure 6-2. Gram stain of Campylobacter fetus.

Enzyme-linked immunosorbent assay (ELISA) is used for the rapid detection of rotavirus antigen in stool. ${ }^{368}$ Electron microscopy can also be used and is more accurate in newborns than the rotazyme. ${ }^{205}$ Other viral causes of diarrhea, such as Norwalk agent, noncultivatable adenoviruses, calicivirus, etc., can be directly visualized by electron microscopy of stool, or diagnosed indirectly by means of serology. ${ }^{147}$ Serologic diagnosis is possible for viral and bacterial causes, including campylobacter, ${ }^{183}$ but is rarely used in acute cases. It is most useful for epidemiologic study, in the diagnosis of chronic diarrhea, or for cases with atypical courses or extragastrointestinal manifestations. Chronic diarrhea may be due to Giardia, also diagnosed by visualization of the cysts or trophozoites in the stool or the trophozoites in duodenal aspirates. ${ }^{255}$ The latter can be obtained by direct suction of duodenal contents, duodenal biopsy, or by a string test. In this method, string is enclosed in a capsule, which is swallowed by the patient and then pulled back after $4 \mathrm{~h}$. After this time, it has usually become soaked with duodenal mucus and can be studied for the presence of parasites. ${ }^{322}$ Countercurrent immunoelectrophoresis can also be used to detect Giardia antigens in feces ${ }^{86}$ Amebic trophozoites with ingested red blood cells are best seen in wet mount preparations of ulcer scrapings or in rectal mucus. Serology may also be useful in the diagnosis of amebiasis. ${ }^{97}$ Associations of Yersinia gastroenteritis with arthritis and thyroid disease (usually encountered in the convalescent period) can also be defined serologically. ${ }^{242}$

Toxin assay is most useful for the diagnosis of $C$. difficile-associated diarrhea. Counterimmunoelectrophoresis or ELISA can be used for this purpose, but both depend on the specificity of the antibody, a nonstandardized testing material at this time. ${ }^{417}$ Selective culture media are required for growth of $C$. difficile from stool. ${ }^{49}$ 


\section{Treatment}

The treatment of gastroenteritis can be considered in three different ways: supportive, symptomatic, and antimicrobial. The supportive therapy of gastroenteritis refers to the use of fluids, electrolytes, and nutritional intake appropriate to the age of the patient and the manifestations of the infection. Patients with toxigenic, watery diarrhea need to be watched closely for dehydration, although this may also be a manifestation of shigellosis, even in the absence of profuse diarrhea. This is due to a "third space effect" referable to the accumulation of large volumes of fluid and electrolytes within the lumen of the bowel before the advent of fulminant diarrhea. This is particularly a problem in young infants. In many situations, rehydration can be accomplished orally by use of hypotonic ( $\mathrm{Na}$ of $40-50 \mathrm{mEq} /$ liter and approximately $5-10 \%$ carbohydrate) electrolyte solutions. ${ }^{123}$ A rice-based electrolyte solution has been particularly effective. ${ }^{290}$ Rehydration can be done more precisely in hospital with monitoring of serum electrolyte concentrations. Patients with hypertonic dehydration and those with hypotension secondary to intravascular volume depletion require hospitalization, intravenous fluids, and careful monitoring of intravascular volume and electrolyte content. The vast majority of patients, however, can be managed with oral rehydration and their course is usually self-limited. Most practitioners use a brief period of "gastrointestinal rest" in school-age patients and a clear fluid program for these patients for the remainder of a $24-48$-h period. This is more difficult to do in young infants, where dehydration can rapidly occur; therefore, these patients are usually managed with more aggressive fluid replacement from the onset of their symptoms. Feeding stimulates the gastrointestinal tract in three ways, namely, stimulation of the gastrocolic reflex, responses to bulk within the gastrointestinal lumen, and osmotic effects of intralumenal contents. Thus, it seems logical to feed infrequently and with small volumes, and to avoid solids or excessive amounts of sucrose. It should be kept in mind that a considerable number of infants rapidly develop disaccharidase deficiencies, which lead to lactose and sugar intolerances and malabsorption.

Symptomatic therapy of diarrhea is a controversial issue. Table 6-6 outlines some of the therapies that have been tried in order to control the discomfort associated with gastroenteritis. These are rarely useful in infants and children and may, in fact, be harmful. The simplest approach is to avoid solids and allow the gastrointestinal tract to expel the infectious agents and their products as quickly as possible. After all, diarrhea and vomiting are host defense mechanisms, as well as signs of infection.

Specific antimicrobial therapy ${ }^{120}$ is rarely indicated in most diarrhea syndromes with some exceptions (Table 6-7). The course of Shigella infection can be effectively shortened by early antimicrobial therapy, but the advantages of therapy become fewer as spontaneous improvement 
TABLE 6-6. Pitfalls of Symptomatic Treatment for Pediatric Patients with Infectious Diarrhea

\begin{tabular}{llc}
\hline \multicolumn{1}{c}{ Agent } & \multicolumn{1}{c}{ Effect } & Reference \\
\hline Lactobacillus & No prophylactic effect & 76 \\
& No therapeutic effect & 291 \\
Loperamide & Drowsiness/coma & 235 \\
Kaolin-pectin & No therapeutic effect & 304 \\
Diphenoxylate with & Increased toxicity of & 274 \\
atropine/codeine & bacterial diarrhea & 127 \\
Iodoxychloroquine & Optic neuropathy & 275 \\
Diiodohydroxyquin & & 143 \\
Oral rehydration fluids & Chronic diarrhea & \\
\hline
\end{tabular}

occurs. ${ }^{135}$ Bacteriologic excretion is also reduced and this may prevent spread to susceptible contacts. Campylobacter ${ }^{10}$ infections and cholera can also be treated with antibiotics, but unlike Shigella infections, the clinical course is not affected. ${ }^{319}$ The major effect is on bacterial excretion. When Salmonella ${ }^{192}$ and Yersinia ${ }^{284}$ infections are restricted to the gastrointestinal tract, antibiotic therapy affects neither the course of the illness nor bacterial excretion. The role of antibiotic therapy in the treatment of $E$. coli infections, whether due to enterotoxigenic, adherent, or invasive strains, is unclear, as is the treatment of $C$. difficile-associated diarrhea. ${ }^{360}$ Whenever antibiotics are used, the risks of the drug, selection of resistant strains, and the expense must be borne in mind. Trimethoprim/sulfamethoxazole (or amoxicillin if the bacteria are sensitive) can be effectively used in the treatment of severe $E$. coli diarrhea not due to enterotoxin-producing strains. ${ }^{383}$ Since many antibiotics can also cause diarrhea, the indications for their use must be clear. ${ }^{403}$ Remember also that indiscriminate use of antibiotics to prevent diarrhea in travelers and family contacts has led to the widespread development of plasmid-mediated resistance in several enteropathogens. ${ }^{111}$

Intestinal giardiasis can be treated with either quinacrine $(7 \mathrm{mg} / \mathrm{kg} /$ day divided t.i.d., maximum $300 \mathrm{mg} /$ day $) \times 5$ days or furazolidine in the same dose $\times 10$ days. The latter drug is often better tolerated in children under 5 years of age. ${ }^{85}$ If the patient is symptomatic, Entamoeba histolytica intestinal infections (amebiasis) can be treated with either metronidazole $(50 \mathrm{mg} / \mathrm{kg} /$ day divided q $8 \mathrm{~h}$; maximum $2 \mathrm{~g} /$ day $)$ or chloroquine phosphate. ${ }^{201} \mathrm{~A}$ 10-day course is usual. Asymptomatic patients who excrete amebic cysts can be given diiodohydroxyquin $30-40 \mathrm{mg}$ / $\mathrm{kg}$ /day $\times 20$ days (divided q $8 \mathrm{~h}$, maximum $2 \mathrm{mg}$ /day) or diloxamide furoate $20 \mathrm{mg} / \mathrm{kg} /$ day (divided t.i.d.) $\times 10$ days.

The diagnosis and treatment of other intestinal protozoan infections including those caused by Dietamoeba fragilis, Balantidium coli, and Isospora belli have recently been reviewed. ${ }^{410}$ 


\section{Complications}

Infectious gastroenteritis is usually uncomplicated. Any parent can attest to the unhappiness it creates in the home, and we are all aware of the distressing effect these infections have on us. In the majority of cases, however, the illness rarely lasts longer than 2 days in its peak intensity and more than 5 in total. Nonetheless, young infants are particularly prone to secondary effects of infectious gastroenteritis, including dehydration, lactose intolerance, and chronic diarrhea. ${ }^{19}$ Disaccharidase deficiencies may be due to the direct effects of the bacteria on the epithelial cells containing these enzymes. Several weeks to months may be required for reepithelialization and complete recovery of disaccharidase enzyme activity. Steatorrhea may also be encountered in young infants with viral gastroenteritis. ${ }^{226}$ These effects are particularly prevalent in infants acquiring gastroenteritis in the first 3 months of life, and may last up to 1 month. These factors should be considered in planning dietary management of young infants during convalescence.

Bacterial and yeast overgrowth may also be seen as sequelae to infectious gastroenteritis or due to antibiotic therapy. In such instances, Pseudomonas aeruginos $a^{325}$ and Candida albicans ${ }^{185}$ have been implicated in the pathogenesis of symptomatic exacerbations, although their causative roles are controversial. Discontinuation of the offending antibiotic is usually the treatment of choice.

TABLE 6-7. Antimicrobial Treatment of Acute Infectious Diarrhea

Shigella

Ampicillin $100 \mathrm{mg} / \mathrm{kg} /$ day

or

Trimethoprim/sulfamethoxazole 10 (TMP)/50 (SMZ) $\mathrm{mg} / \mathrm{kg} /$ day

Moxalactam $100 \mathrm{mg} / \mathrm{kg} /$ day

or

Chloramphenicol $75 \mathrm{mg} / \mathrm{kg} /$ day

$\times 7$

days

Campylobacter

Oral erythromycin $40 \mathrm{mg} / \mathrm{kg} /$ day $\times 5$ days

E. coli

Oral colistin $15 \mathrm{mg} / \mathrm{kg} /$ day $\times 3$ days

C. difficile

Oral vancomycin $50 \mathrm{mg} / \mathrm{kg} /$ day $\times 10$ days

Oral metronidazole $30 \mathrm{mg} / \mathrm{kg} /$ day $\times 10$ days

Cholera

Oral trimethoprim/sulfamethoxazole $10(\mathrm{TMP}) / 50(\mathrm{SMZ}) \mathrm{mg} / \mathrm{kg} /$ day $\times 3$ days

Oral tetracycline (for children $>8$ years) $30 \mathrm{mg} / \mathrm{kg} /$ day $\times 3$ days 
Chronic diarrhea is always a possibility after an acute episode of infectious gastroenteritis. This complication can be due to enzyme deficiencies, malabsorption, bacterial overgrowth in the upper small bowel, or the presence of specific adherent $E$. coli organisms. ${ }^{126}$

The gravest complications of gastrointestinal infections are extragastrointestinal involvement. Hence, Salmonella bacteremia and focal Salmonella infections outside the gastrointestinal tract may be life-threatening. This is also true with other bacterial and parasitic causes of gastroenteritis (e.g., amebic liver abscess after gastrointestinal amebiasis). Although invasion beyond the gastrointestinal tract is rare with viral causes of gastroenteritis, dehydration, electrolyte abnormalities, and their consequences may be grave complications. Moreover, these agents may complicate the course of patients with serious underlying conditions. For example, gastroenteritis associated with adenovirus, rotavirus, coxsackievirus, and $C$. difficile contributes to excessive mortality in bone marrow transplant recipients. ${ }^{414}$

Bacteria associated with gastroenteritis are most likely to invade beyond the gastrointestinal tract in hosts predisposed by young or old age, chronic disease, underlying malignancies, hemoglobinopathies, and immunodeficiency syndromes, as well as immunosuppressive states induced by drugs or intercurrent illnesses.

\section{Prevention}

The critical difference between the frequency and severity of diarrheas in developed countries and those in rural underdeveloped areas relates to the availability of public health facilities and level of hygienic practices. Proper sewage disposal, clean drinking water, and available facilities for handwashing, preparation and storage of food, and adequate nutrition are of major importance.

Attempts to curtail the expression of diarrhea syndromes by use of vaccination have been largely unsuccessful. ${ }^{104}$ This is due to the inadequacy of currently available vaccines and the extreme heterogeneity among causative agents. Of the currently available products, cholera vaccine is most frequently used. This product is a formalin-killed whole bacterial cell vaccine and confers effective immunity in approximately $50-70 \%$ of cases. Unfortunately, this immunity lasts for only 2-4 months and requires frequent boosting. In many situations, the vaccine side effects (local pain, fever) outweigh the benefits. This is particularly true for American travelers, whose risk of acquiring cholera seems very small. ${ }^{363}$ Other vaccines are in a more experimental stage of development and their use will probably be restricted to travelers, curtailment of specific outbreaks, or particularly high-risk populations.

In institutional outbreaks, antibiotic therapy may be used to control 
the spread of shigellosis. One must be very careful to identify the causative organism and its susceptibilities, lest an inappropriate antibiotic is used. In selected circumstances, antibiotics may also be used to prevent spread of Campylobacter, Shigella, and Vibrio cholerae within family units. It should be remembered that the later in the illness these antibiotics are used, the less likely they are to influence the clinical course and the more prone to favor the selection of resistant strains. When used in community outbreaks, this approach has been associated with development of resistance among Salmonella, Shigella, and E. coli strains.

Nosocomial gastroenteritis is an important problem and often reflects the simultaneous spread of several pathogens, including rotavirus, Salmonella and, occasionally, E. coli. ${ }^{366}$ Principles of prevention are similar to those discussed for day-care centers and institutions. Handwashing is the most important preventive measure, followed by adequate space and staff, and proper disposal of diapers and excreta.

Travelers can best avoid diarrhea by careful attention to eating and drinking habits. ${ }^{111}$ Avoiding preformed toxins in contaminated food and water is critical. Although antimicrobials have been used, their toxicities and the variable susceptibilities of infectious agents have led to failure in many cases. Doxycycline has been used to prevent traveler's diarrhea with some effectiveness, but recently, doxycycline-resistant enterotoxigenic $E$. coli have become a problem in several geographic areas. ${ }^{338}$ Trimethoprim/sulfamethoxazole may also be effective, but this has not been evaluated in young children. ${ }^{106}$ Prophylactic use of lactobacilli is ineffective, ${ }^{76}$ as is the use of diphenoxylate with atropine and other antimotility drugs. These are particularly dangerous if Shigella species, amoeba, or enterotoxigenic bacteria are present. Subsalicylate bismuth has been used to protect against diarrhea. The large dosages recommended may fill a suitcase, and can also lead to excessive salicylate absorption in young children. ${ }^{296}$ Any of these approaches for traveler's diarrhea is intended only as prophylaxis. Onset of diarrhea despite their use should stimulate an aggressive search for the etiologic diagnosis and specific management.

Breast-feeding remains an essential defense for the prevention of infectious gastroenteritis in developing countries. ${ }^{404}$ The immune substances provided in breast milk create an effective first line of defense against ingested enteric pathogens and can reduce the frequency and severity of diarrhea in many infants. ${ }^{270}$ Human milk even has the capacity to kill Giardia, amoeba, and Trichomonas. ${ }^{134}$ Even though gastrointestinal colonization (and, therefore, possible communicability) of $V$. cholerae is not reduced by the presence of breast milk antibodies against cholera toxin and lipopolysaccharide (endotoxin), disease is reduced. ${ }^{137}$ Although this approach is strongly recommended for developing populations, the primary roles of adequate nutrition and personal and community hygiene also deserve emphasis. 


\section{Rotavirus Infection}

\section{Epidemiology}

Rotavirus infections deserve extra comment because they are probably the most common cause of acute infectious diarrhea in young infants and children in industrialized countries. In one recent survey in Trinidad, rotavirus was associated with $23 \%$ of cases of diarrhea, whereas Salmonella, the next most common recognized cause, was present in only $7 \%{ }^{168}$ Our knowledge of human rotavirus infections is relatively young with regard to its clinical expression, characteristics of the virus, and prospects for prevention. ${ }^{368}$

\section{Diagnosis}

The diagnosis of rotavirus infections has been facilitated by the development of an immunoassay for the detection of rotavirus antigen in stool. The sensitivity of this test is comparable to that of electron microscopy, but both methods require the presence of approximately $10^{7}$ virus particles/ml of stool. ${ }^{323}$

\section{Clinical Manifestations}

The entire spectrum of rotavirus infection is yet to be described. Gastrointestinal disease has been noted in individuals of all ages ranging from newborns to adults. Nosocomial outbreaks have been described in nurseries, maternity units, and institutions for the aged. Although upper respiratory infection has been noted in as many as half of the patients with rotavirus infection, attempts to detect rotavirus antigen in respiratory secretions have rarely been successful. ${ }^{399}$ Most rotavirus infections manifest as self-limited gastroenteritis, although chronic diarrhea has been described in a child with X-linked immunodeficiency. ${ }^{341}$

Most young infants in the first 2 years of life have some lactose intolerance after rotavirus gastroenteritis. Because this may last up to 2 or 3 weeks, it is useful to restrict lactose-containing foods for this period of time, especially in the young patients with more severe clinical illness. ${ }^{170}$

Rare complications associated with rotavirus gastroenteritis have been described, including intussusception, ${ }^{203}$ Reye syndrome and encephalitis, ${ }^{333}$ sudden infant death syndrome, ${ }^{416}$ and fatal disease in young infants with severe dehydration. ${ }^{62}$

\section{Treatment/Prevention}

The disease is extremely frequent in winter months in temperate climates and nosocomial spread is unusually high. ${ }^{321}$ As usual with enteric infections, handwashing is critical. ${ }^{334}$ Our knowledge of the pathogenesis of 
this disease is improving and preliminary experience with an oral vaccine is encouraging. ${ }^{393}$ One recent study, however, may also provide a useful approach. ${ }^{23}$ These investigators administered $4 \mathrm{ml}$ of pooled human serum immunoglobulin orally four times a day to premature babies in the first week of life during an outbreak of rotavirus gastroenteritis in a newborn nursery. They were able to prevent diarrhea in 13 of 14 infants treated with gammaglobulin, while only 5 of 11 infants treated with placebo remained asymptomatic. If confirmed, this approach may offer a means of reducing the morbidity of rotavirus in closed populations and in protecting certain high-risk individuals.

\section{Salmonellosis}

\section{Pathogenesis}

Salmonella are ubiquitous bacteria that have the capacity to persist within phagocytic cells. The bacteria have several pathogenic capabilities, including invasiveness, resistance to phagocytosis, and resistance to intracellular killing. Host factors that favor invasion include achlorhydria and other underlying gastrointestinal abnormalities, hemoglobinopathies, malignancies, immunosuppression, and the extremes of age. Infants in the first 3 months of life seem at particularly high risk. ${ }^{271}$ Malnutrition and debilitation due to a variety of causes are also major determinants of complicated salmonellosis. The size of the inoculum, which may be very great in areas with poor hygiene, may also determine invasiveness and virulence of this organism. In many respects, these infections resemble tuberculosis and brucellosis more closely than disease due to acute pyogenic pathogens. Although most of the time Salmonella infections are limited to the gastrointestinal tract, occasionally these bacteria invade other sites, resulting in chronic and relapsing infections, including typhoid and enteric fevers.

\section{Epidemiology}

Patients with liver and biliary tract disease, and infants under the age of 3 months, are particularly prone to excrete Salmonella organisms long after infection. In one series, $27 \%$ of these infants were still shedding Salmonella organisms in their stools 8 weeks after acute gastroenteritis. ${ }^{193}$ The incidence of extragastrointestinal complications also seems enhanced in infants $<3$ years of age. ${ }^{91}$

Marijuana was recently implicated as the vehicle for spread of salmonellosis in 85 people in four states. ${ }^{380}$ The bulk of Salmonella infections, however, still emanate from contaminated food, mostly fowl and dairy products. Pets, particularly turtles, frogs, dogs and cats, are frequently 
implicated as reservoirs as well. ${ }^{79}$ Person-to-person spread is significant in outbreaks involving infants in families ${ }^{407}$ and day-care centers. ${ }^{222}$

\section{Clinical Manifestations}

When Salmonella organisms invade beyond the gastrointestinal tract, the expression of clinical infection is extremely wide (Table 6-8). Abscesses of almost every organ and tissue of the body have been reported, as have acute and persistent bacteremias. Recurrent bacteremias are occasionally seen in patients with concomitant gastrointestinal parasitosis, such as intestinal schistosomiasis. Perhaps the parasites erode the intestinal epithelial defenses and allow Salmonella organisms to periodically enter the vascular system. It is important to remember that predisposed patients (see Epidemiology above) are more likely to have extragastrointestinal manifestations.

\section{Therapy}

Although Salmonella gastroenteritis usually should not be treated with antibiotics, several exceptions are noteworthy. These include infants under 3 months of age ${ }^{271}$ and the elderly, as well as those predisposed by malnutrition, debilitation, and other underlying conditions. Occasionally, patients with ulcerative colitis are thought to have an exacerbation of their underlying disease, when, in fact, they have an intercurrent infection with an enteric pathogen. ${ }^{207}$ In such cases, granulomatous histopathologic changes may be seen with Salmonella infection; however, the possibility of a combined infection should not be forgotten. This is illustrated by the reported coincidence of tuberculous and Salmonella osteomyelitis. ${ }^{374}$

Several characteristics of extragastrointestinal salmonellosis need to be

\section{TABLE 6-8. Extragastrointestinal Complications of Salmonella Infections}

Enteric fever/septicemia"'

Meningitis ${ }^{91}$

Osteomyelitis"

Arthritis $2 \times 1$

Urinary tract infection ${ }^{29}$

Soft tissue abscess ${ }^{209}$

Endophthalmitis ${ }^{401}$

Endocarditis ${ }^{175}$

Pericarditis $^{374}$

Mycotic aneurysm ${ }^{2 \times 8}$

Erythema nodosum ${ }^{26+4}$ 
remembered, if therapy is to be appropriately prescribed. These infections are generally insidious in onset (often extragastrointestinal infections are noted 2-6 months after the episode of gastroenteritis). In addition, the lesions are often localized with minimal systemic signs and symptoms. The degree of destruction of bone and other tissues, however, may be extensive. ${ }^{281}$ Antibiotic therapy needs to be prolonged in almost all cases (a minimum of 3 weeks for acute extragastrointestinal infections such as meningitis, and at least 3 months for more chronic extragastrointestinal manifestations, such as osteomyelitis and endocarditis). Often, it is necessary to combine such antibiotic therapy with surgical drainage. In all such cases, careful monitoring of compliance, serum concentrations of antibiotics, and radiographic and other laboratory parameters should be followed extremely closely. Relapses with shorter durations of therapy (and occasionally with long durations of therapy) may be seen several months after completion of apparently adequate regimens.

In choosing antibiotics, one must be aware of the community prevalence of Salmonella susceptibility patterns, often affected by antibiotic use in animals. ${ }^{276}$

\section{Control}

Community and personal hygiene, with emphasis on sewage control and clean food and water, remain the major mechanisms for control of Salmonella infections. Handwashing and proper disposal of feces are appropriate for isolation of these patients in hospital and at home. The greatest reservoirs of Salmonella organisms, however, exist in the food chain and in human carriers. Vaccine development research continues, but a useful product is far from a reality at this time. ${ }^{13}$

\section{Campylobacteriosis}

Campylobacter infections are becoming more widely recognized worldwide, ${ }^{278}$ now that the bacteria's microbiologic characteristics (e.g., the need to incubate the stool culture at $42^{\circ} \mathrm{C}$ and in a specific gaseous environment) are more familiar. ${ }^{43}$

\section{Epidemiology}

Like other enteric bacterial pathogens, Campylobacter species seem widespread in nature. Thus, outbreaks have been described in association with contaminated water, ${ }^{287}$ raw milk, ${ }^{250}$ processed milk; ${ }^{182}$ also implicated have been healthy and ill cats, ${ }^{44}$ puppies, ${ }^{41}$ hamsters, ${ }^{130}$ and ducks. ${ }^{263}$ Humans may also serve as reservoirs, as noted in neonatal infections (spread from mother to newborn infant $)^{9}$ and in day-care centers. ${ }^{45}$ 


\section{Clinical Manifestations}

The usual expression of Campylobacter infection is gastroenteritis. However, in some populations, such as in India and Bangladesh, asymptomatic infections are common. ${ }^{136}$ In newborns, the disease may be mild with diarrhea but no fever and no bacteremia. ${ }^{9}$ Abdominal distension is common in infants less than 3 months of age. ${ }^{269}$ In others, the disease may simulate a full-blown attack of ulcerative colitis. ${ }^{69}$ In one such case, the use of steroids in a 4-year-old with chronic enterocolitis resulted in death before recognition of the presence of campylobacteriosis. ${ }^{78}$ Occasionally, as with Shigella gastroenteritis, seizures may accompany diarrhea. ${ }^{232} \mathrm{Cam}$ pylobacter appendicitis has also been reported. ${ }^{68}$

\section{Complications}

Bacteremia ${ }^{317}$ hemolytic-uremic syndrome, focal abscesses, and erythema nodosum are described (Table 6-9). The duration of fever, diarrhea, and excretion of $C$. fetus in the stool are increased in immunodeficient children. ${ }^{252}$ The arthritis described with Campylobacter gastroenteritis may be associated with the acute or convalescent phase of the intestinal infection. Except in rare cases in the acute phase, the joint fluid is usually sterile. This "reactive arthritis" has been, as have other enteric-associated arthritides, associated with a high prevalence of the haplotype HLA-B27. For example, five of seven such patients in Finland had this haplotype, whereas it is present only in $14 \%$ of the normal Finnish population. ${ }^{210}$ Placentitis with resultant abortion has also been confirmed in a number of cases. ${ }^{80}$ It is likely that more extragastrointestinal manifestations of campylobacteriosis will be recognized as microbiologic recognition of this bacteria increases.

TABLE 6-9. Extragastrointestinal

Complications of Campylobacter

Infections

Arthritis
Bacteremia $^{353}$
Colitis $^{78}$
Meningitis $^{273}$
Hemolytic-uremic syndrome
Erythema nodosum $^{359}$
Guillain-Barré syndrome
Convulsions
Pancreatitis
Vascular infections $^{344}$




\section{Treatment}

Treatment of these infections, if they are localized to the gastrointestinal tract, is possible with erythromycin or tetracycline. Bacteriologic shedding is curtailed; however, the clinical course is not usually altered.$^{285}$ Rarely, resistant strains are found. Thus, in vitro susceptibility studies should be carried out in complicated cases with persistent infection. More serious invasive campylobacteriosis should be treated with ampicillin, chloramphenicol, aminoglycosides, or imipenem (thienamycin) ${ }^{6}$ Other control measures for Campylobacter revolve around the same principles of hygiene and isolation outlined for other enteric bacterial pathogens.

\section{Shigellosis}

\section{Diagnosis}

Shigellosis is frequent worldwide, but is more prevalent in warmer climates. The persons affected most often are children 1-5 years old ${ }^{42}$ Rapid diagnosis is important because treatment, if initiated early, can decrease bacteriologic excretion and duration of clinical illness. Thus, knowledge of contact with shigellosis (such as in day-care centers or from household members) might facilitate early diagnosis and treatment. The presence of blood or mucus, or both, in the stools, and the presence of neutrophils on microscopic examination of the stool, are also helpful features. The presence of peripheral blood leukocytosis is less consistent, although analysis of the differential white blood cell count might be helpful. In a recent study of this feature of shigellosis, $71 \%$ of patients with Shigella gastroenteritis had more bands than segmented neutrophils in their peripheral white blood cell count. ${ }^{131}$ However, this was also noted in $22 \%$ of patients with diarrhea due to Salmonella or E. coli.

\section{Treatment}

Treatment of shigellosis is indicated if the diagnosis is made early in the course of illness, as well as in certain hosts at high risk for septicemia and other extragastrointestinal complications. This includes newborns, patients with severe malnutrition, immunosuppressed patients, and those with hemoglobinopathies including sickle-cell anemia. Knowledge of the susceptibility pattern of Shigella in the community is essential for the initial prescription of effective therapy. For example, a recent outbreak of shigellosis associated with many deaths in Zaire was due to Shigella dysenteriae resistant to ampicillin, chloramphenicol, sulfonamides, and tetracyclines. ${ }^{133}$ Plasmid-mediated multiple antibiotic resistance of this type can spread quickly through a community and cause many problems. 
Eighteen cases of Shigella resistant to trimethoprim-sulfamethoxazole have also been reported. ${ }^{125}$

\section{Complications}

Some of the complications of shigellosis are described in Table 6-10. Shigella bacteremia with focal infections is a particular threat to infants and children with malnutrition, dehydration, and immunosuppression. ${ }^{103}$ In these patients, there is often leukopenia, rather than leukocytosis and little or no fever. Shigella infections need to be taken seriously, in consideration of antibiotic resistance, their invasive nature, and the potential for extragastrointestinal spread and mortality in selected hosts.

\section{Yersiniosis}

Although Yersinia infections are frequent and well-described in some countries of the world, they are less common in others. The manifestations of Yersinia infection are diverse. Young children most commonly develop acute febrile diarrhea syndromes after primary infection with these bacteria, whereas children over 5 years of age often present with fever and abdominal pain. Diagnosis of Yersinia should be based on culture of the bacteria, since there are serious limitations in the use of serologic methods (agglutinins) in infants and in immunosuppressed patients, and cross-reactions with Brucella and autoantibodies are common. ${ }^{50}$

\section{Epidemiology}

Outbreaks of yersiniosis have become commonplace in North America, where infection with Yersinia previously was considered rare. Some Yer-

TABLE 6-10. Extragastrointestinal

Complications of Shigella Infections

Septicemia ${ }^{103}$

Splenic abscess $^{367}$

Hepatitis $^{369}$

Hemolytic-uremic syndrome ${ }^{144}$

Vulvovaginitis $^{92}$

Keratitis $^{329}$

Meningitis $^{24}$

Pneumonitis ${ }^{24}$

Postinfectious arthritis ${ }^{24}$ 
sinia outbreaks in rural areas are attributable to contamination of milk products..$^{364}$ In other cases, nosocomial infections have been recognized. In one such recent outbreak, nine hospitalized patients apparently became infected by person-to-person spread. ${ }^{308}$ These outbreaks may also occur in families and are not restricted to the classic pathogenic types, as illustrated by a recent outbreak in Canada due to biotype $1 .{ }^{243}$

\section{Clinical Manifestations}

In addition to the gastroenteritis syndrome described in the previous section, many school-age children with acute Yersinia infections manifest severe abdominal pain. ${ }^{174}$ This feature of acute yersiniosis is also seen with infection by a related bacteria, Yersinia pseudotuberculosis, a common cause of acute abdominal pain associated with mesenteric lymphadenitis. ${ }^{115}$ Indeed, the abdominal pain has been so remarkable that many of these patients have had appendectomies before the recognition of yersiniosis as the cause. Yersinia enterocolitica can also cause intussusception, ${ }^{57}$ gastrointestinal ulcerations, and a clinical and histopathologic picture resembling ulcerative colitis or acute ileitis. ${ }^{389}$

\section{Extragastrointestinal Manifestations}

Many infectious and postinfectious clinical manifestations have been associated with Yersinia infection (Table 6-11). As in the case of infection with other enteric pathogens, there may be a predisposition to septicemia in patients with hemoglobinopathies and other predisposing and immunocompromising illnesses. ${ }^{162}$ Septicemia is particularly prevalent in immunocompromised patients, but can also be seen in normal patients. ${ }^{370}$

Many complications of Yersinia infection are due to direct bacterial invasion of a specific tissue or organ. In other cases, the evidence that Yersinia participates in the pathogenesis of the condition is less clear. For example Yersinia have been implicated in some cases of glomerulonephritis, thyroid disease, and arthritis, although the evidence is retrospective and based only on serologic criteria. The known cross-reactivity of Yersinia with other microbial and host tissue antigens complicates interpretation of these reports. ${ }^{257}$ Nevertheless, there is little doubt that the acute septicemic form of arthritis is associated with Yersinia infection, since the organism has been cultured from both the bloodstream and the joint fluid. ${ }^{379}$ Postinfectious types of Yersinia arthritis are less clearly associated with Yersinia infections, although it is said that the presence of IgA antibody to Yersinia is strong evidence in favor of this association. ${ }^{141}$ In many of these cases, the disease resembles rheumatoid arthritis and parallels exist with the arthritic syndromes seen in the convalescent stage of other enteric infections. In one report, $56 \%$ of patients with 
TABLE 6-11. Extragastrointestinal

Complications of Yersinia Infections

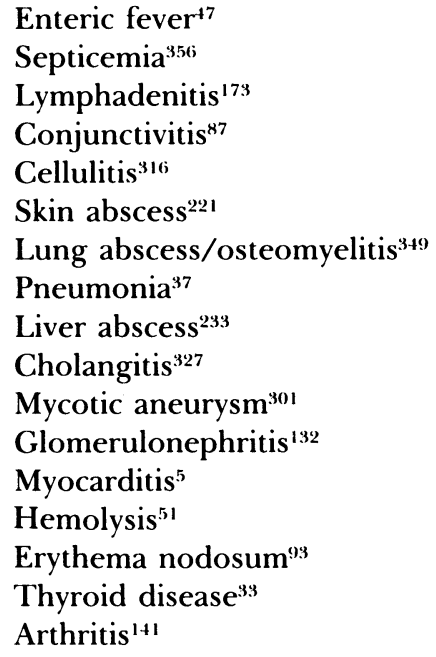

arthritic complications of acute Yersinia infections were of the HLA-B27 halotype. ${ }^{96}$ Thus, genetic and acquired infectious factors may predetermine the expression of arthritis in some of these patients.

\section{Treatment}

The treatment of yersiniosis is fruitless when the infection is confined to the gastrointestinal tract in normal hosts. Indications for treatment of Yersinia gastroenteritis in other hosts are listed in Table 6-12. Extragastrointestinal septic complications should be treated aggressively with appropriate antibiotic therapy (Table 6-13). I prefer moxalactam 200 $\mathrm{mg} / \mathrm{kg} /$ day, although trimethoprim/sulfamethoxazole, cefotaxime, or aminoglycosides may also be used. Surgical drainage may also be necessary in some cases.

\section{Cholera}

\section{Epidemiology/Pathogenesis}

Vibrio cholerae infection most frequently manifests as acute diarrhea, and is one of the major causes of gastroenteritis in developing countries. The current pandemic began in 1961 in Indonesia, and has since spread to 
TABLE 6-12. Indications for Antibiotic Therapy of Yersinia enterocolitica Gastroenteritis

$<3$ months of age

Leukemia/lymphoma

Acquired or congenital immune deficiency disease

Moderate/severe malnutrition

Thallasemia

Appendicitis

Ulcerative colitis or other inflammatory bowel disease

Associated symptomatic intestinal parasitosis

many countries in Asia, Africa, and Europe. Foci in Texas and Louisiana have been identified, where transmission via gulf waters has been documented. ${ }^{178}$ More frequently, infection in the United States is noted after travel to endemic countries. ${ }^{363}$

Man is the only host for Vibrio cholerae, and spread is maintained by contamination of water sources and, to a small extent, by chronic biliary carriage and stool excretion. Highest attack rates are seen in children between the ages of 1 and 5 years. ${ }^{64}$

The bacteria remain localized to the gastrointestinal tract in almost all cases. Disease is caused by release of a potent enterotoxin leading to fluid and electrolyte secretion into the lumen of the bowel, with consequent dehydration and metabolic imbalance. ${ }^{64}$

Other Vibrio species can also cause gastroenteritis ${ }^{320}$ and a wide spectrum of clinical infection. ${ }^{17}$

TABLE 6-13. In Vitro Susceptibilities of Yersinia enterocolitica ${ }^{344}$

Highly susceptible to

Cefotoxine

Moxalactain

Trimethoprim/sulfamethoxazole

Aminoglycosides (gentamicin, amikacin, tobramycin)

Moderately (or variably) susceptible to

Kanamycin

Tetracycline

Chloramphenicol

Rifampin

Resistant to

Ampicillin

Erythromycin

Penicillin

Cloxacillin

Cephalothin

Carbenicillin 


\section{Clinical Manifestations}

Cholera is manifest by the abrupt onset of painless, watery diarrhea and vomiting. All degrees of illness are seen, including hypotension, cardiovascular collapse, and severe muscle cramps due to electrolyte depletion in far-advanced cases.

\section{Diagnosis}

The epidemiologic history and clinical characteristics are important. Fecal leukocytes are absent when the stool is examined microscopically; however, abundant numbers of Vibrio-shaped organisms may be seen with gram or methylene blue stain. Confirmation of the diagnosis is made by culture of Vibrio cholerae on thiosulfate-citrate-bile salt-sucrose (TCBS) agar.

\section{Treatment}

Replacement of water and electrolytes is of paramount importance. This can usually be accomplished by the oral route. Specific therapy for shock may be indicated as well. Bacterial excretion is reduced by the administration of tetracycline in a dose of $30 \mathrm{mg} / \mathrm{kg} /$ day, divided 4 times daily for 3 days. Doxycycline $4 \mathrm{mg} / \mathrm{kg} /$ day in a single oral dose is also effective. ${ }^{330}$

\section{Prevention}

Improvements in sewage disposal and the quality of drinking water are important, and public health measures have been instrumental in curtailing large outbreaks. Immunization may also be effective in endemic areas, as discussed in Chapter 1. Since the adherence of Vibrio cholerae to gastrointestinal epithelial cells is inhibited by $\operatorname{IgA}$ antibody, breast-feeding is an important method of preventing this disease in early infancy. ${ }^{227}$

\section{Giardiasis}

The diagnosis and management of acute giardiasis, as well as the chronicity of diarrhea in some cases, and the propensity for spread of disease in day-care centers, have been discussed in the section on gastroenteritis. Some other aspects of Giardia infection are described below.

\section{Epidemiology}

Giardia is considered to be the most common intestinal parasite in the United States and in Great Britain. ${ }^{84}$ For example, infection rates of 30- 
$90 \%$ were found in recent surveys of day-care centers in New Orleans. ${ }^{84}$ Children who wear diapers, many of whom are asymptomatic, ${ }^{128}$ are particular reservoirs for this organism in closed populations. Person-toperson transmission and foodborne ${ }^{282}$ and waterborne ${ }^{108}$ spread have been reported. Other hosts likely to acquire Giardia frequently are selected populations of homosexuals and patients with altered intestinal immunity and hypogammaglobulinemia. ${ }^{225}$ Treatment in the latter group may need to be prolonged, since control of symptoms may not be associated with eradication of the parasite.

\section{Clinical Manifestations/Treatment}

The younger the patient, the more likely he will be symptomatic. Most patients under 1 year of age who have Giardia organisms in their stools have diarrhea, often with symptoms of poor growth. ${ }^{84}$ Chronic urticaria is a rare association. ${ }^{155}$ Diarrhea, vomiting, anorexia, and failure to thrive are very common in children under 5 years of age. Because of this, it is recommended that Giardia infection in this age group should be treated in all cases. Those over 5 years of age usually have more abdominal cramps and may have intermittent loose stools and constipation. The natural course of illness in older children and adults is often 4-6 weeks, during which the stools become normal. In some patients, the course may be more chronic with intermittent abdominal pain, occasional loose stools, and malabsorption. Malabsorption may include the inability to absorb antimicrobials and other drugs. ${ }^{84}$

Furazolidone $7 \mathrm{mg} / \mathrm{kg} /$ day, divided three times daily, should be given for at least 7-10 days (Chapter 2). Shorter courses are prone to relapse. ${ }^{267}$

\section{Complications}

Other complications of giardiasis are listed in Table 6-14. Mesenteric lymphoid hyperplasia is sometimes visualized if these patients are treated surgically. Allergic reactions to Giardia have manifest as urticaria with associated eosinophilia and increased serum concentrations of $\operatorname{IgE}$; occasionally, giardiasis is found in patients with asthma. Although unproven in controlled studies, it has been claimed that successful treatment of giardiasis in these cases reduced the frequency of asthmatic attacks.

\section{Prevention}

It is difficult to eradicate the parasite from human reservoirs and infected water supplies. Chlorination of water is generally ineffective without loss of palatability. Passage through a filter with a pore size less than $3 \mu \mathrm{m}$ is usually necessary to eliminate the organism. In family units and in the community, careful handwashing and disposal of soiled diapers will help prevent spread. 
TABLE 6-14. Complications of Giardiasis ${ }^{84}$

Chronic diarrhea/abdominal pain/failure to thrive

Malabsorption

Protein-losing enteropathy ${ }^{358}$

Biliary tract obstruction

Mesenteric lymphadenitis

Exercise-induced diarrhea

Peripheral neuropathy

Urticaria

Ulcerative colitis ${ }^{3(4)}$

\section{Amebiasis}

\section{Epidemiology}

It is estimated that approximately $10 \%$ of the world's population is infected with Entamoeba histolytica, the causative parasite in amebiasis. ${ }^{201}$ In some countries the figure may be as high as $30 \%$. This includes some areas in the southwestern regions of the United States and Central America. Recently, amebiasis was the fourth leading cause of death in Mexico City. ${ }^{25+}$ The diagnosis needs to be sought aggressively and early. It should be considered high among the differential diagnoses of dysentery and extragastrointestinal febrile illnesses in patients recently living or traveling in endemic areas. The vast majority of cases are water-borne, but person-to-person spread has been noted in institutions for the mentally retarded and in family units. ${ }^{109}$ Recently, 36 cases in the United States were transmitted by colonic irrigations. ${ }^{172}$

\section{Clinical Manifestations}

Amebiasis may take many forms. The commonest is asymptomatic infection, with or without a mild diarrhea syndrome at the onset. Uncomplicated colitis with mild dysentery is the rule, after an incubation period ranging anywhere from 1 to 8 weeks. Some patients, thereafter, become free of the parasite; others develop ameboma, which are tumorous lesions of the colonic mucosa, and others become asymptomatic cyst excretors. All of these should be treated.

The disease in infants may be more difficult to diagnose and may be extremely fulminant. In a recent series, two infants ages 6 and 7 weeks died quickly with an infantile disseminated form of amebiasis. ${ }^{109}$ In this form of disease, diarrhea is followed by amebic infection of the liver, peritoneal cavity, and sometimes, pericardium. ${ }^{119}$ Hematochezia, dysentery with appendicitis, and exacerbation of ulcerative colitis (or a true amebic ulcerative colitis) may also be seen in infants and children. ${ }^{25+}$ 


\section{Extragastrointestinal Amebiasis}

Although invasion beyond the gastrointestinal tract occurs in less than $1 \%$ of patients with amebiasis, the diagnosis is often difficult and the outcome can be disastrous. Liver abscess is the most frequent extragastrointestinal manifestation. Colitis is usually present, but may not be obvious in many cases, unless sigmoidoscopy is performed. Fever and hepatomegaly are the most common presenting features; however, anemia, leukocytosis with a left shift, and elevation of the right hemidiaphragm are frequently present. ${ }^{158}$ Infants are particularly prone to extragastrointestinal invasion. Hence, in a recent review of amebic liver abscesses, most of the children were under 3 years of age. ${ }^{151}$ Remarkably, two-thirds of these presented with cough or breathing difficulty.

Other extragastrointestinal manifestations of amebiasis include peritonitis, pleuritis, pericarditis, ${ }^{119}$ and, less frequently, lung and brain ${ }^{166}$ involvement. Most of these occur as a result of direct extension from the gastrointestinal tract or liver to adjacent structures. Thus, skin lesions often are perianal or involve the genitals. Rarely, this disease can be spread by sexual contact; this may be more frequent in homosexuals. Colitis is one of the most important manifestations of amebiasis. If this is mistaken for ulcerative colitis in patients with underlying amebiasis, it may be disastrous.

\section{Diagnosis}

Fresh stools are often necessary for visualization of the trophozoites; however, concentrated specimens can be used to find cysts, the most common form in asymptomatic excretors. Formalin kills trophozoites, hence both examinations are necessary. It is important to realize the trophozoites and cysts may not be present in the stool of some patients, despite the presence of colonic lesions due to amebiasis. Serology and direct visualization of colonic or rectal mucosal lesions may be required for the diagnosis. When the latter procedures are carried out, fresh wet preparations of suspicious lesions and biopsy specimens should be examined. ${ }^{201}$ Some practice is necessary in reading stool and tissue preparations for the presence of amebae. Misdiagnoses are common, since leukocytes may be mistaken for trophozoites. ${ }^{208}$

Liver abscesses should be more easily diagnosed with refinements in scan techniques. Radioisotope-labelled scans, ultrasonography, and computerized axial tomography can all be used. The latter is probably the most sensitive method available and can be used to diagnose liver and spleen abscesses due to bacteria, parasites, and fungi. ${ }^{26}$ Infants, immunocompromised patients, and patients with heavy infestations and persistent signs should receive this examination. Most patients with hepatic liver abscess also have indirect hemagglutination antibodies. ${ }^{97}$ 


\section{Therapy}

Therapy for amebic dysentery and cyst excretors is discussed in the section on gastroenteritis. Extragastrointestinal amebiasis should be treated with metronidazole $35-50 \mathrm{mg} / \mathrm{kg} /$ day, divided three times daily $\times 10$ days. When large liver abscesses or other complications (i.e., peritonitis, pericarditis, pleuritis) are present, dehydroemetine in a dose of $1.5 \mathrm{mg} / \mathrm{kg} /$ day (maximum $90 \mathrm{mg}$ ) should be administered intramuscularly once daily for 5-7 days as well.

The response to medical therapy is usually dramatic, with a reduction in fever and toxicity within $24-48 \mathrm{~h}$. By 5 days, most patients have recovered. If not, persistence of signs in the presence of a focal abscess should suggest the need for aspiration and drainage. Open surgical drainage may be required if reaccumulation occurs after needle aspiration. ${ }^{1}$ Large painful hepatic lesions, or leaking or fluctuant lesions, should be treated surgically as well as medically.

Diagnostic and therapeutic methods of control are improving the outlook for amebiasis, as is hygiene and improvement in sanitation and drinking water. Nevertheless, this infection remains ubiquitous and can be highly virulent in young infants and debilitated hosts. Confusion with inflammatory bowel disease can readily occur, particularly in patients with fulminant gastrointestinal amebiasis in countries with low endemicity. ${ }^{74}$

\section{Stomatitis}

Inflammation of the oral cavity is often a component of pharyngotonsillitis, exanthematous communicable diseases, and noninfectious conditions. When ulcers or vesicles are present, several specific syndromes come to mind. Glossitis has many causes, including local trauma, moniliasis, and acute Haemophilus influenzae infection. ${ }^{112}$ Gingival lesions due to group A Streptococcus may appear cyst-like in young infants. ${ }^{289}$

\section{Acute Stomatitis}

Herpes Simplex in Normal Hosts. The causes of acute stomatitis are diverse (Table 6-15). In preschool children, herpes simplex is probably the most common cause of diffuse stomatitis. The tongue, gingiva, and often the lips, are also involved. Since these lesions are quite painful, the patient may be very irritable and may refuse to eat. Fever is often present, with temperatures in the range of $39-40^{\circ} \mathrm{C}$ for $3-5$ days, and toxicity can be significant. Rarely, patients have lesions extending into the trachea and may require hospitalization for respiratory support; others need parenteral hydration and nutrition. The clinical course is generally between 1 and 2 weeks, during which time considerable weight loss may occur. 
TABLE 6-15. Causes of Acute Stomatitis

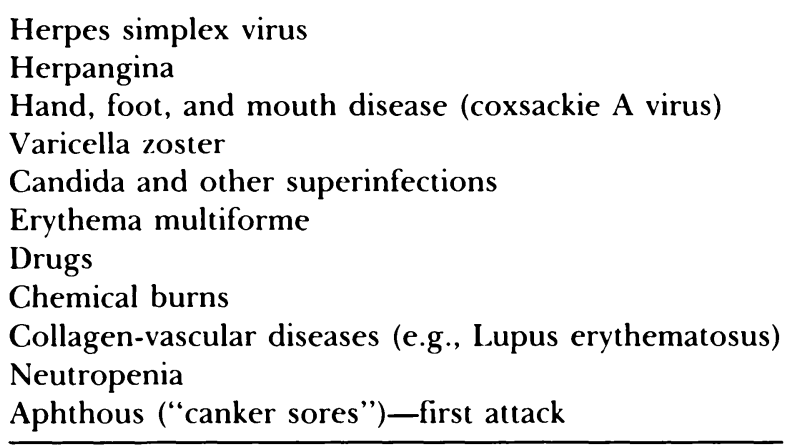

In older patients, weight loss and fatigue are particularly troublesome components. Although topical anesthetics (such as lidocaine), ice chips, ice cream, and antiviral drugs, have been used, they rarely decrease the clinical course or significantly reduce viral excretion. Moreover, systemic toxicity (seizures) has been reported with the use of topical lidocaine. ${ }^{259}$ Nevertheless, the patient with severe lesions may obtain some relief with one of these approaches. Oral acyclovir may be effective in reducing viral excretion and clinical illness, but experience with this treatment is limited.

Herpes Simplex in Immunocompromised Hosts. Primary herpes infection in immunocompromised patients is probably more dangerous then reactivation, as systemic dissemination may be more frequent and severe. In either case, this condition, like varicella zoster infection, requires treatment with systemic antiviral drugs. Both vidarabine and acyclovir are effective ${ }^{395}$ Acyclovir is used in a dose of $30 \mathrm{mg} / \mathrm{kg}$ intravenously, divided $\mathrm{q} 8 \mathrm{~h}$. The drug is continued for 7-10 days or for approximately 2 days after resolution of the active lesions.

Varicella Zoster. Patients with chicken pox often have ulcerations on the palate, and, occasionally, on the buccal mucosa. These are generally of no consequence. When the patient is immunocompromised, extensive mucosal lesions suggest an increased risk for visceral spread. Antiviral chemotherapy, as suggested above for herpes simplex stomatitis, should be instituted.

Other Causes of Stomatitis. Other infectious causes of acute oral ulceration include the hand, foot, and mouth syndrome, usually due to coxsackie A virus, although enterovirus 71 has also been described as causative. ${ }^{171}$ Although vesicular lesions are generally present on the hands and feet, this is not always so.

Rarely, staphylococcal or anaerobic infections of areas of traumatized mucosa may lead to ulceration and focal infection. Appropriate smear 
and culture examinations may provide a clue to the infectious etiology. Good oral hygiene usually suffices as treatment. When lesions are extensive or progressive, specific antimicrobial therapy should be instituted. As noted in Table 6-15, noninfectious causes may also be responsible for acute stomatitis. The first indication of the presence of inflammatory bowel disease may, in fact, be oral ulcerations.

Herpangina. Ulcers on the tonsil or in the peritonsillar area may be due to coxsackie A virus. These are often extremely painful. Occasionally, this may be due to herpes simplex virus. ${ }^{238}$ This should be kept in mind if the patient is immunocompromised, as discussed above.

Candidiasis (moniliasis, oral thrush). The management of mouth ulcers and plaques due to Candida overgrowth is twofold. One is to try and discontinue use of the offending antibiotic or other predisposing factor. The other is the use of oral nystatin, clotrimazole, or other topical antifungal preparations. Repeated administration by swab or mouth rinse is needed. In severe cases, this should be done at least before every meal and at bedtime. When this occurs in immunocompromised hosts, or when esophagitis is present, or both, although systemic treatment with ketoconazole is preferred, clinical improvement is expected in only $5 \%$ of patients and eradication of Candida in only $36 \% .{ }^{167}$

\section{Recurrent Stomatitis}

Aphthous Ulcers (canker sores). Although commonly believed to be due to herpes simplex virus, this is, in fact, rarely the cause of recurrent stomatitis, except in immunocompromised patients. Unfortunately, the commonest cause of recurrent single or multiple oral ulcerations is idiopathic (aphthous ulcers). Although they may have no cause, they certainly are painful! They may be single or multiple, but are generally confined to the buccal mucosa and lips. Occasionally, they are more extensive, even involving the trachea. The pathogenesis of this condition is unclear, although autoimmunity (the demonstration of antibodies against mucosal antigens), and mucosal injury in genetically predisposed hosts have been postulated. ${ }^{411}$ Treatment of this condition is entirely symptomatic. Topical steroids (administered as mouth rinses or gargles), or a mouth wash consisting of combinations of tetracycline and amphotericin, have been used. ${ }^{95}$ Although controlled trials suggest that these therapeutic practices are efficacious, the exact cause of the condition and pathognomonic laboratory findings are lacking. Hence, other causes of recurrent ulcerations should be ruled out (Table 6-16). 
TABLE 6-16. Classification of Recurrent Stomatitis

\author{
Aphthous (idiopathic)_-“canker sores” \\ Cicatricial pemphigoid \\ Pemphigus vulgaris \\ Lichen planus \\ Pernicious anemia \\ Ulcerative colitis \\ Crohn disease \\ Celiac sprue \\ Behçet syndrome \\ Herpes simplex \\ Erythema multiforme ${ }^{31}$
}

Noninfectious Causes Including Behçet Syndrome. Among the causes of recurrent stomatitis (Table 6-16) are primary skin or mucosal disorders. ${ }^{34}$ Inflammatory bowel disease, collagen-vascular diseases, and Behcet syndrome may also present as recurrent stomatitis. Behçet syndrome is rare in childhood, but has been described in a patient as young as 2 years. ${ }^{266}$ This condition is manifest by febrile episodes associated with painful recurrent mucous membrane ulcerations, genital ulcers (of the penis, scrotum, vagina, vulva), skin involvement (erythema nodosum, pyoderma), eye inflammation (iritis), arthralgia, arthritis, and central nervous system involvement (meningitis, intracranial hypertension, dementia, encephalopathy). Occasionally, colitis has also been noted. The recurrent nature of these conditions, associated with aseptic meningitis, should suggest the diagnosis. The CSF usually has $<200$ cells $/ \mathrm{mm}^{3}$ of mixed neutrophilic and mononuclear character; CSF protein concentration may be slightly elevated, but the glucose is normal and cultures are negative. The cause is unknown and there is no specific treatment. The more extensive the CNS involvement is, the poorer the prognosis.

\title{
Esophagitis
}

\section{Pathogenesis}

Infections of the esophagus are rare. They are occasionally seen postoperatively, where Staphylococcus species or anaerobic upper respiratory flora may be involved. In such cases, definitive diagnosis may be obtained by directly visualizing the lesion and obtaining appropriate smears and cultures. Antibiotic therapy is fairly straightforward. This is a very rare complication of modern approaches to esophageal surgery or trauma. 


\section{Etiology}

The majority of patients who develop infections of the esophagus are debilitated in some fashion. Hence, both herpes simplex and Candida albicans, the leading infectious causes of esophagitis, have been described in patients with severe malnutrition, congenital and acquired immunodeficiencies, and posttraumatically. However, both infections may be seen in normal children as well. In fact, a healthy 10 -year-old was recently described with herpes simplex esophagitis. ${ }^{30}$ In such a case, the condition is often associated with oropharyngeal and gingival primary herpes stomatitis. This has also been described with Candida albicans infections in normal children and in patients with chronic mucocutaneous candidiasis, where both laryngitis and esophagitis were present. ${ }^{202}$ Esophageal tuberculosis has also been reported. ${ }^{152}$

\section{Diagnosis}

Because the management of herpes simplex and of Candida albicans infections are so different, aggressive approaches to diagnosis are necessary. Clinical clues include fever, pain on swallowing, and retrosternal discomfort. When the patient has severe underlying disease, such as lymphoma or leukemia, or is known to have an immunodeficiency syndrome, including chronic mucocutaneous candidiasis, esophagoscopy and appropriate smears and cultures of suspicious lesions should be obtained. ${ }^{181}$ Malignancy or immunosuppression have been associated with fatal outcomes, as recently noted for Candida esophagitis in a patient with leukemia. ${ }^{180}$

Radiographic demonstration of mucosal irregularities is the most consistent finding in esophagitis, although direct visualization through the endoscope is sometimes needed to see small lesions. Some clinicians prefer to use radiography and a clinical trial of ketoconazole therapy in a high-risk patient with severe underlying disease, thrombocytopenia, or other contraindications to endoscopy. However, even when the oropharyngeal surfaces are covered with lesions due to Candida, the possibility of a treatable herpes simplex esophagitis cannot be ruled out. We, therefore, prefer to administer platelets and proceed with endoscopy and definitive microbiologic diagnosis.

\section{Treatment: Candida Esophagitis}

Candida albicans esophagitis has been treated with a variety of topical antifungals in viscous and other vehicles. The approach to these patients has been revolutionized by the introduction of oral ketoconazole. ${ }^{142}$ This drug in a dosage of $5-10 \mathrm{mg} / \mathrm{kg} /$ day, given as a single dose, is usually associated with symptomatic relief within the first week of therapy, except in the most severely affected individuals. Treatment should be continued 
for several weeks after resolution of the clinical and microbiologic features of the disease. In patients with chronic mucocutaneous candidiasis, treatment needs to be continued indefinitely. Nonetheless, this is a major advance in the treatment of these patients. One should look for emergence of resistant organisms, side effects of ketoconazole therapy, and other manifestations of the underlying disease. Intravenous amphotericin $\mathrm{B}$ may be required in resistant cases.

\section{Treatment: Herpes Esophagitis}

Acyclovir, $30 \mathrm{mg} / \mathrm{kg} /$ day, divided q $8 \mathrm{~h}$, will generally effect cure of herpes simplex esophagitis within 7-10 days. This is a rare diagnosis, but a potentially fatal one. When the host is immunocompromised, it becomes even more important to diagnose and treat this condition very aggressively. Adequate precautions should be taken to limit exposure of high-risk contacts to patients with oropharyngeal herpes simplex infections with or without esophageal involvement.

\section{Tuberculosis}

Tuberculosis has also been described as a cause of esophagitis. Diagnosis depends on a high degree of suspicion and specific endoscopic and microbiologic findings. Treatment is the same as for systemic tuberculosis.

\section{Complications}

Rarely, patients with esophagitis may have perforations that lead to mediastinitis. In such cases, toxicity is marked, and high fever, severe retrosternal pain, and respiratory embarrassment are often present. This is an acute medical emergency requiring aggressive and specific chemotherapy and drainage if purulent material is present.

\section{Hepatitis}

Hepatitis in newborns is discussed in Chapter 3 , particularly with regard to the transmission of infection from mother to newborn. Control measures for individual cases, protection of high-risk susceptible individuals, and management of outbreaks are discussed in Chapter 1; indications, doses, and side effects of passive and active immunizations are included.

\section{Epidemiology}

Hepatitis may be a manifestation of systemic infection or infection localized to the liver. Examples of the former include the jaundice noted in patients with bacterial sepsis and urinary tract infection, as well as the 
occasional involvement of the liver in tuberculosis, brucellosis, histoplasmosis, gonorrhea, $Q$ fever, and viremia (Table 6-17). The vast majority of isolated cases of hepatitis are due to hepatitis A and B viruses, as well as to a group of poorly characterized agents, currently designated as non-A, non-B. Rarely, two types of hepatitis may coexist. ${ }^{406}$

The relative frequency of the various causes of hepatitis varies according to age, socioeconomic characteristics, and other epidemiologic factors. In a recent survey in Stockholm, $30 \%$ of cases of hepatitis were due to type A, $46 \%$ to type $\mathrm{B}$, and the rest, presumably, to non-A, non-B. ${ }^{400}$

Hepatitis A. Hepatitis A is spread predominantly by fecal-oral contact and has an incubation period of 15-40 days. Attendance at day-care centers is currently the most important single associated factor in the spread of this disease in North America, accounting for approximately $10 \%$ of cases; ${ }^{392}$ this includes most symptomatic disease in adults as well. Common sources associated with fecally contaminated milk, food, and water may be responsible for large outbreaks. ${ }^{52}$ Transfusion of hepatitis

TABLE 6-17. Classification of Hepatitis

\begin{tabular}{l} 
Acute hepatitis \\
Subclinical \\
Symptomatic $\quad$ Nonicteric \\
Icteric \\
Fulminant \\
Hepatitis A \\
Hepatitis B \\
Hepatitis non-A, non-B \\
Other viruses \\
$\quad$ Cytomegalovirus \\
$\quad$ Herpes simplex \\
$\quad$ Coxsackie ${ }^{214}$ \\
$\quad$ Adenovirus \\
$\quad$ Epstein-Barr virus \\
$\quad$ Yellow fever \\
$\quad$ Rubella \\
Toxoplasma infection \\
Brucella infection \\
Syphilis \\
Leptospira infection \\
Q fever (Coxiella burnettii) \\
Chronic hepatitis \\
Subclinical: HB Ag carriers \\
Persistent: HB Ag in serum + portal triaditis \\
Active: HB Ag in serum + symptoms + \\
hepatocellular necrosis \\
\hline
\end{tabular}


A-containing blood, donated during the brief viremic phase of the infection (approximately 2 weeks before illness), can, rarely, cause posttransfusion hepatitis. ${ }^{362}$

Hepatitis B. Hepatitis B is usually spread by blood and blood products, although sexual transmission is not uncommon, particularly among homosexual men. Dialysis and transplant patients are also at high risk. ${ }^{17}$ However, dialysis does not usually present a risk for transmission of hepatitis A. ${ }^{246}$

Travel and a history of contact with hepatitis B are also frequently identified risk factors for infection with this virus. Occasionally, spread among classroom contacts ${ }^{279}$ and wrestlers ${ }^{190}$ has been noted. Residents of institutions for the mentally retarded have a high prevalence of illness and chronic carriage, probably related to living conditions. ${ }^{405}$ The incubation period is $1-6$ months and asymptomatic carriage is frequent. The prevalence of asymptomatic hepatitis of all types is partly responsible for the difficulties encountered in controlling these infections.

The Carrier State. There are an estimated 200 million cases of hepatitis $\mathrm{B}$ in the world at this time. Most of these are present in asymptomatic carriers. ${ }^{344}$ Since hepatitis B has been identified in blood, CSF, ${ }^{215}$ tears, ${ }^{90}$ saliva, semen ${ }^{343}$ and even in the vesicle fluid of a patient with concurrent hepatitis B and herpes zoster, ${ }^{272}$ opportunities for dissemination are great. Spread to and from individuals with certain occupations, such as dentists and oral surgeons, often presents a practical problem. ${ }^{310}$ The attack rate among these individuals has been estimated to range from $1 / 40$ to $1 / 400$ exposures, although the majority of these are expressed as asymptomatic infection. A chronic carrier state has been described for non-A, non-B hepatitis as well. In one such case, the patient's serum remained infectious for chimpanzees over a 6-year period (even in the absence of elevated liver enzymes). ${ }^{376}$ There is no carrier state for type A.

Non-A, Non-B Hepatitis. Drug addiction is a common finding in the histories of patients with non-A, non-B hepatitis; however, blood transfusions are frequently responsible in this group as well. Hemophilia presents a risk for both hepatitis B and non-A, non-B, with chronic liver abnormalities in as many as $8 \%$ of patients. ${ }^{315}$

\section{Etiology}

Viruses cause most cases of acute and chronic hepatitis, ${ }^{160}$ although this organ can be affected by almost all microorganisms (Table 6-17). Some of the parasitic causes of liver disease are included in Table 6-18. Hepatitis $B$ virus consists of four different subtypes, and it is likely that nonA, non-B hepatitis represents several different virus types as well. ${ }^{164}$ 
TABLE 6-18. Parasitic Infections of the Liver

Amebiasis

Toxocariasis (visceral larva migrans)

Echinococcosis

Schistosomiasis

Clonorchiasis and other liver flukes

Among these is included the delta agent, usually associated with $\mathrm{HB}_{\mathrm{s}} \mathrm{Ag}$, and almost always seen in drug addicts. ${ }^{258}$ Occasionally, virulent virus infections can involve the liver and, in some cases, may be fatal. This has been reported for herpes simplex (in normal ${ }^{239}$ and transplant patients), ${ }^{114}$ coxsackieviruses, ${ }^{239}$ and adenovirus. ${ }^{365}$

\section{Clinical Manifestations}

Over $90 \%$ of children with hepatitis are asymptomatic. ${ }^{71}$ In others, malaise, weakness, anorexia, and vague abdominal pain are first noted. This may be followed by nausea and vomiting, weakness, weight loss, more severe abdominal pain, and jaundice (Fig. 6-3). Occasionally, diarrhea, chills, and fever herald a more acute onset. The clinical signs and symptoms usually do not permit differentiation between the different causes, although myalgia and pharyngitis may be more frequently seen with type $A$, and a maculopapular erythematous rash and arthralgia with hepatitis B. When the latter occurs in the preicteric phase, this is often due to immune complex-mediated disease and serum complement concentrations may be low. This, as well as aplastic anemia, have also been reported with non-A, non-B infection. ${ }^{294}$ These patients can have frank arthritis and vasculitis with malignant hypertension. Children of all ages can be affected, as exemplified by an 8-month-old infant in whom the latter two signs were associated with biopsy evidence of chronic hepatitis. ${ }^{311}$

A papular erythematous, nonpruritic rash involving the face and extremities may also be seen with nonicteric hepatitis. This is called Gianotti disease and is often associated with lymphadenopathy as well ${ }^{337}$ (Fig. 6-4). The identical syndrome may be due to Epstein-Barr virus ${ }^{198}$, rather than hepatitis. ${ }^{335}$

The onset of hepatitis A is generally more abrupt than that of hepatitis B, although there is considerable overlap. When hepatitis becomes clinically evident by jaundice, serum bilirubin concentrations are usually above $3 \mathrm{mg} / 100 \mathrm{ml}$. In such cases, the presence of dark urine and chalky, lightly pigmented stools is often noted. Vomiting and dehydration may be prominent features in some of these patients. When these progress, fulminant hepatitis needs to be considered. This is extremely rare for all types of hepatitis, particularly type A. It may occur in up to $1 \%$ of cases 
Figure 6-3. Scleral and cutaneous jaundice in patient with acute hepatitis. For color reproduction of this figure see frontmatter.

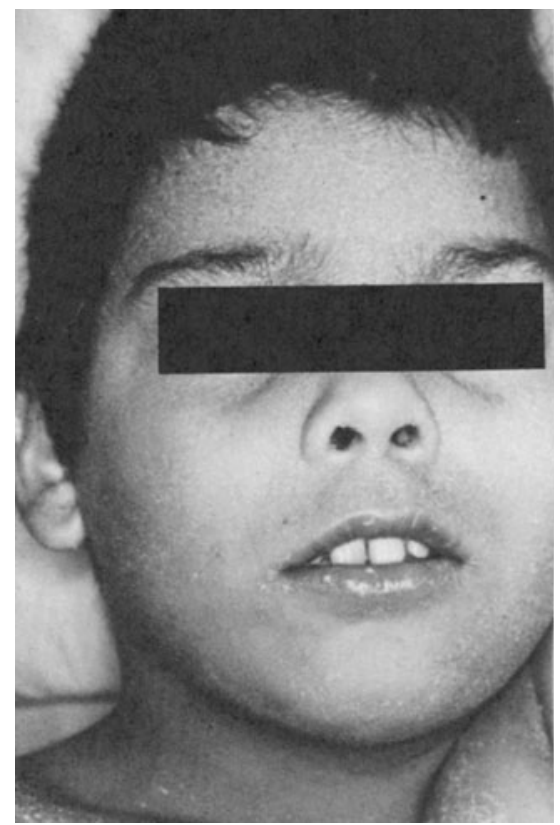

of type $\mathrm{B}$, where the mortality rate is at least $80 \%$. Deepening jaundice, encephalopathy, personality changes, somnolence, and progressive vomiting suggest this catastrophic event. Coma may then supervene. Physical examination in these patients may reveal hepatomegaly or a nonpalpable liver indicating severe hepatic necrosis. Liver tenderness is often marked in the early stages of hepatitis, but may be absent shortly thereafter.

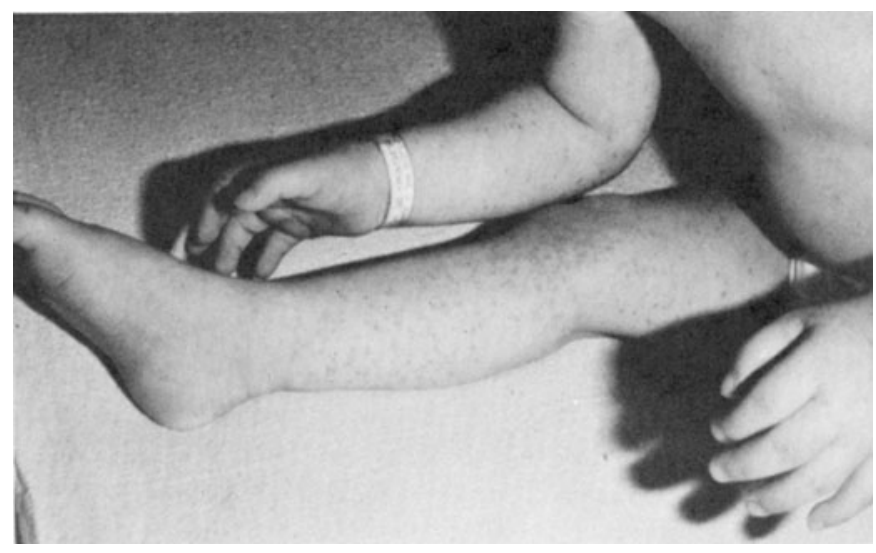

Figure 6-4. Papular acrodermatitis of Gianotti disease. For color reproduction of this figure see frontmatter. 


\section{Diagnosis}

Hepatitis is most specifically suggested by scleral and skin jaundice, although sometimes fever, rash, and arthritis may be the only clinical signs. The most sensitive laboratory indicators of hepatitis are elevated concentrations of hepatocellular enzymes. Serum glutamic pyruvic transaminase (SGPT) (alanine aminotransferase) are most specific; however, hyperbilirubinemia (usually equal direct and indirect components), elevated concentrations of alkaline phosphatase, serum glutamic oxaloacetic transaminase (SGOT), and lactic acid dehydrogenase enzymes are also present. The prothrombin time may be prolonged and the patient may not be able to metabolize many drugs that are normally cleared by the liver.

Etiologic diagnosis is critical to the management of hepatitis (Table 619). Hepatitis A can be diagnosed early by the detection of IgM antibody to this virus. This antibody may persist in the blood for up to 5 months..$^{392}$ A fourfold or greater rise of IgG antibody to this viral antigen is also diagnostic. Remember, IgG is passively transferred to newborns and can also be acquired via transfusion.

The serologic diagnosis of hepatitis $\mathbf{B}$ is complicated by the fact that the host responds to both surface and core antigens, and not always in a predictable fashion. Finding hepatitis $B$ antigen in the serum of a patient indicates either acute disease or the carrier state. The presence of antibody to hepatitis B surface or core antigens indicates acute infection or

TABLE 6-19. Serodiagnosis of Hepatitis

Acute hepatitis A

Hepatitis A: Past infection or passive immunization

Acute hepatitis B

Hepatitis B: Past infection or passive immunization

Chronic carrier hepatitis B

Chronic persistent hepatitis B

Chronic active hepatitis B
Anti-HAV IgM

Fourfold or greater rise in anti-HAV IgG Anti-HAV IgG

$\mathrm{HB}_{\mathrm{s}} \mathrm{Ag}$ (see chronic hepatitis also)

Fourfold or greater rise in anti- $\mathrm{HB}_{\mathrm{s}}$ or anti-HB

Anti-HB,

Anti-HB \pm anti-HB

$\mathrm{HB}_{\mathrm{s}} \mathrm{Ag}>6$ months

$\mathrm{HB}_{\mathrm{s}} \mathrm{Ag}>6$ months + elevated liver enzymes

$\mathrm{HB}_{\mathrm{s}} \mathrm{Ag}>6$ months + elevated liver enzymes + liver biopsy showing hepatocellular necrosis beyond the portal triads

Immune response to vaccination Anti- $\mathrm{HB}_{\mathrm{s}}$ 
previous infection with these viruses; however, fourfold rises of either of these antibodies in appropriately timed acute and convalescent sera are diagnostic of recent infection. ${ }^{7}$ Occasionally, hepatitis B surface antigen can disappear from the blood during fulminant hepatitis. This may be due to a presence of an excessive amount of antibody. ${ }^{375}$ The presence of IgM antibody to core antigen (anti-HBc IgM) may also distinguish acute type $B$ hepatitis from past infection with this virus. ${ }^{216}$

Liver biopsy is not usually needed for diagnosis, but can suggest the etiology or prognosis of hepatitis. Widespread granular swelling of hepatocytes, so-called ballooning, is characteristic of acute viral hepatitis. Precise dating of a lesion is not possible, but in latter stages cellular necrosis subsides and phagocytosis and portal infiltrates predominate. In chronic persistent hepatitis, there is minimal hepatocellular necrosis and lymphoplasmacytic inflammation is limited to portal tracts. Chronic active hepatitis features more widespread inflammation and necrosis, particularly at the interfaces of liver cells and connective tissue.

Granulomatous hepatitis can result from a wide variety of infectious (e.g., mycobacteria, histoplasma, parasitic) and noninfectious (e.g., sarcoidosis, drug-induced, immune deficiency) causes. ${ }^{157}$

\section{Treatment}

There is no specific treatment for acute hepatitis other than supportive care. The patient is often weak and may be dehydrated. Drugs, including alcohol, that are metabolized through the liver should be avoided, as should severe physical and emotional stress. Corticosteroids do not help. ${ }^{396}$

The patient with progressive hepatic injury in the acute stage will require management of the complications associated with liver failure. ${ }^{16}$ In such cases, neomycin is given orally and by enema to reduce the load of intestinal bacteria and absorption of their metabolic products. Vitamin $\mathrm{K}$, electrolytes, and fluids, as well as a low-protein diet, are also prescribed. There is little to suggest that other specific therapies are useful. In one report interferon therapy was associated with improvement in three of five patients with fulminant hepatitis, but controlled studies are not available. ${ }^{219}$ Heroic management of liver failure has included dialysis, exchange transfusion, ${ }^{240}$ and cross-circulation experiments, in an effort to reduce circulating metabolic toxins in the affected individual. Management of acute renal failure, which may be due to tubular necrosis that accompanies liver failure, may also be indicated. The prognosis in such cases is extremely grave and death is usually due to bleeding, electrolyte disturbances, encephalopathy, or superinfection.

The treatment of chronic active hepatitis is still in the experimental stages. There is some evidence that interferon, or interferon plus adenine arabinoside, may benefit these patients; ${ }^{345}$ however, adenine arabinoside 
has little effect when used alone. ${ }^{28}$ Corticosteroids ${ }^{211}$ and immunosuppressive therapy ${ }^{386}$ are not useful.

\section{Prognosis/Complications}

Since hepatitis may be only one component of a systemic infection, extrahepatic complications are often present. Hence, patients with herpes simplex hepatic infection may also manifest skin and neurologic involvement, and adenovirus infection and tuberculosis often have pulmonary pathology. With hepatitis due to type A, type B, and non-A, non-B viruses, acute fulmination and chronic persistent and active hepatitis may occur. ${ }^{305}$ These are least frequent in young children and in those with type $A$. Two percent of patients with hepatitis $\mathrm{B}$ and up to $25 \%$ of those with non-A, non-B disease may develop persistent or chronic active changes. ${ }^{400}$ Patients with acute hepatitis may also have aplastic anemia, ${ }^{418}$ pancreatitis, renal failure, pericarditis, ${ }^{3}$ membranous nephropathy, ${ }^{378}$ and central nervous system (CNS) manifestations, including meningoencephalitis. ${ }^{54}$ Occasionally, the CNS manifestations may occur in the prodromal period, in which meningitis, peripheral neuropathies, myelitis, and encephalitis have been reported. ${ }^{153}$ Although immunity is usually lifelong after recovery from infection, repeated episodes of hepatitis B due to different subtypes are possible. ${ }^{373}$

Chronic active hepatitis (as indicated by at least three times the normal concentration of serum transaminases for longer than 6 months) may be seen in some cases of hepatitis B even when serologic markers are not present. ${ }^{390}$ The development of chronic hepatitis is a particular risk of leukemic children, occurring in one-half of children in a recent study. ${ }^{231,390}$

One of the most important complications of chronic hepatitis B infection is the development of hepatocellular carcinoma. Predominantly a complication seen in adults, hepatoma has also been noted in a child 7 years after perinatal infection. ${ }^{32}$ Evidence for a causative role has been provided by the demonstration of the integration of hepatitis B viral DNA into liver cell genomes. ${ }^{354}$ Although hepatocellular carcinoma is relatively infrequent in North America, it is the leading cause of death from cancer worldwide.

\section{Prevention}

Use of passive and active immunization for the prevention of hepatitis is discussed in Chapter 1 and, for newborns, in Chapter 3. Several points deserve emphasis. Hepatitis A outbreaks in day-care centers require aggressive action. Passive immunization of the students, day-care center employees, and adult members of the households of infants wearing 
diapers who attend day-care centers should be instituted quickly. ${ }^{150}$ This is because the majority of the children who wear diapers will have asymptomatic infection, and spread is common among adults exposed to these children. ${ }^{149}$ Since many of these children will be in the first 2 years of life, their active immunizations should be deferred for 3 months after the use of immune globulin. Fecal shedding of hepatitis A virus is most intense 1 week before and 1 week after peak elevation of serum glutamic pyruvic transaminase, but the reported range is from 19 days before peak to 25 days afterwards. ${ }^{234}$ Moreover, hepatitis A virus may remain viable in dried fecal material for a month at room temperature. ${ }^{247}$ These data should be considered in formulating isolation recommendations for fecally incontinent hospitalized patients with unexplained liver abnormalities. Such patients present an increased risk of nosocomial spread of hepatitis. ${ }^{280}$

Dentists and surgeons should use gloves, masks, and protective eye wear ${ }^{310}$ to protect themselves from acquiring hepatitis B from their patients, and, if they are carriers, to prevent spread to their patients.

The frequency of spread of non-A, non-B hepatitis can be reduced (by approximately $30 \%$ ) by screening donor blood for alanine aminotransferase concentrations ${ }^{8}$. Screening blood and blood products for the presence of hepatitis B surface antigen is also effective.

\section{Parasitic Causes of Hepatitis}

Several parasitic infections, such as amebiasis, are common worldwide and involve the liver as their primary target site (Table 6-18).

Toxocariasis. Toxocariasis (most frequently seen in 1-4-year-olds) is usually acquired by ingestion of infected dog and cat feces, or soil containing these materials. Sandboxes in playgrounds are a very high-risk site. Infected patients are usually asymptomatic, although a small number develop fever, cough, wheezing, and some also have weight loss and hepatomegaly. Pulmonary infiltrates may be present transiently. The diagnosis is most specifically suggested by the presence of hepatomegaly, eosinophilia, and elevated serum concentrations of IgE. The diagnosis can be confirmed by the measurement of Toxocara ELISA antibodies. Thiabendazole treatment is usually helpful (Chapter 2).

Echinococcosis. Echinococcus eggs are present in dog feces and may be ingested by young children. Hepatomegaly is the most prominent sign and is usually due to the presence of single or multiple cysts, most often in the right lobe of the liver. Eosinophilia is commonly present and lung involvement may also be apparent. Ultrasound, radioisotope scanning, or computerized axial tomography are most useful for diagnosis, which 
is confirmed by appropriate serology. ${ }^{148}$ Treatment consists of surgical removal of the cyst, although mebendazole ${ }^{194}$ (Chapter 2), and another benzimidazole-carbamate, albendazole, ${ }^{332}$ may also be useful in selected cases.

Schistosomiasis. Schistosomiasis is prevalent worldwide and is acquired by young children in the toddler age group when they walk barefoot in water. The parasite is carried by fresh water snails whose eggs (cercariae) penetrate the skin. The first manifestation of this infection is often called "swimmer's itch," and is associated with a pruritic skin rash and hematochezia. ${ }^{371}$ Subsequently, a serum sickness-like reaction may occur with a rash, fever, eosinophilia, and arthralgia. This is sometimes called "Katayama fever." In a very few patients, hepatomegaly and subsequent cirrhosis, portal hypertension, and splenomegaly occur. ${ }^{397}$ The most serious threat to such patients is progressive liver failure with portal hypertension and hemorrhage from esophageal varices. ${ }^{412}$ The diagnosis is made by detection of ova in stools, urine, or rectal biopsy (Fig. 6-5). Treatment consists of therapy with oxamniquine ${ }^{371}$ or praziquantel (Chapter 2).

Liver Flukes. Clonorchis sinensis, Opisthorchis viverrini (seen in Russia and Southeast Asia), and Fasciola hepatica may also cause hepatic injury, most commonly manifest as cholangitis. ${ }^{372}$ They are acquired by eating insufficiently cooked fish or meat. The diagnosis is made by visualization of eggs in the stool. No effective treatment is known, although praziquantel may prove useful in some cases (Chapter 2).

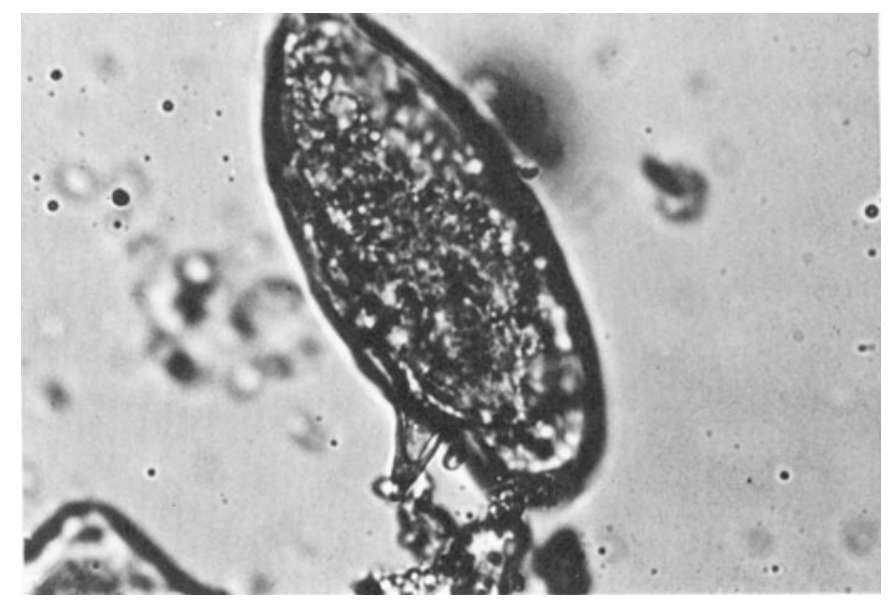

Figure 6-5. Ovum of Schistosoma mansoni. 


\section{Hepatic, Splenic, and other Intraabdominal Abscesses}

\section{Pathogenesis/Etiology}

Intraabdominal abscesses are most frequently seen after peritoneal soiling due to rupture of the appendix or other viscus, secondary to inflammatory or traumatic conditions. Abscesses of the liver and other intraabdominal sites are seen after venous catheterizations, abdominal surgery, and in immunocompromised patients. The location of the abscess is often dependent on the source of the infection and the position of the patient. After diffuse peritoneal soiling, localization under the liver (subhepatic abscess) or under the diaphragm (subdiaphragmatic) can be seen. Although they are extraperitoneal, renal, adrenal, and other retroperitoneal abscesses have many of the characteristics of intraabdominal abscesses and the principles of diagnosis and management are the same.

No age group is immune to intraabdominal abscess formation; however, the condition is relatively rare at all ages. Newborns may be particularly susceptible because of their immunologic immaturity and their exposure to vascular cannulations and bacteremic episodes during intensive care. Enteric organisms, and Listeria, Pseudomonas, and Candida abscesses may be found in the livers of such patients. ${ }^{265}$

Patients with chronic granulomatous disease or leukemia may have staphylococcal liver abscesses or mixed infections, including anaerobic bacteria. ${ }^{73}$ Intraabdominal sepsis after peritoneal soiling is commonly polymicrobial, and anaerobic bacteria are frequently involved..$^{25}$ Amoeba, parasites, such as echinococcus, ${ }^{189}$ enteric bacteria, and streptococci ${ }^{262}$ should be considered in the etiologic spectrum of microbes causing liver abscesses.

Splenic abscesses are unusual, only 11 cases being diagnosed over a 30 -year period in a major United States medical center ${ }^{340}$ However, this diagnosis should be considered in patients who have been bacteremic, in individuals who abuse intravenous drugs, and in others who have appropriate symptoms. A variety of infections, including those with enteric bacteria, Staphylococcus, and $C$. difficile and other anaerobes may be involved. ${ }^{391}$

\section{Clinical Manifestations}

Fever, abdominal pain, and hepatomegaly are the major signs of hepatic abscess. Similar features are noted in association with left-sided pain when splenic abscess is present. Other causes of intraabdominal sepsis are more difficult to localize clinically; however, perirectal masses and tenderness may be present with pus collections in the pelvic area. ${ }^{55}$ Shoulder tip discomfort may be a sign of subdiaphragmatic abscess, as may 
chest pain and respiratory signs. Anemia, fever of unknown origin, or gastrointestinal or urinary obstruction are occasionally the only signs.

\section{Diagnosis}

Modern noninvasive techniques such as radionuclide scans and computerized tomography have simplified the diagnosis of intraabdominal abscesses. ${ }^{121}$ Ultrasonography or "11'indium-labelled leukocyte scans can also be used, although the latter technique is still investigational ${ }^{65}$ Confirmation of the etiology often requires percutaneous needle aspiration, laparoscopy, or laparatomy.

\section{Treatment}

The diagnosis of an intraabdominal abscess should prompt a review of the pathogenesis. Neglected appendicitis, other foci leading to bacteremia, or immunodeficiency may thus be found. The abscess itself should be aspirated by the percutaneous route in order to establish an etiologic diagnosis. This can be guided by ultrasonography ${ }^{36}$ or computerized tomography ${ }^{388}$ These techniques can also be used to treat some of these lesions. In selected cases, however, laparatomy and more complete drainage are critical to therapeutic success. ${ }^{391}$

It is clear from a review of the etiology of intraabdominal abscesses that polymicrobial infections are common, ${ }^{55}$ as are bacterial, parasitic, protozoan, and fungal causes. Blind therapy of these lesions is, therefore, fraught with hazard. Microbiologic, serologic, and histopathologic data are often essential for appropriate management. Antimicrobial therapy should usually be continued for approximately 4-10 weeks, with shorter courses made possible by complete drainage of the lesion. ${ }^{293}$

\section{Cholecystitis}

\section{Pathogenesis/Epidemiology}

Cholecystitis is uncommon in the pediatric population. As in adults, obese girls seem at higher risk, " as do pregnant individuals, particularly those with associated urinary tract infections. ${ }^{348}$ Other predisposing factors include hemolytic diseases (e.g., sickle-cell disease and glucose-6-phosphate dehydrogenase deficiency) congenital anomalies of the biliary tree, pancreatitis, and traumatic liver injury.

\section{Etiology}

The incidence of cholecystitis without biliary calculi seems more frequent in children than in adults. In such circumstances, infection of the bile 
and gallbladder may be a complication of a systemic infection, such as scarlet fever, ${ }^{98}$ leptospirosis, ${ }^{27}$ or secondary to gastrointestinal infection. The bacteriology of acute cholecystitis in children is predominantly that of enteric bacteria, such as E. coli, Klebsiella, Streptococcus faecalis, and anaerobic bacteria. Patients with Salmonella infection, including typhoid, and those with mucocutaneous lymph node syndrome may also have gallbladder involvement in the early or late convalescent stages of their illnesses. Various causes of biliary obstruction, such as ascariasis, may also be responsible. Rarely, air in the biliary tract (emphysematous cholecystitis) may indicate the presence of infection due to gas-producing bacteria. ${ }^{324}$

\section{Clinical Manifestations}

Abdominal pain is marked in acute cholecystitis. Occasionally, a palpable mass in the right upper quadrant may provide a clue to the presence of cholecystitis or hydrops of the gallbladder. Nausea and vomiting are often present as well, but fever may be absent in two-thirds of cases.

\section{Diagnosis}

Although jaundice or subclinical hyperbilirubinemia is uncommon in patients with cholecystitis, patients with underlying liver or biliary tract disease may have persistent elevations of serum bilirubin and alkaline phosphatase. Patients with hemolytic diseases should also be carefully examined for the presence of biliary tract stones. Oral or intravenous cholecystograms may help confirm the diagnosis, as may ultrasonography or tomography.

\section{Treatment}

Cholecystectomy is the treatment of choice for this condition. Antibiotics are rarely needed, except if complications of surgery occur. In rarer circumstances where surgery is not possible, antibiotic therapy directed against enteric bacilli, such as combinations of metronidazole or clindamycin with aminoglycosides or cefoperazone, is useful. Kanamycin, amikacin, and cefoperazone penetrate into the bile and gallbladder wall particularly well. ${ }^{156}$ Although cefamandole penetrates into bile, ${ }^{309}$ this drug should be used only if specific microbiologic cultures (i.e., bile, gallbladder, or blood) demonstrate a susceptible causative organism. When cholecystitis is associated with calculi that cannot be removed, congenital anomalies of the biliary tract, cholangitis, or peritonitis, antibiotic therapy may be an important adjunct to biliary drainage.

Thus, cholecystitis is rarely a primary infection of infants and children, but more commonly presents as a complication of a congenital or trau- 
matic condition, obstruction, calculi, hemolytic disease, or associated with systemic infectious or inflammatory diseases.

\section{Cholangitis}

\section{Clinical Features/Pathogenesis/Etiology}

The most common predisposing condition for recurrent cholangitis is portoenterostomy, often used to correct biliary atresia. These patients have nausea and vomiting, fever, shaking chills, paralytic ileus, or other signs of acute abdominal distress. Bacterial hepatitis may also be present. Because of this risk, trimethoprim/sulfamethoxazole and phenobarbital (to increase bilirubin conjugation and excretion) prophylaxis is often prescribed for 1 year after such an operation..$^{22}$

Other factors that may predispose to cholangitis include acquired or congenital structural defects of the hepatobiliary system, generalized sepsis, and biliary tract stones and surgery. Underlying disease is not always present. For example, a normal 10-week-old presented with fever of unknown origin, hepatosplenomegaly, anemia, and increased partial thromboplastin time. ${ }^{413}$ Liver biopsy provided the etiologic diagnosis, a useful procedure in the diagnosis of cholangitis. In this case, Enterobacter agglomerans was cultured, which was responsive to therapy.

Parasitic infestations, particularly infections with liver flukes (see Hepatitis), and, rarely, ascariasis may also present as cholangitis.

\section{Diagnosis}

It should be remembered that cholangitis in older patients is characterized by severe shaking chills, right upper quadrant pain, and occasionally, right shoulder pain. Nausea, vomiting, signs of acute abdominal injury, and jaundice may also be present. Diagnosis is made on the basis of blood cultures, abnormal liver function tests, and cholecystography. Computerized axial tomography or ultrasonography may show a dilated biliary tract or stones. If a liver biopsy is carried out, a blood culture obtained after biopsy may be useful, as organisms are often liberated into the systemic circulation by this procedure. Urine culture is useful in all cases of hepatic and biliary infection because of the possibility of associated urinary tract infection.

\section{Treatment}

Treatment of cholangitis is the same as described above for cholecystitis. Trimethoprim/sulfamethoxazole may be used in selected patients because of its excellent penetration into biliary tissue. ${ }^{163}$ Remember, the 
majority of these patients have underlying diseases and control of cholangitis usually brings about dramatic, but temporary, relief, if the predisposing factors are not corrected. Patients with portoenterostomies, in fact, suffer from recurrent cholangitis, and liver failure may result unless effective drainage is carried out.

\section{Pancreatitis}

\section{Pathogenesis}

The pancreas may be infected in a variety of ways, none of which is very common. First, it may occur as part of a generalized process, as in mumps or coxsackie virus infections. This is much less commonly noted in bacterial infections, although patients with septic shock may have pancreatic involvement secondary to direct bacterial invasion, endotoxin, or hypoxemia.

Pancreatitis, with or without abscess formation, may also be associated with bacterial superinfections after trauma and surgery.

Finally, late complications of the direct effects of infection or an interplay of infectious agent and genetic, drug-induced, or autoimmune factors may produce diabetes mellitus. This is seen in congenital rubella ${ }^{253}$ and, occasionally, after acquired mumps or coxsackie virus infections. ${ }^{199}$

\section{Etiology}

Some infectious and noninfectious causes of pancreatitis are listed in Table 6-20. The evidence for mycoplasma infections is serologic and caution is urged in accepting these case reports as proof of a direct causative relationship. ${ }^{277}$

\section{Clinical Manifestations}

Acute pancreatitis is most commonly heralded by severe abdominal pain. This may be referred to the back, the epigastrium, or the lower abdomen. Such pain, after abdominal trauma, is highly suggestive of pancreatic injury. Vomiting may also be present in both the acute and chronic forms of the disease. Complications of pancreatitis may lead to the presence of paralytic ileus, pleural effusions, or ascites. ${ }^{184}$

\section{Diagnosis}

The above clinical signs may be associated with an increase in the peripheral white blood cell count, hyperbilirubinemia, elevated or reduced serum concentrations of calcium, and hypercholesterolemia. Serum am- 


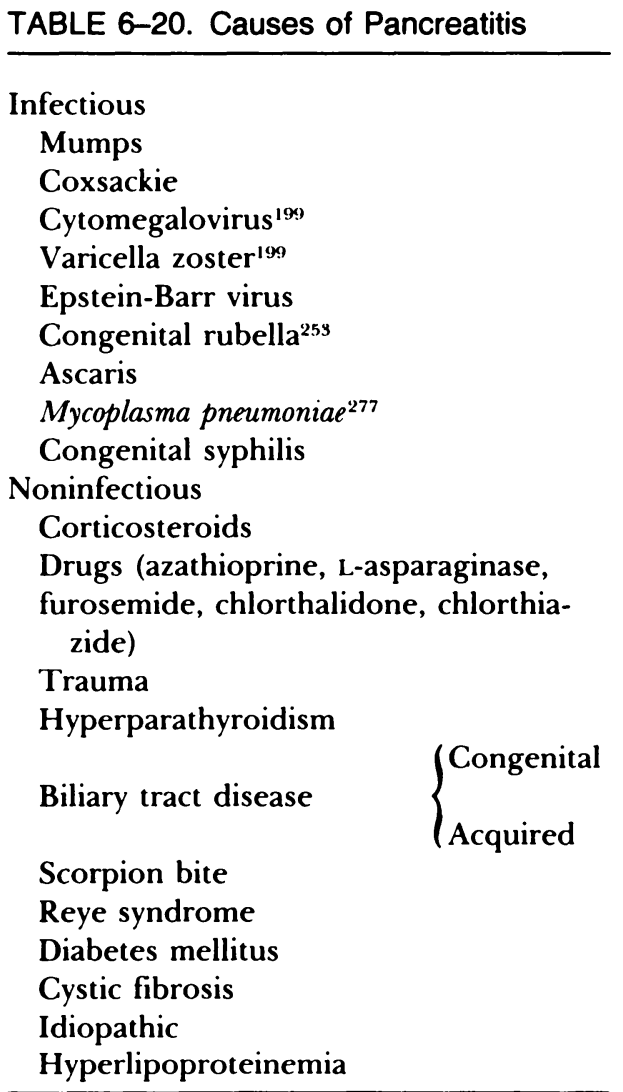

ylase and lipase levels are usually elevated. Although it is stated that serum amylase levels three times normal values are diagnostic, this may also be seen in occasional cases of parotitis, mumps, biliary disease, bacteremia, and abdominal trauma. Ultrasonography may demonstrate reduced echodensity of the pancreatic tissue or a pseudocyst. ${ }^{83} \mathrm{Com}$ puterized tomography may also be useful when cysts are present.

\section{Complications}

As mentioned above, gastrointestinal and peritoneal complications have been noted, usually after traumatic pancreatitis. Sepsis and pancreatitis may also increase the risk of developing pancreatic abscesses, associated pneumonias, and peritonitis.

A late complication of pancreatic involvement by infectious pancreatitis may be the development of diabetes mellitus. ${ }^{67}$ The pathogenesis is felt to involve pancreatic injury with formation of antibodies against pancreatic islet cell tissue and the development of diabetes mellitus several years later. ${ }^{15}$ These autoantibodies have also been demonstrated in both 
coxsackie virus and mumps virus infections in the absence of pancreatitis. ${ }^{159}$ Pancreatic abscess is a rare complication of septicemia or traumatic pancreatitis. $^{314}$

\section{Management}

Pancreatitis is rarely diagnosed as an isolated illness. Generally, treatment is directed at the infectious cause, such as septicemia, or parasitic infection. In other situations, therapy may be directed at peritonitis, associated pneumonia, or, in rare cases, pancreatic abscess. In the latter instance, anaerobic bacteria and enteric organisms may be found as well as Staphylococcus aureus. Aggressive diagnostic procedures with appropriate microbiologic studies are indicated. Patients with pancreatitis associated with trauma, surgery, or biliary tract diseases rarely require antibiotic therapy. Pseudocysts usually contain sterile fluid filled with debris and digested tissue, and generally do not require antibiotic therapy or prophylaxis.

\section{Peritonitis}

\section{Pathogenesis}

There are several ways in which peritonitis may occur, and the microbiologic causes are extremely diverse (Table 6-21). Peritonitis is most commonly a complication of peritoneal dialysis or perforated bowel. Approximately $1 / 100-1 / 1000$ dialysis episodes may be associated with peritonitis. ${ }^{2+8}$ In part, this may be due to the fact that peritoneal dialysate may be inhibitory to polymorphonuclear phagocytosis and intracellular bactericidal activity. ${ }^{107}$ Staphylococcal nasal carriers may also be at risk for dialysis-associated staphylococcal peritonitis. ${ }^{351}$

Many cases occur in situations where bowel perforation develops after appendicitis or after surgery. A rare exception is bowel perforation due to ventriculo-peritoneal shunt irritation. ${ }^{350}$

Primary peritonitis occurs in patients with ascites due to a wide variety of underlying conditions, including liver disease, nephrotic syndrome, and postoperative conditions. Normal subjects may also develop peritonitis, although this comprises $<1 \%$ of cases of acute abdominal infection.

\section{Etiology (Table 6-21)}

This infection, in patients undergoing peritoneal dialysis (many on a continuous basis at home), is sometimes referred to as "ambulatory peritonitis" (Table 6-22). Staphylococci account for $30-40 \%$ of infections 
TABLE 6-21. Classification of Peritonitis

\begin{tabular}{|c|c|}
\hline Type & Most Common Infectious Agent \\
\hline Primary & $\begin{array}{l}\text { Streptococcus pneumoniae, Streptococcus } \\
\text { pyogenes }\end{array}$ \\
\hline Bowel perforation & $\begin{array}{l}\text { E. coli, B. fragilis, group D Streptococ- } \\
\text { cus, Candida }\end{array}$ \\
\hline Peritoneal dialysis & $\begin{array}{l}\text { Staphylococcus epidermidis, Staphylococcus } \\
\text { aureus, gram-negative enteric bacilli, } \\
\text { Yeasts }\end{array}$ \\
\hline $\begin{array}{l}\text { Nephrotic syndrome } \\
\text { Other }\end{array}$ & Streptococcus pneumoniae, E. coli \\
\hline V-P shunt & $\begin{array}{l}\text { S. aureus, } S \text {. epidermidis, gram-negative } \\
\text { enteric bacilli }\end{array}$ \\
\hline Septicemia & Variable \\
\hline Tuberculosis & M. tuberculosis \\
\hline Pelvic inflammatory disease & $\begin{array}{l}N . \text { gonorrhoeae, Ureaplasma urealyticum, } \\
\text { Chlamydia trachomatis, anaerobic bac- } \\
\text { teria. } \\
\text { Actinomyces (with intrauterine con- } \\
\text { traceptive device). } \\
\text { S. pneumoniae (with intrauterine con- } \\
\text { traceptive device). }{ }^{145}\end{array}$ \\
\hline
\end{tabular}

in these patients. ${ }^{213}$ In one-third, sterile fluid is obtained, and, in some circumstances, peritonitis may be a response to endotoxin. ${ }^{188}$ In others, atypical mycobacteria (Mycobacterium chelonei) may be responsible. In one particular outbreak, 5/22 patients undergoing intermittent chronic peritoneal dialysis acquired mycobacterial peritonitis by cross-infection through a contaminated dialysis machine. ${ }^{20}$ Candida albicans ${ }^{176}$ (and other species including C. parapsilosis), ${ }^{217}$ Drechslera spicifera, ${ }^{283}$ Bordetella bronchi-

TABLE 6-22. Infectious Causes of Ambulatory Peritonitis

Staphylococcus epidermidis

Staphylococcus aureus

E. coli

Pseudomonas aeruginosa

Anaerobic bacteria

Candida spp.

Aspergillus

Nocardia

Mixed 
septica, ${ }^{60}$ and Aspergillus and Nocardia ${ }^{13}$ infections have also been described. Thus, the microbiology of ambulatory peritonitis is diverse indeed!

Infants and children with nephrotic syndrome may also develop peritonitis, particularly when ascites and hypogammaglobulinemia are present. In a recent review of 310 children with nephrotic syndrome, 24 episodes were documented in 19 children. ${ }^{206}$ Thirteen were due to pneumococcus, five to $E$. coli, one to Bacteroides fragilis, and one to $\alpha$-Streptococcus species. Others have reported streptococci, including group B Streptococcus, ${ }^{21}$ and Haemophilus influenzae. ${ }^{70}$

In newborns undergoing gastrointestinal surgery the peritoneal cavity may be contaminated with $E$. coli, B. fragilis, and group D streptococci. ${ }^{35}$ Fungal peritonitis may also occur after bowel perforation. ${ }^{306}$

Although less frequent today, tuberculous peritonitis is seen in countries in which tuberculosis is prevalent. These patients suffer from chronic abdominal pain and gastrointestinal dysfunction. ${ }^{99}$

Primary peritonitis (i.e., in normal hosts without a known predisposing condition) are usually due to pneumococci, streptococci, or enteric gramnegative bacteria. Anaerobic bacteria (e.g., Fusobacterium necrophorum) may rarely be causative, ${ }^{245}$ as may Clostridium perfringens ${ }^{409}$ and Haemophilus influenzae. ${ }^{138}$

\section{Clinical Manifestations}

Peritonitis is characterized by diffuse abdominal distension and, sometimes, a rigid abdomen. In many of these cases, rebound tenderness is obvious and bowel sounds may be reduced or absent. Fever, ascites, vomiting, and, occasionally, diarrhea, may also be present. In some cases, the abdominal pain may be severe enough to mimic appendicitis. Pneumoperitoneum (demonstration of gas in the peritoneal cavity) may indicate bowel perforation or the presence of E. coli ${ }^{302}$ or Clostridium welchii. ${ }^{361}$

\section{Diagnosis}

When the above clinical signs are noted, a plain radiograph of the abdomen may reveal free air or paralytic ileus. Aspiration of peritoneal fluid is the next step. Gram stain may reveal the causative organism, although yeasts may also be seen in unstained wet preparations. Cultures should be appropriate for aerobic and anaerobic bacteria, as well as for fungi and, in selected cases, acid-fast bacilli. Peritoneal biopsy may be useful in cases with more chronic presentations and where tuberculosis is suspected. Finding peritoneal granuloma raises an interesting, albeit rare, differential diagnosis (Table 6-23).

In patients receiving peritoneal dialysis, examination of the dialysate 


\begin{tabular}{l} 
TABLE 6-23. Causes of Granulomatous \\
Peritonitis \\
\hline Tuberculosis \\
Histoplasmosis \\
Coccidiomycosis \\
Blastomycosis \\
Cryptococcosis \\
Candidiasis \\
Actinomycosis \\
Nocardiosis \\
Syphilis \\
Brucellosis \\
Tularemia \\
Foreign body reactions (e.g., talc) \\
Hypersensitivity (e.g., beryllium) \\
\hline
\end{tabular}

for the presence of leukocytes and bacteria can be very helpful. ${ }^{200}$ An increase in the number of leukocytes should prompt early therapy for staphylococci, unless the gram smear suggests other etiologies. Cultures should be obtained in all cases and antimicrobial therapy adjusted appropriately.

\section{Treatment}

Treatment is generally guided by the results of the gram stain and, later, by microbiologic culture. Nonetheless, several clues can be provided by knowledge of the most likely etiologies of the various forms of peritonitis (Table 6-21). Hence, antistaphylococcal therapy is indicated early for treatment of peritonitis in patients receiving peritoneal dialysis. Neonatal peritonitis associated with gastrointestinal perforation can be treated with combinations of ampicillin, gentamicin, and clindamycin, in consideration of the bacterial flora found in many of these cases. ${ }^{35}$ The cornerstone of treatment of bacterial peritonitis due to bowel perforation in individuals of all ages includes early surgery to repair the leak, debridement of necrotic tissue, and drainage of any abscesses that are present. Peritoneal lavage with or without antibiotics seems to add little to these procedures. ${ }^{169}$ Parenteral antibiotic therapy is usually adequate, since most drugs diffuse extremely well into the inflamed peritoneal cavity. For example, approximately $68 \%$ of the serum concentration of gentamicin was found in the peritoneal fluid in such patients in a recent study. ${ }^{312}$ Those considering using povidone-iodine for lavaging the contaminated peritoneal cavity should pay heed to the mortality associated with this procedure in experimental peritonitis in dogs. ${ }^{48}$ Remember, the peritoneal surface is extremely large and absorptive, and aminoglycosides, iodine, and other substances may rapidly reach the systemic circulation. 
Patients receiving peritoneal dialysis present some special problems ${ }^{248}$ as a result of the diversity of causes and the presence of the dialysis catheter. When the catheter malfunctions, it must be removed. In other cases, early effective antibiotic therapy may avoid the need to remove the catheter. The most frequent bacterial causes of peritonitis in patients receiving dialysis can be treated early by adding antibiotics to the dialysis fluid. ${ }^{124}$ In general, most antibiotics, such as cephapirin, gentamicin, nafcillin, ticarcillin, and vancomycin are stable for $24 \mathrm{~h}$ at room temperature in dialysis fluid. ${ }^{352}$ This may be a problem with penicillin, however, since approximately $25 \%$ of activity is lost during this period of time. Systemic antibiotics can also be used, ${ }^{200}$ as most $\beta$-lactams enter the peritoneal fluid easily. ${ }^{40 x}$

Although early therapy is directed against the common bacterial causes (Table 6-21), the possibility of yeast infection should also be kept in mind. ${ }^{306}$ In such circumstances amphotericin $B$ has been used intravenously or combined with the intraperitoneal route. ${ }^{283}$ A peritoneal dialysate final concentration of amphotericin B of approximately $2-5 \mu \mathrm{g} / \mathrm{ml}$ will inhibit most Candida species; however, even this concentration of amphotericin may be prohibitively painful. Flucytosine and miconazole have also been used in the treatment of fungal peritonitis. ${ }^{217}$ In general, it is useful to begin to treat these fungal infections by the oral route (e.g., flucytosine, ketoconazole) although combined systemic and intraperitoneal therapy may be required. Cases that remain resistant to therapy will probably require catheter removal.

The duration of antibiotic therapy is variable, and depends on the specific cause of peritonitis and host factors. The less immunocompromised the host, the shorter is the duration of therapy. In all instances, this should be at least a week. Since many patients are abnormal (nephrotic syndrome, cirrhosis, renal failure), at least 2 weeks of therapy is needed. Tuberculous peritonitis, of course, may require 9 months to a year of therapy with at least two first-line drugs (e.g., isoniazid and rifampin).

\section{Prevention}

Prevention may be useful in patients undergoing chronic ambulatory peritoneal dialysis. A recent study demonstrated that $1 \mathrm{~g}$ of cloxacillin given at bedtime reduced the frequency of staphylococcal infections in these patients. ${ }^{129}$ Extension of these observations by other workers may suggest alternative chemoprophylactic regimens.

\section{Complications}

Complications of peritonitis can be seen in two stages. Initially, dehydration, septicemia, shock, and death may occur in acute bacterial sepsis and in peritonitis associated with bowel gangrene or perforation. Tuberculous peritonitis, if untreated, may also be fatal in as many as $50 \%$ 
of cases. More frequently, however, peritonitis leads to the formation of intraperitoneal abscesses, particularly when Staphylococcus aureus or Pseudomonas aeruginosa are involved. Persistent fever and/or leukocytosis are warning signals that this complication may be developing. ${ }^{218}$ Adhesions and intermittent abdominal pain syndromes are also seen. Rarely, hydronephrosis and hydroureter may occur in response to peritoneal irritation. The pathogenesis is thought to be similar to that responsible for paralytic ileus. ${ }^{230}$ The long-term prognosis for patients with most forms of peritonitis is excellent, if abscesses are carefully drained and adequate antimicrobial therapy provided.

\section{Appendicitis}

Appendicitis is the most common abdominal condition requiring surgery in North America. The problem is one of obstruction with secondary infection, and the outcome depends on the speed of diagnosis. Patients with symptoms lasting longer than approximately $48 \mathrm{~h}$ are likely to have gangrenous changes of perforation, both of which are associated with increased morbidity and subsequent complications. The diagnosis is often difficult because of the many conditions that can be associated with acute abdominal pain and fever, and the nonspecific signs seen with appendicitis. The younger the patient, the more difficult is the diagnosis.

\section{Etiology}

Obstruction is usually secondary to unknown causes, although impaction of pinworms, fecal material, and foreign bodies has been described. Sometimes, extrinsic compression or bowel edema due to infection may predispose the patient to appendicitis.

\section{Differential Diagnosis}

It should be remembered that pneumonia may also cause fever and abdominal pain. Hence, a chest X-ray should routinely be obtained in patients with this presentation. Moreover, influenza $B$ may present with severe abdominal pain, even in the absence of respiratory signs. ${ }^{223}$ Gastrointestinal and lymphatic (mesenteric lymphadenitis) infections due to Yersinia enterocolitica, $Y$. pseudotuberculosis, and Campylobacter may also result in "pseudoappendicitis" syndromes, even in newborns with colic. ${ }^{251}$ In fact, many of these patients have been operated on early in their course of disease before diarrhea became obvious. Urinary tract infection, pancreatitis, atypical measles, and, occasionally, enterovirus infections ${ }^{223}$ may also mimic appendicitis. Add to these hepatitis, infectious mononucleosis, ovarian pathology, intussusception, volvulus, Meckel diverticulum, and 
school phobia, and one can easily understand the difficulty in making an early diagnosis in many patients.

\section{Clinical Manifestations}

In patients over the age of 2 years, abdominal pain, nausea, vomiting, and anorexia are the most consistent findings in acute appendicitis. ${ }^{249}$ In those under 2 years, fever, vomiting, diarrhea, and abdominal distension are more prevalent. Leukocytosis with a shift to the left may be present, although this does not specifically indicate the diagnosis. Nor does the radiographic finding of ileus. Free air in the peritoneal cavity suggests perforation. Experience with radioisotope scanning is limited and, because of the time factor involved, may not be a useful approach.

The diagnosis of appendicitis in newborns is even more difficult and the mortality rate in infants may be $50 \%$ or greater. ${ }^{357}$ Edema of the abdominal wall and abdominal distension are important signs, albeit late ones, in this age group.

\section{Complications}

The mortality rate in appendicitis in North America is approximately $0.2 \%$ overall, and $0.5 \%$ when gangrene is present. However, in children under the age of 8 years, mortality rates of $2-3 \%$ have been reported. ${ }^{249}$ Wound infection, peritonitis, septicemia, bowel obstruction, and intraperitoneal abscesses in and around organs, such as the liver, are also seen.

\section{Treatment/Prevention}

Although acute appendicitis and its great imitator, mesenteric lymphadenitis, cannot be prevented, some of the complications of surgery in these patients can be. There is evidence that prophylactic administration of antibiotics is not very useful in acute appendicitis without gangrene or perforation. ${ }^{299}$ However, perioperative prophylactic antibiotics are useful in patients with gangrene or impending or early perforation. ${ }^{59} \mathrm{~A}$ combination of clindamycin plus gentamicin is useful in this situation. ${ }^{161}$ When either peritonitis or abscess formation is not present at the time of the operation, antibiotics can be discontinued on the day of surgery (they are usually started approximately $\mathbf{l} \mathrm{h}$ before operation).

When peritonitis is present, appropriate smears and cultures should be obtained and antibiotics continued for approximately 1 week. Antibiotics active against Bacteroides fragilis and Pseudomonas aeruginosa are important components of the medical management of perforated appendicitis. ${ }^{161}$ Anaerobic cultures should be included and defervescence is expected within 48-72 h. Should discharge, fever, severe abdominal pain, 
ileus, etc., continue, attempts to diagnose intraperitoneal abscesses that may have been missed at operation, or that developed subsequently, should be made. When discovered, these should be surgically drained and treated with appropriate antibiotics. Removal of necrotic tissue, adequate drainage, and nutritional support are the mainstays of treatment of these patients.

\section{References}

1. Abuabara SF, Barrett JA, Han T: Amebic liver abscess. Arch Surg 117:239$244,1982$.

2. Adeyokunnu AA, Hendrickse RG: Salmonella osteomyelitis in childhood. Arch Dis Child 55:175-184, 1980.

3. Adler R, Takahashi M, Wright HT Jr.: Acute pericarditis associated with hepatitis B infection. Pediatrics 61:716-719, 1978.

4. Adler SP, Chandrika T, Berman WF: Clostridium difficile associted with pseudomembranous colitis. Am J Dis Child 135:820-822, 1981.

5. Agner E, Larsen JH, Leth A: Yersinia enterocolitica carditis as a differential diagnosis-and the prognosis of this disease. Scand J Rheumatol 7:26-28, 1978.

6. Ahonkhai VI, Cherubin CE, Sierra MF, et al.: In vitro susceptibility of Campylobacter fetus subsp. jejuni to $\mathrm{N}$-formimidoyl thienamycin, rosaramicin, cefoperazone, and other antimicrobial agents. Antimicrob Agents Chemother 20:850-851, 1981.

7. Ahtone J, Maynard JE: Laboratory diagnosis of hepatitis B. JAMA 249:20672069, 1983.

8. Alter HJ, Purcell RH, Holland PV, et al.: Donor transaminase and recipient hepatitis. Impact on blood transfusion services. JAMA 246:630-634, 1981.

9. Anders BJ, Lauer BA, Paisley JW: Campylobacter gastroenteritis in neonates. Am J Dis Child 135:900-902, 1981.

10. Anders B, Paisley JW, Lauer BA, et al.: Double-blind placebo controlled trial of erythromycin for treatment of campylobacter enteritis. Lancet i:131132, 1982.

11. Andrassy RJ, Treadwell TA, Ratner IA, et al.: Gallbladder disease in children and adolescents. Am J Surg 132:19-21, 1976.

12. Andreani T, Le Charpentier Y, Brouet J-C, et al.: Acquired immunodeficiency with intestinal cryptosporidiosis: Possible transmission by Haitian whole blood. Lancet i:1187-1191, 1983.

13. Arfania, D, Everett ED, Nolph KD, et al.: Uncommon causes of peritonitis in patients undergoing peritoneal dialysis. Arch Intern Med 141:61-64, 1981.

14. Aronson M, Gump DW, Harrow E, et al.: Probable scombroid fish poisoning-Vermont. Morbid Mortal Wkly Rep 21:261, 1972.

15. Asplin CM, Cooney MK, Crossley JR, et al.: Coxsackie $B_{4}$ infection and islet cell antibodies three years before overt diabetes. J Pediatr 101:398-400, 1982. 
16. Auslander MO, Gitnick GL: Vigorous medical management of acute fulminant hepatitis. Arch Intern Med 137:599-601, 1977.

17. Bachman B, Boyd Jr. WP, Lieb S, et al.: Marine noncholera Vibrio infections in Florida. South Med J 76:296-303, 1983.

18. Baliga R: Strongyloidiasis in childhood. Pediatr Infect Dis 1:114-116, 1982.

19. Bampoe V, Avigad S, Sapsford RJ, et al.: Lactase degradation by human enteric bacteria. Lancet ii:125-127, 1979.

20. Band, JD, Ward, JI, Fraser DW, et al.: Peritonitis due to a Mycobacterium chelonei-like organism associated with intermittent chronic peritoneal dialysis. J Infect Dis 145:9-17, 1982.

21. Bannatyne RM, Stringel G, Simpson JS: Spontaneous peritonitis due to group B streptococci. Can Med Assoc J 121:442-443, 1979.

22. Barkin RM, Lilly JR: Biliary atresia and the Kasai operation: continuing care. J Pediatr 96:1015-1019, 1980.

23. Barnes GL, Hewson PH, McLellan JA, et al.: A randomized trial of oral gammaglobulin in low-birth-weight infants infected with rotavirus. Lancet i:1371-1373, 1982.

24. Barrett-Connor E, Connor JD: Extraintestinal manifestations of shigellosis. Am J Gastroenterol 53:234-245, 1970.

25. Bartlett JG: Recent development in the management of anaerobic infections. Rev Infect Dis 5:235-245, 1983.

26. Bartley DL, Hughes WT, Parvey LS, et al.: Computed tomography of hepatic and splenic fungal abscesses in leukemic children. Pediatr Infect Dis 1:317$321,1982$.

27. Barton LL, Escobedo MB, Keating JP, et al.: Leptospirosis with acalculous cholecystitis. Am J Dis Child 126:350-351, 1973.

28. Bassendine MF, Chadwick RG, Salmeron J, et al.: Adenine arabinoside therapy in $\mathrm{HB}$, Ag-positive chronic liver disease: a controlled study. Gastroenterology 80:1016-1022, 1981.

29. Bassily SB, Kilpatrick ME, Farid Z, et al.: Chronic salmonella bacteriuria with intermittent bacteremia treated with low doses of amoxicillin or ampicillin. Antimicrob Agents Chemother 20:630-633, 1981.

30. Bastian JF, Kaufman IA: Herpes simplex esophagitis in a healthy 10-yearold boy. J Pediatr 100:426-427, 1982.

31. Bean SF, Quezada RK: Recurrent oral erythema multiforme. JAMA 249:2810-2812, 1983.

32. Beasley RP, Shiao I-Sen, Wu TC, et al.: Hepatoma in an $\mathrm{HB}_{\mathrm{s}} \mathrm{Ag}$ carrierseven years after perinatal infection. J Pediatr 101:83-84, 1982.

33. Bech K, Clemmensen $\mathrm{O}$, Larsen $\mathrm{JH}$, et al.: Cell-mediated immunity to Yersinia enterocolitica serotype 3 in patients with thyroid diseases. Allergy 33:82-88, 1978.

34. Bell GF, Rogers III RS: Observations on the diagnosis of recurrent aphthous stomatitis. Mayo Clin Proc 57:297-302, 1982.

35. Bell MJ, Ternberg JL, Bower RJ: The microbial flora and antimicrobial therapy of neonatal peritonitis. J Pediatr Surg 15:569-573, 1980.

36. Berger LA, Obsorne DR: Treatment of pyogenic liver abscesses by percutaneous needle aspiration. Lancet i:132-134, 1982.

37. Bigler RD, Atkins RR, Wing EJ: Yersinia enterocolitica lung infection. Arch Intern Med 141:1529-1530, 1981. 
38. Black RE, Brown KH, Becker S, et al.: Longitudinal studies of infectious diseases and physical growth of children in rural Bangladesh II. Incidence of diarrhea and association with known pathogens. Am J Epidemiol 115:315-323, 1982.

39. Black RE, Jackson RJ, Tsai T, et al.: Epidemic Yersinia enterocolitica infection due to contaminated chocolate milk. N Engl J Med 298:76-79, 1978.

40. Blacklow NR, Schreiber DS, Trier JS: Viral enteritis. In: Seminars in Infectious Disease I. (Ed. L. Weinstein, B.N. Fields) New York, Stratton Intercontinental, pp. 256-277, 1978.

41. Blaser MJ, LaForce FM, Wilson NA, et al.: Reservoirs for human campylobacteriosis. J Infect Dis 141:665-669, 1980.

42. Blaser MJ, Pollard RA, Feldman RA: Shigella infections in the United States, 1974-1980. J Infect Dis 147:771-775, 1983.

43. Blaser MJ, Reller LB: Campylobacter enteritis. N Engl J Med 305:14441452, 1981.

44. Blaser MJ, Waldman RJ, Barrett T, et al.: Outbreaks of Campylobacter enteritis in two extended families: evidence for person-to-person transmission. J Pediatr 98:254-257, 1981.

45. Blaser MJ, Weiss SH, Barrett TJ: Campylobacter enteritis associated with a healthy cat. JAMA 247:816, 1982.

46. Blaskovic PJ, Freitag RM, McLaughlin B: Detection of adenoviruses in stools of children with nonbacterial gastroenteritis. Can Med Assoc J 127:16, 1982.

47. Bliddal J, Kaliszan S: Prolonged monosymptomatic fever due to Yersinia enterocolitica. Acta Med Scand 201:387-389, 1977.

48. Bolton JS, Bornside GH, Cohn Jr. I: Intraperitoneal povidone iodine in experimental canine and murine peritonitis. Am J Surg 137:780-785, 1979.

49. Borriello SP, Honour P: Simplified procedure for the routine isolation of Clostridium difficile from faeces. J Clin Pathol 34:1124-1127, 1981.

50. Bottone EJ, Sheehan DJ: Yersinia enterocolitica: guidelines for serologic diagnosis of human infections. Rev Infect Dis 5:898-906, 1983.

51. Bouza E, Dominquez A, Mesequer M, et al.: Yersinia enterocolitica septicemia. Am J Clin Pathol 74:404-409, 1980.

52. Bowen GS, McCarthy MA: Hepatitis A associated with a hardware store water fountain and a contaminated well in Lancaster County, Pennsylvania, 1980. Am J Epidemiol 117:695-705, 1983.

53. Brandt CD, Kim HW, Rodriquez WJ, et al.: Pediatric viral gastroenteritis during eight years of study. J Clin Microbiol 18:71-78, 1983.

54. Bromberg K, Newhall DN, Peter G: Hepatitis A and meningoencephalitis. JAMA 247:815, 1982.

55. Brook I, Martin WJ: Aerobic and anaerobic bacteriology of perirectal abscess in children. Pediatrics 66:282-284, 1980.

56. Buchta RM: Campylobacter enteritis associated with convulsions. Am J Dis Child 137:919, 1983.

57. Burchfield DJ, Rawlings D, Hamrick $\mathrm{HJ}$ : Intussusception associated with Yersinia enterocolitica gastroenteritis. Am J Dis Child 137:803-804, 1983.

58. Burke V, Gracey M, Robinson J, et al.: The microbiology of childhood gastroenteritis: Aeromonas species and other infective agents. J Infect Dis 148:68-74, 1983. 
59. Busuttil RW, Davidson RK, Fine M, et al.: Effect of prophylactic antibiotics in acute nonperforated appendicitis. Ann Surg 194:502-509, 1981.

60. Byrd LH, Anama L, Gutkin M, et al.: Bordetella bronchiseptica peritonitis associated with continuous ambulatory peritoneal dialysis. J Clin Microbiol 14:232-233, 1981.

61. Cantey JR, O'Hanley PD, Blake RK: Prevention of E. coli colonization and diarrhea by immune secretory immunoglobulin A. Clin Res 25:27A, 1977.

62. Carlson JAK, Middleton PJ, Szymanski MT, et al.: Fetal rotavirus gastroenteritis. Am J Dis Child 132:477-479, 1978.

63. Carpenter CCJ: The pathophysiology of secretory diarrheas. Med Clin $\mathbf{N}$ Am 66:597-610, 1982.

64. Carpenter Jr. CCJ, Mahmoud AAF, Warren KS: Algorithms in the diagnosis and management of exotic diseases. XXVI. Cholera. J Infect Dis 136:461$464,1977$.

65. Carroll B, Silverman PM, Goodwin DA, et al.: Ultrasonography and indium" $"$ " white blood cell scanning for the detection of intraabdominal abscesses. Radiology 140:155-160, 1981.

66. Champsaur H, Andremont A, Mathieu D, et al.: Cholera-like illness due to Aeromonas sobria. J Infect Dis 145:248-253, 1982.

67. Champsaur HF, Bottazzo GF, Bertrams J, et al.: Virologic, immunologic, and genetic factors in insulin-dependent diabetes mellitus. J Pediatr 100:1520, 1982.

68. Chan FTH, Stringel G, Mackenzie AMR: Isolation of Campylobacter jejuni from an appendix. J Clin Microbiol 18:422-424, 1983.

69. Chandra L, Barrowman JA, Kutty KP, et al.: Campylobacter infection mimicking a relapse of ulcerative colitis. Can Med Assoc J 126:389-390, 1982.

70. Chang MJ, Controni G: Primary peritonitis due to Haemophilus influenzae type b in a previously healthy child. J Clin Microbiol 18:725-726, 1983.

71. Chilton L: Viral hepatitis in school-aged children. Pediatr Rev 4:105-111, 1982.

72. Chrystie IL, Totterdell BM, Banatvala JE: Asymptomatic endemic rotavirus infections in the newborn. Lancet $\mathrm{i}: 1176,1978$.

73. Chusid MJ: Pyogenic hepatic abscess in infancy and childhood. Pediatrics 62:554-559, 1978.

74. Clark RM, Frost PG: Fulminating necrotizing amebic colitis with perforation: case report and review. Can Med Assoc J 128:1424-1427, 1983.

75. Clausen CR, Christie DL: Chronic diarrhea in infants caused by adherent enteropathogenic Eschericheria coli. J Pediatr 100:358-361, 1982.

76. Clements ML, Levine MM, Black RE, et al.: Lactobacillus prophylaxis for diarrhea due to enterotoxigenic Escherichia coli. Antimicrob Agents Chemother 20:104-108, 1981.

77. Cline BL: Current drug regimens for the treatment of intestinal helminth infections. Med Clin North Am 66:721-742, 1982.

78. Coffin CM, L'Heureaux P, Dehner LP: Campylobacter-associated enterocolitis in childhood. Am J Clin Pathol 78:117-123, 1982.

79. Cohen ML, Potter M, Pollard R, et al.: Turtle-associated salmonellosis in the United States. JAMA 243:1247-1249, 1980. 
80. Coid CR, Fox H: Short Review: Campylobacters as placental pathogens. Placenta 4:295-306, 1983.

81. Constant OC, Bentley OC, Denman AM, et al.: The Guillain-Barré syndrome following Campylobacter enteritis with recovery after plasmapheresis. J Infect 6:89-91, 1983.

82. Copperstock M, Riegle L, Woodruff CW, et al.: Influence of age, sex, and diet on asymptomatic colonization of infants with Clostridium difficile. J Clin Microbiol 17:830-833, 1983.

83. Cox KL, Ament ME, Sample WF, et al.: The ultrasonic and biochemical diagnosis of pancreatitis in children. J Pediatr 96:407-411, 1980.

84. Craft JC: Giardia and giardiasis in childhood. Pediatr Infect Dis 1:196-211, 1982.

85. Craft JC, Murphy T, Nelson JD: Furazolidone and quinacrine. Am J Dis Child 135:164-166, 1981.

86. Craft JC, Nelson JD: Diagnosis of giardiasis by counterimmunoelectrophoresis of feces. J Infect Dis 145:499-504, 1982.

87. Crichton EP: Suppurative conjunctivitis caused by Yersinia enterocolitica. Can Med Assoc J 118:22-24, 1978.

88. Cubitt WD, McSwiggan DA: Calicivirus gastroenteritis in north west London. Lancet ii:975-977, 1981.

89. Cubitt WD, McSwiggan DA, Arstall S: An outbreak of calicivirus infection in a mother and baby unit. J Clin Pathol 33:1095-1098, 1980.

90. Darrell RW, Jacob GB: Hepatitis B surface antigen in human tears. Arch Ophthalmol 96:674-676, 1978.

91. Davis RC: Salmonella sepsis in infancy. Am J Dis Child 135:1096-1099, 1981 .

92. Davis TC: Chronic vulvovaginitis in children due to Shigella flexneri. Pediatrics 56:41-44, 1975.

93. Debois J, Vandepitte J, Degreef H: Yersinia enterocolitica as a cause of erythema nodosum. Dermatologica 156:65-78, 1978.

94. De Mol P, Hemelhof W, Butzler JP, et al.: Enteropathogenic agents in children with diarrhoea in rural Zaire. Lancet i:516-518, 1983.

95. Denman AM, Schiff AA: Recurrent oral ulceration treated with mysteclin: a controlled study. Br Med J 1:1248-1249, 1979.

96. Dequeker J, Jamar R, Walravens M: HLA-B27, arthritis and Yersinia enterocolitica infection. J Rheumatol 7:706-710, 1980.

97. Despommier DD: The laboratory diagnosis of Entamoeba histolytica. Bull NY Acad Med 57:212-216, 1981.

98. Dickenson SJ, Corley G, Santulli TV: Acute cholecystitis as a sequel of scarlet fever. Am J Dis Child 121:331-333, 1971.

99. Dineen P, Homan WP, Grafe WR: Tuberculous peritonitis: 43 years' experience in diagnosis and treatment. Ann Surg 184:717-722, 1976.

100. Dolin R, Reichman RC, Roessner KD, et al.: Detection by immune electron microscopy of the Snow Mountain agent of acute viral gastroenteritis. J Infect Dis 146:184-189, 1982.

101. Donta ST, Sullivan N, Wilkins TD: Differential effects of Clostridium difficile toxins on tissue-cultured cells. J Clin Microbiol 15:1157-1158, 1982.

102. Drake AA, Gilchrist MJR, Washington JA, II, et al.: Diarrhea due to Campylobacter fetus subspecies jejuni. Mayo Clin Proc 56:414-423, 1981. 
103. Duncan B, Fulginiti VA, Sieber OF, et al.: Shigella sepsis. Am J Dis Child 135:151-154, 1981.

104. DuPont HL: Recent developments in immunization against diarrheal diseases. South Med J 68:1027-1034, 1975.

105. DuPont HL: Enteropathogenic organisms. New etiologic agents and concepts of disease. Med Clin North Am 62:945-960, 1978.

106. DuPont HL, Galindo E, Evans DG, et al.: Prevention of travelers' diarrhea with trimethoprim-sulfamethoxazole and trimethoprim alone. Gastroenterology 84:75-80, 1983.

107. Duwe AK, Vas SI, Weatherhead JW: Effect of the composition of peritoneal dialysis fluid on chemiluminescence, phagocytosis, and bactericidal activity in vitro. Infect Immun 33:130-135, 1981.

108. Dykes AC, Juranek DD, Lorenz RA, et al.: Municipal waterborne giardiasis: an epidemic investigation. Ann Intern Med 92:165-170, 1980.

109. Dykes AC, Ruebush TK II, Gorelkin L, et al.: Extraintestinal amebiasis in infancy: report of three patients and epidemiologic investigations of their families. Pediatrics 65:799-803, 1980.

110. Editorial: Microbial adhesion, colonization and virulence. Lancet ii:508$510,1981$.

111. Editorial: Traveller's diarrhoea. Lancet i:777-778, 1982.

112. Edwards MS, Reynolds GES III: Acute glossitis due to Hemophilus influenzae type b. J Pediatr 93:532-533, 1978.

113. Eisenstein TK, Sultzer BM: Salmonella vaccines: Protection by endotoxin protein and lipopolysaccharide in two different mouse strains. In: Seminars in Infectious Disease, Vol. IV: Bacterial Vaccines, (Robbins JB, Hill JC, Sadoff JC, eds), p 423. Thieme-Stratton, New York, 1982.

114. Elliott WC, Houghton DC, Bryant RE, et al.: Herpes simplex type 1 hepatitis in renal transplantation. Arch Intern Med 140:1656-1660, 1980.

115. El-Maraghi NRH, Mair NS: The histopathology of enteric infection with Yersinia pseudotuberculosis. Am J Clin Pathol 71:631-639, 1979.

116. Elstner CL, Lindsay AN, Book LS, et al.: Lack of relationship of Clostridium difficile to antibiotic-associated diarrhea in children. Pediatr Infect Dis 2:364366, 1983.

117. Ettenger RB, Tong MJ, Landing BH, et al.: Hepatitis B infection in pediatric dialysis and transplant patients: significance of e antigen. J Pediatr 97:550$553,1980$.

118. Evans HE, Sampath AC, Douglass F, et al.: Shigella bacteremia in a patient. Am J Dis Child 123:238-239, 1972.

119. Everett ED: Pericarditis due to Entamoeba histolytica. South Med J 65:501502, 1972.

120. Fekety R: Recent advances in management of bacterial diarrhea. Rev Infect Dis 5:246-257, 1983.

121. Ferrucci JT Jr, vanSonnenberg E: Intra-abdominal abscess. radiological diagnosis and treatment. JAMA 246:2728-2733, 1981.

122. Field RJ, Overturf GD, Strunk R: Opsonization of Salmonella enteriditis lipopolysaccharide in sickle cell disease. Pediatr Res 15:107-111, 1981.

123. Finberg L: The role of oral electrolyte-glucose solutions in hydration for children-international and domestic aspects. J Pediatr 96:51-54, 1980. 
124. Fine RN, Salusky IB, Hall T, et al.: Peritonitis in children undergoing continuous ambulatory peritoneal dialysis. Pediatrics 71:806-809, 1983.

125. Finlayson M: Shigella sonnei resistant to cotrimoxazole. Can Med Assoc J 123:718-723, 1980.

126. Fitzgerald JF, Clark JH: Chronic diarrhea. Ped Clin North Am 29:221-231, 1982.

127. Fleisher DI, Hepler RS, Landau JW: Blindness during diiodohydroxyquin (Diodoquin $^{\circledR}$ ) therapy: a case report. Pediatrics 54:106-108, 1974.

128. Flores EC, Plumb SC, McNeese MC: Intestinal parasitosis in an urban pediatric clinic population. Am J Dis Child 137:754-756, 1983.

129. Forward K, Stiver G, Ferguson I, et al.: Prophylactic antibiotics in the prevention of peritonitis complicating continuous ambulatory peritoneal dialysis (CAPD). Twenty-First Interscience Conference on Antimicrobial Agents and Chemotherapy, November 1981, Chicago, IL, Abstract No. 99.

130. Fox JG, Hering AM, Ackerman JI, et al.: The pet hamster as a potential reservoir of human campylobacteriosis. J Infect Dis 147:784, 1983.

131. Fried D, Maytal J, Hanukoglu A: The differential leukocyte count in shigellosis. Infection 10:13-14, 1982.

132. Friedberg M, Larsen S, Denneberg T: Yersinia enterocolitica and glomerulonephritis. Lancet i:498-499, 1978.

133. Frost JA, Rowe B, Vandepitte J, et al.: Plasmid characterisation in the investigation of an epidemic caused by multiply resistant Shigella dysenteriae type 1 in Central Africa. Lancet ii:1074-1076, 1981.

134. Gillin FD, Reiner DS, Wang C-S: Human milk kills parasitic intestinal protozoa. Science 221:1290-1292, 1983.

135. Gilman RH, Koster F, Islam S, et al.: Randomized trial of high- and lowdose ampicillin therapy for treatment of severe dysentery due to Shigella dysenteriae type 1. Antimicrob Agents Chemother 17:402-405, 1980.

136. Glass RI, Stoll BJ, Huq MI, et al.: Epidemiologic and clinical features of endemic Campylobacter jejuni infection in Bangladesh. J Infect Dis 148:292296, 1983.

137. Glass RI, Svennerholm A-M, Stoll BJ, et al.: Protection against cholera in breast-fed children by antibodies in breast milk. N Engl J Med 308:13891392, 1983.

138. Gorski J, Ingall D, Yogev R: Primary peritonitis associated with Hemophilus influenzae bacteremia in a normal child. Clin Pediatr 22:183, 1983.

139. Goscienski PJ, Haltalin KC: Rose spots associated with shigellosis. Am J Dis Child 119:152-154, 1970.

140. Goudarzi HA, Mason LB: Fatal rectal bleeding due to tuberculosis of the cecum. JAMA 247:667-668, 1982.

141. Granfors K, Vijanen M, Tiilikainen A, et al.: Persistence of IgM, IgG, and IgA antibodies to Yersinia in yersinia arthritis. J Infect Dis 141:424-429, 1980.

142. Graybill JR, Herndon JH, Kniker WT, et al.: Ketoconazole treatment of chronic mucocutaneous candidiasis. Arch Dermatol 116:1137-1141, 1980.

143. Greene HL, Grishan FK: Excessive fluid intake as a cause of chronic diarrhea in young children. J Pediatr 102:836-840, 1983.

144. Greenough III WB: Hemolytic-uremic syndrome after shigellosis. N Engl J Med 293:305-306, 1975. 
145. Gruer LD, Collingham KE, Edwards CW: Pneumococcal peritonitis associated with an IUCD. Lancet ii:677, 1983.

146. Guerrant RL, Lahita RG, Winn Jr. WC, et al.: Campylobacteriosis in man: pathogenic mechanisms and review of 91 bloodstream infections. Am J Med 65:584-592, 1978.

147. Gunn RA, Janowski HT, Lieb S, et al.: Norwalk virus gastroenteritis following raw oyster consumption. Am J Epidemiol 115:348-351, 1982.

148. Haddad CG, Agrawal N, Litwin MS: Diagnosis and treatment of echinococcal cyst of the liver. South Med J 76:300-303, 1983.

149. Hadler SC, Erben JJ, Francis DP: Risk factors for hepatitis A in day-care centers. J Infect Dis 145:255-261, 1982.

150. Hadler SC, Erben JJ, Matthews D, et al.: Effect of immunoglobulin on Hepatitis A in day-care centers. JAMA 249:48-53, 1983.

151. Haffar A, Boland FJ, Edwards MS: Amebic liver abscess in children. Pediatr Infect Dis 1:322-327, 1982.

152. Hamilton R, Mellow M, Braun NMT: Esophageal tuberculosis presenting with dysphagia. J Pediatr 91:678-679, 1977.

153. Hammond GW, MacDougall BK, Plummer F, et al.: Encephalitis during the prodromal stage of acute hepatitis A. Can Med Assoc J 126:269-270, 1982.

154. Hamrick HJ, Drake WR Jr, Jones HM, et al.: Two cases of dipylidiasis (dog tapeworm infection) in children: update on an old problem. Pediatrics 72:114-117, 1983.

155. Hamrick HJ, Moore GW: Giardiasis causing urticaria in a child. Am J Dis Child 137:761-763, 1983.

156. Hansbrough JF, Clark JE, Reimer LG: Concentrations of kanamycin and amikacin in human gallbladder bile and wall. Antimicrob Agents Chemother 20:515-517, 1981.

157. Harrington PT, Gutierrez JJ, Ramirez-Ronda CH, et al.: Granulomatous hepatitis. Rev Infect Dis 4:638-655, 1982.

158. Harrison HR, Crowe CP, Fulginiti VA: Amebic liver abscess in children: clinical and epidemiologic features. Pediatrics 64:923-928, 1979.

159. Helmke $\mathrm{K}$, Otten $\mathrm{A}$, Willems $\mathrm{W}$ : Islet cell antibodies in children with mumps infection. Lancet ii:211-212, 1980.

160. Hersey DF, Shaw ED: Viral agents in hepatitis. Lab Invest 19:558-572, 1968.

161. Heseltine PNR, Yellin AE, Appleman MD, et al.: Perforated and gangrenous appendicitis: an analysis of antibiotic failures. J Infect Dis 148:322-329, 1983.

162. Hewstone AS, Davidson GP: Yersinia enterocolitica septicemia with arthritis in a thalassemic child. Med J Aust 1:1035-1038, 1972.

163. Hitch DC, Lilly JR, Reller LB, et al.: Biliary flora and antimicrobial concentrations after Kasai's operation. J Pediatr Surg 14:648-652, 1979.

164. Hollinger FB, Mosley JW, Szmuness W, et al.: Transfusion-transmitted viruses study: experimental evidence for two non-A, non-B hepatitis agents. J Infect Dis 142:400-407, 1980.

165. Holmes JR Plunkett $T$, Pate $P$, et al.: Emetic food poisoning caused by Bacillus cereus. Arch Intern Med 141:766-767, 1981.

166. Hughes FB, Faehnle ST, Simon JL: Multiple cerebral abscesses complicating hepatopulmonary amebiasis. J Pediatr 86:95, 1975. 
167. Hughes WT, Bartley DL, Patterson GG, et al.: Ketoconazole and candidiasis: a controlled study. J Infect Dis 147:1060-1063, 1983.

168. Hull BP, Bassett SD, Swanston WH, et al.: The relative importance of rotavirus and other pathogens in the etiology of gastroenteritis in Trinidadian children. Am J Trop Med Hyg 31:142-148, 1982.

169. Hunt JL: Generalized peritonitis. To irrigate or not to irrigate the abdominal cavity. Arch Surg 117:209-212, 1982.

170. Hyams JS, Krause PJ, Gleason PA: Lactose malabsorption following rotavirus infection in young children. J Pediatr 99:916-918, 1981.

171. Ishimaru Y, Nakano S, Yamaoka K, et al.: Outbreaks of hand, foot and mouth disease by enterovirus 71. Arch Dis Child 55:583-588, 1980.

172. Istre GR, Kreiss K, Hopkins RS, et al.: An outbreak of amebiasis spread by colonic irrigation at a chiropractic clinic. N Engl J Med 307:339-342, 1982.

173. Jaffe KM, Smith AL: Yersinia enterocolitica cervical lymphadenitis. J Pediatr 97:937-938, 1980.

174. Jepsen OB, Korner B, Lauritsen KB, et al.: Yersinia enterocolitica infection in patients with acute surgical abdominal disease. Scand J Infect Dis 8:189194, 1976.

175. Joffe HS, Prosser GL, Chesler E, et al.: Salmonella endocarditis. Am J Dis Child 127:578-581, 1974.

176. Johnson DE, Conroy M-M, Foker JE, et al.: Candida peritonitis in the newborn infant. J Pediatr 97:298-300, 1980.

177. Johnston JM, Andes WA, Glasser G: Vibrio vulnificus. JAMA 249:1756-1757, 1983.

178. Johnston JM, Martin DL, Perdue J, et al.: Cholera on a Gulf Coast oil rig. N Engl J Med 309:523-526, 1983.

179. Jokiph L, Pohjola S, Jokiph AMM: Cryptosporidium: a frequent finding in patients with gastrointestinal symptoms. Lancet ii:358-360, 1983.

180. Jones JM: Necrotizing Candida esophagitis. Failure of symptoms and roentgenographic findings to reflect severity. JAMA 244:2190-2191, 1980.

181. Jones JM: The recognition and management of Candida esophagitis. Hosp Pract 16:64A-V, 1981.

182. Jones PH, Willis AT, Robinson DA, et al.: Campylobacter enteritis associated with the consumption of free school milk. J Hyg Camb 87:155-162, 1981.

183. Kaldor J, Pritchard H, Serpell A, et al.: Serum antibodies in Campylobacter enteritis. J Clin Microbiol 18:1-4, 1983.

184. Kalwinsky D, Frittelli G, Oski FA: Pancreatitis presenting as unexplained ascites. Am J Dis Child 128:734-736, 1974.

185. Kane JG, Chretien JH, Ganagusi VF: Diarrhea caused by Candida. Lancet i:335-336, 1976.

186. Kaplan JE, Gary GW, Baron RC, et al.: Epidemiology of Norwalk gastroenteritis and the role of Norwalk virus in outbreaks of acute nonbacterial gastroenteritis. Ann Intern Med 96:756-761, 1982.

187. Kappus KD, Marks JS, Holman RC, et al.: An outbreak of Norwalk gastroenteritis associated with swimming in a pool and secondary person-toperson transmission. Am J Epidemiol 116:834-839, 1982.

188. Karanicolas S, Oreopoulos DG, Izatt SH, et al.: Epidemic of aseptic peri- 
tonitis caused by endotoxin during chronic peritoneal dialysis. N Engl J Med 296:1336-1337, 1977.

189. Kasai Y, Koshino I, Kawanishi N, et al.: Alveolar echinococcosis of the liver. Ann Surg 191:145-152, 1980.

190. Kashiwagi S, Hayashi J, Ikematsu H, et al.: An outbreak of hepatitis B in members of a high school Sumo wrestling club. JAMA 248:213-214, 1982.

191. Katz M: Diarrhea in a young child. JAMA 246:778, 1981.

192. Kazemi M, Gumpert TC, Marks MI: A controlled trial of sulfamethoxazoletrimethoprim, ampicillin or no therapy in the treatment of Salmonella gastroenteritis in Children. J Pediatr 83:646, 1973.

193. Kazemi M, Gumpert G, Marks MI: Clinical spectrum and carrier state of nontyphoidal Salmonella infections in infants and children. Can Med Assoc J 110:1253-1258, 1974.

194. Kern P: Human echinococcosis: follow-up of 23 patients treated with mebendazole. Infection 11:17-24, 1983.

195. Kerr AA, McQuillin J, Downham MAPS, et al.: Gastric 'flu: influenza B causing abdominal symptoms in children. Lancet $\mathrm{i}: 291-295,1975$.

196. Kerr CP: Chronic abdominal pain and eosinophilia. Clin Pediatr 22:655656, 1983.

197. Kim K, DuPont HL, Pickering LK: Outbreaks of diarrhea associated with Clostridium difficile and its toxin in day-care centers: evidence of person-toperson spread. J Pediatr 102:376-382, 1983.

198. Kim YJ, Way BH, Garcia RR: Gianotti-Crosti syndrome in an infant with Epstein-Barr virus infection. Pediatr Infect Dis 2:239-243, 1983.

199. King ML, Bidwell D, Banatvala JE, et al.: Coxsackie-B-virus-specific IgM responses in children with insulin-dependent (juvenile-onset; type 1) diabetes mellitus. Lancet i:1397-1399, 1983.

200. Knight KR, Polak A, Crump J, et al.: Laboratory diagnosis and oral treatment of CAPD peritonitis. Lancet ii:1301-1304, 1982.

201. Knight R: The chemotherapy of amoebiasis. J Antimicrob Agents Chemother 6:577-593, 1980.

202. Kobayashi RH, Rosenblatt HM, Carney JM, et al.: Candida esophagitis and laryngitis in chronic mucocutaneous candidiasis. Pediatrics 66:380-384, 1980.

203. Konno T, Suzuki H, Kutsuzawa T, et al.: Human rotavirus infection in infants and young children with intussusception. J Med Virol 2:265-269, 1978.

204. Koopman JS, Eckert EA, Greenberg HB, et al.: Norwalk virus enteric illness acquired by swimming exposure. Am J Epidemiol 115:173-177, 1982.

205. Krause PJ, Hyams JS, Middleton PJ, et al.: Unreliability of rotazyme ELISA test in neonates. J Pediatr 103:259-262, 1983.

206. Krensky AM, Grupe WE, Ingelfinger JR: Peritonitis in childhood nephrotic syndrome. Pediatr Res 15:695, 1981.

207. Kressner MS, Williams SE, Biempica L, et al.: Salmonellosis complicating ulcerative colitis. JAMA 248:584-585, 1982.

208. Krogstad DJ, Spencer Jr. HC, Healy GR: Amebiasis: epidemiologic studies in the United States, 1971-1974. Ann Intern Med 88:89-97, 1978.

209. Kurtz JB: Leg abscesses caused by Salmonella heidelberg. Lancet i:200$201,1976$. 
210. Kusunen TU, Kauranen O, Martio J, et al.: Reactive arthritis after Campylobacter jejuni enteritis in patients with HLA-B27. Lancet i:1312-1313, 1980.

211. Lam KC, Lai CL, Trepo C, et al.: Deleterious effect of prednisolone in $\mathbf{H B}_{\mathrm{s}}$ Ag-positive chronic active hepatitis. N Engl J Med 304:380-386, 1981.

212. Lambert M, Marion E, Coche E, et al.: Campylobacter enteritis and erythema nodosum. Lancet i:1409, 1982.

213. Lancet: Ambulatory peritonitis. Editorial i:1 104-1 105, 1982.

214. Lansky LL, Krugman S, Hug G: Anicteric coxsackie B hepatitis. J Pediatr 94:64-65, 1979.

215. Leidig E, Dannecker G, Berg PA, et al.: Hepatitis B antigens in cerebrospinal fluid. Lancet i:898, 1981.

216. Lemon SM, Gates NL, Simms TE, et al.: IgM antibody to hepatitis B core antigen as a diagnostic parameter of acute infection with hepatitis $B$ virus. J Infect Dis 143:803-809, 1981.

217. Lempert KD, Jones JM: Flucytosine-miconazole treatment of Candida peritonitis. Its use during continuous ambulatory peritoneal dialysis. Arch Intern Med 142:577-578, 1982.

218. Lennard ES, Dellinger EP, Wertz MJ, et al.: Implications of leukocytosis and fever at conclusion of antibiotic therapy for intra-abdominal sepsis. Ann Surg 195:19-24, 1982.

219. Levin S, Hahn T: Interferon system in acute viral hepatitis. Lancet i:592$594,1982$.

220. Levine MM, DuPont HL, Khodabandelou M, et al.: Long-term shigellacarrier state. Lancet i:1169-1171, 1973.

221. Lewis JF, Alexander J: Facial abscess due to Yersinia enterocolitica. Am J Clin Pathol 66:1016-1018, 1976.

222. Lieb S, Gunn RA, Taylor DN: Salmonellosis in a day-care center. J Pediatr 100:1004-1005, 1982.

223. Liebman WM, St. Geme Jr. JW: Enteroviral pseudoappendicitis. Am J Dis Child 120:77-78, 1970.

224. Liston TE: Clostridium difficile toxin associated with chronic diarrhea and failure to gain weight. Clin Pediatr 22:458-460, 1983.

225. LoGalbo PR, Sampson HA, Buckley RH: Symptomatic giardiasis in three patients with X-Linked agammaglobulinemia. J Pediatr 101:78-80, 1982.

226. MacLean Jr. WC, Klein GL, de Romana GL, et al.: Transient steatorrhea following episodes of mild diarrhea in early infancy. J Pediatr 92:562-565, 1978.

227. Majumdar AS, Ghose AC: Protective properties of anticholera antibodies in human colostrum. Infect Immun 36:962-965, 1982.

228. Maki M, Maki R, Vesikari T: Faecal leucocytes in Campylobacter-associated diarrhoea in infants. Acta Paediatr Scand 68:271-272, 1979.

229. Maki M, Vesikari T, Rantala I, et al.: Yersiniosis in children. Arch Dis Child 55:861-865, 1980.

230. Makker SP, Tucker AS, Izant Jr. RJ, et al.: Nonobstructive hydronephrosis and hydroureter associated with peritonitis. N Engl J Med 287:535-537, 1972.

231. Malone W, Novak R: Outcome of hepatitis in children with acute leukemia. Am J Dis Child 134:584-587, 1980. 
232. Malowany M, Lewin S, Geller M, et al.: Seizures associated with Campylobacter enteritis. Am J Dis Child 136:1028, 1982.

233. Mantse L, West J, Cossman $\mathrm{HH}$, et al.: Liver abscess due to Yersinia enterocolitica. Can Med Assoc J 119:922-923, 1978.

234. Mao JS, Yu PH, Ding ZS, et al.: Patterns of shedding of hepatitis A virus antigen in feces of antibody responses in patients with naturally acquired type A hepatitis. J Infect Dis 142:654-659, 1980.

235. Marcovitch H: Loperamide in "toddler diarrhoea." Lancet i:1413, 1980.

236. Mardh PA, Helin I, Colleen I, et al.: Clostridium difficile toxin in faecal specimens of healthy children and children with diarrhoea. Acta Paediatr Scand 71:275-278, 1982.

237. Margolis B: Dog tapeworm infestation in an infant. Am J Dis Child 137:702, 1983.

238. Marks MI: Herpangina and pleurodynia associated wtih Herpes simplex virus. Pediatrics 48:305-307, 1971.

239. Marks MI, Joncas JH, Mauer SM: Fatal hepatitis in siblings: isolation of coxsackievirus B5 and Herpes simplex virus. Can Med Assoc J 102:13911393, 1970.

240. Marks MI, Mauer SM, Goldman H: Exchange transfusion in the treatment of hepatic coma. J Pediatr 75:418-430, 1969.

241. Marks MI, Pai CH, Lafleur L, et al.: Yersinia enterocolitica gastroenteritis: a prospective study of clinical, bacteriologic, and epidemiologic features. J Pediatr 96:26-31, 1980.

242. Marsal L, Winbald S, Wollheim FA: Yersinia enterocolitica arthritis in southern Sweden: a four-year follow-up study. Br Med J 283:101, 1981.

243. Martin T, Kasian GF, Stead S: Family outbreak of yersiniosis. J Clin Microbiol 16:622-626, 1982.

244. Marty AT, Webb TA, Stubbs KG, et al.: Inflammatory abdominal aortic aneurysm infected by Campylobacter fetus. JAMA 249:1 190-1 192, 1983.

245. Matthews P: Primary anaerobic peritonitis. Br Med J 1:903, 1979.

246. Mayor GH, Klein AM, Kelly TJ, et al.: Antibody to hepatitis A and hemodialysis. Am J Epidemiol 116:821-827, 1982.

247. McCaustland KA, Bond WW, Bradley DW, et al.: Survival of hepatitis a virus in feces after drying and storage for 1 month. J Clin Microbiol 16:957958, 1982.

248. McClung MR: Peritonitis in children receiving continuous ambulatory peritoneal dialysis. Pediatr Infect Dis 2:328-332, 1983.

249. McFee AS: Diagnosing appendicitis in the pediatric patient. Infect Surg $30: 42-49,1982$.

250. McNaughton RD, Leyland R, Mueller L: Outbreak of Campylobacter enteritis due to consumption of raw milk. Can Med Assoc 126:657-658, 1982.

251. McNeeley DF, Cohen I: Isolation of Yersinia pseudotuberculosis from feces of a newborn. Am J Dis Child 137:916, 1983.

252. Melamed I, Bujanover Y, Igra YS, et al.: Campylobacter enteritis in normal and immunodeficient children. Am J Dis Child 137:752-753, 1983.

253. Menser MA, Forrest JM, Bransby RD: Rubella infections and diabetes mellitus. Lancet i:57-60, 1978.

254. Merritt RJ, Coughlin E, Thomas DW: Spectrum of amebiasis in children. Am J Dis Child 136:785-789, 1982. 
255. Meyer EA, Jarroll EL: Giardiasis. J Epidemiol 111:1-12, 1980.

256. Miller RA, Holmberg Jr. RE, Clausen CR: Life-threatening diarrhea caused by Cryptosporidium in a child undergoing therapy for acute lymphocytic leukemia. J Pediatr 103:256-259, 1983.

257. Mittal KR, Ricciardi ID, Tizard IR: Indirect hemagglutination employing enterobacterial common antigen and Yersinia somatic antigen: a technique to differentiate brucellosis from infections involving cross-reacting Yersinia enterocolitica. J Clin Microbiol 11:149-152, 1980.

258. Moestrup T, Hansson BG, Widell A, et al.: Clinical aspects of delta infection. Br Med J 286:87-90, 1983.

259. Mofenson HC, Caraccio TR, Miller H, et al.: Lidocaine toxicity from topical mucosal application. Clin Pediatr 22:190-192, 1983.

260. Molla AM, Rahman M, Sarker SA, et al.: Stool electrolyte content and purging rates in diarrhea caused by rotavirus, enterotoxigenic $E$. coli, and $V$. cholerae in children. J Pediatr 98:835-838, 1981.

261. Monto AS, Koopman JS, Longini IM, et al.: The Tecumseh study. XII. Enteric agents in the community, 1976-1981. J Infect Dis 148:284-291, 1983.

262. Moore-Gillon JC, Eykyn SJ, Phillips I: Microbiology of pyogenic liver abscess. Br Med J 283:819-821, 1981.

263. Moors DCF: Campylobacter jejuni-Nova Scotia. Can Dis Wkly Rep 7-33:165, 1981 .

264. Morrison WM, Matheson JAB, Hutchison RB, et al.: Salmonella gastroenteritis associated with erythema nodosum. Br Med J 286:765, 1983.

265. Moss TJ, Pysher TJ: Hepatic abscess in neonates. Am J Dis Child 135:726728, 1981.

266. Mundy TM, Miller III JJ: Behcet's disease presenting as chronic aphthous stomatitis in a child. Pediatrics 62:205-208, 1978.

267. Murphy TV, Nelson JD: Five $v$ ten days' therapy with furazolidone for giardiasis. Am J Dis Child 137:267-270, 1983.

268. Nalin DR, Rhead J, Rennels M, et al.: Cannabis, hypochlorhydria, and cholera. Lancet ii:859-862, 1978.

269. Naqvi SH, Dunkle LM, Clapper MA: Age-specific presentation of Campylobacter enteritis in children. Clin Pediatr 22:98-100, 1983.

270. Narayanan I, Bala S, Prakash K, et al.: Partial supplementation with expressed breast-milk for prevention of infection in low-birth-weight infants. Lancet ii:561-563, 1980.

271. Nelson SJ, Granoff D: Salmonella gastroenteritis in the first three months of life: a review of management and complications. Clin Pediatr 21:709-712, 1982.

272. Norkrans G, Vahlne A, Iwarson S: Herpes zoster and hepatitis B: detection of hepatitis B surface antigen in vesicle fluid. Scand J Infect Dis 13:301$302,1981$.

273. Norrby R, McCloskey RV, Zackrisson G, et al.: Meningitis caused by Campylobacter fetus ssp jejuni. Br Med J 10:1164, 1980.

274. Novak E, Lee JG, Seckman CE, et al.: Unfavorable effect of atropine-diphenoxylate (Lomotil) therapy in lincomycin-caused diarrhea. JAMA 235:1451-1454, 1976. 
275. Oakley Jr. GP: The neurotoxicity of the halogenated hydroxyquinolines. JAMA 225:395-397, 1973.

276. O'Brien TF, Hopkins JD, Gilleece ES, et al.: Molecular epidemiology of antibiotic resistance in Salmonella from animals and human beings in the United States. N Engl J Med 307:1, 1982.

277. Oderda G, Kraut JR: Rising antibody titer to Mycoplasma pneumoniae in acute pancreatitis. Pediatrics 66:305-306, 1980.

278. Olarte J, Perez GI: Campylobacter jejuni in children with diarrhea in Mexico City. Pediatr Infect Dis 2:18-20, 1983.

279. Oleske J, Minnefor A, Cooper Jr. R, et al.: Transmission of hepatitis B in a classroom setting. J Pediatr 97:770-772, 1980.

280. Orenstein WA, Wu E, Wilkins J, et al.: Hospital-acquired hepatitis A: report of an outbreak. Pediatrics 67:494-497, 1981.

281. Ortiz-Neu C, Marr JS, Cherubin CE, et al.: Bone and joint infections due to Salmonella. J Infect Dis 138:820-828, 1978.

282. Osterholm MT, Forfang JC, Ristinen TL, et al.: An outbreak of foodborne giardiasis. N Engl J Med 304:24-28, 1981.

283. O'Sullivan FX, Stuewe BR, Lynch JM, et al.: Peritonitis due to Drechslera spicifera complicating continuous ambulatory peritoneal dialysis. Ann Intern Med 94:213-214, 1981.

284. Pai C, Gillis F, Tuomanen E, et al.: Placebo-controlled double-blind evaluation of trimethoprim-sulfamethoxazole treatment of Yersinia enterocolitica gastroenteritis. J Pediatr 104:308-311, 1984.

285. Pai CH, Gillis F, Tuomanen E, et al.: Erythromycin in treatment of Campylobacter enteritis in children. Am J Dis Child 137:286-288, 1983.

286. Pai CH, Mors V, Toma S: Prevalence of enterotoxigenicity in human and nonhuman isolates of Yersinia enterocolitica. Infect Immun 22:334-338, 1978.

287. Palmer SR, Gully PR, White JM, et al.: Water-borne outbreak of Campylobacter gastroenteritis. Lancet i:287-290, 1983.

288. Parsons R, Gregory J, Palmer DL: Salmonella infections of the abdominal aorta. Rev Infect Dis 5:227-231, 1983.

289. Patamasucon P, Wientzen RL, Schwartz RH: Group A $\beta$-hemolytic streptococci causing pyogenic gingival cyst in infancy. Am J Dis Child 134:617618, 1980.

290. Patra FC, Mahalanabis D, Jalan KN, et al.: Is oral rice electrolyte solution superior to glucose electrolyte solution in infantile diarrhoea? Arch Dis Child 57:910-912, 1982.

291. Pearce JL, Hamilton JR: Controlled trial of orally administered lactobacilli in acute infantile diarrhea. J Pediatr 84:261-262, 1974.

292. Pearson RD, Irons Sr. RP, Irons Jr. RP: Chronic pelvic peritonitis due to the pinworm Enterobius vermicularis. JAMA 245:1340-1341, 1981.

293. Perera MR, Kirk A, Noone P: Presentation, diagnosis and management of liver abscess. Lancet ii:629-632, 1980.

294. Perrillo RP, Pohl DA, Roodman ST, et al.: Acute non-A, non-B hepatitis with serum sickness-like syndrome and aplastic anemia. JAMA 245:494496, 1981. 
295. Phillips RKS, Glazer G, Borriello SP: Non-clostridium difficile pseudomembranous colitis responding to both vancomycin and metronidazole. $\mathrm{Br}$ Med J 283:823, 1981.

296. Pickering LK, Feldman S, Ericsson CD, et al.: Absorption of salicylate and bismuth from a bismuth subsalicylate-containing compound (Pepto-Bismol). J Pediatr 99:654, 1980.

297. Pickering LK, Woodward WE: Diarrhea in day care centers. Pediatr Infect Dis $1: 47-52,1982$.

298. Pierce JE, DuPont HL, Lewis KR: Acute diarrhea in a residential institution for the retarded. Usefulness of fecal leukocyte examination. Am J Dis Child 128:772-775, 1974.

299. Pinto DJ, Sanderson PJ: Rational use of antibiotic therapy after appendicectomy. Br Med J 280:275-277, 1980.

300. Pitkanen T, Ponka A, Pettersson T, et al.: Campylobacter enteritis in $\mathbf{1 8 8}$ hospitalized patients. Arch Intern Med 143:215-219, 1983.

301. Plotkin GR, O'Rourke Jr. JN: Mycotic aneurysm due to Yersinia enterocolitia. Am J Med Sci 281:35-42, 1981.

302. Poilly J-N: Pneumoperitoneum associated with Escherichia coli peritonitis: a report of two cases. Postgrad Med J 46:114-116, 1970.

303. Porter JM, Snowe RJ, Silver D: Tuberculous enteritis with perforation and abscess formation in childhood. Surgery 71:254-257, 1972.

304. Portnoy BL, Pruitt D, Rodriguez JT, et al: Efficacy of anti-diarrheal agents in the treatment of acute diarrhea in children. Clin Res 23:29A, 1975.

305. Psacharopoulos HT, Mowat AP, Davies M, et al.: Fulminant hepatic failure in childhood. Arch Dis Child 55:252-258, 1980.

306. Rahko PS, Davey WP, Wheat LJ, et al.: Treatment of Torulopsis glabrata peritonitis with intraperitoneal amphotericin B. JAMA 249:1187-1188, 1983.

307. Raham M: Streptococcus pyogenes as probable cause of dysentery. Br Med J 286:104-105, 1983.

308. Ratnam S, Mercer E, Picco B, et al.: A nosocomial outbreak of diarrheal disease due to Yersinia enterocolitica serotype 0:5, biotype 1. J Infect Dis 145:242-247, 1982.

309. Ratzan KR, Baker HB, Lauredo I: Excretion of cefamandole, cefazolin, and cephalothin into T-tube bile. Antimicrob Agents Chemother 13:985-987, 1978.

310. Reingold AL, Kane MA, Murphy BL, et al.: Transmission of hepatitis B by an oral surgeon. J Infect Dis 145:262-268, 1982.

311. Reznik VM, Mendoza SA, Self TW, et al.: Hepatitis B-associated vasculitis in an infant. J Pediatr 98:252-254, 1981.

312. Richey GD, Schleupner CJ: Peritoneal fluid concentrations of gentamicin in patients with spontaneous bacterial peritonitis. Antimicrob Agents Chemother 19:312-315, 1981.

313. Richmond SJ, Caul EO, Dunn SM, et al.: An outbreak of gastroenteritis in young children caused by adenoviruses. Lancet i:1178-1180, 1979.

314. Richter JM, Jacoby GA, Schapiro RH, et al.: Pancreatic abscess due to Candida albicans. Ann Intern Med 97:221-222, 1982. 
315. Rickard KA, Dority P, Campbell J, et al.: Hepatitis and haemophilia therapy in Australia. Lancet ii:146-148, 1982.

316. Righter J: Yersinia enterocolitica septicemia associated with cellulitis. Can Med Assoc J 124:1263, 1981.

317. Righter J, Wells WA, Hart GD, et al.: Relapsing septicemia caused by Campylobacter fetus subsp. fetus. Can Med Assoc J 128:686-689, 1983.

318. Riley LW, Remis RS, Helgerson SD, et al.: Hemorrhagic colitis associated with a rare Escherichia coli serotype. N Engl J Med 308:681-685, 1983.

319. Robins-Browne RM, Mackenjee MKR, Bodasing MN, et al.: Treatment of Campylobacter-associated enteritis with erythromycin. Am J Dis Child 137:282-285, 1983.

320. Rodrick GE, Hood MA, Blake NJ: Human Vibrio gastroenteritis. Med Clin North Am 66:665-673, 1982.

321. Rodriguez WJ, Kim HW, Brandt CD, et al.: Rotavirus: a cause of nosocomial infection in the nursery. J Pediatr 101:274-277, 1982.

322. Rosenthal P, Liebman WM: Comparative study of stool examinations, duodenal aspiration, and pediatric entero-test for giardiasis in children. J Pediatr 96:278-279, 1980.

323. Rubenstein AS, Miller MF: Comparison of an enzyme immunoassay with electron microscopic procedures for detecting rotavirus. J Clin Microbiol 15:938-944, 1982.

324. Ruby ST, Gladstone A, Treat M, et al.: Emphysematous cholecystitis. JAMA 249:248-249, 1983.

325. Ruiz-Palacios GM, DuPont HL: Bacterial overgrowth syndrome after acute nonspecific diarrhoea. Lancet i:337-338, 1978.

326. Ruiz-Palacios GM, Torres NI, Ruiz-Palacios BR, et al.: Cholera-like enterotoxin produced by Campylobacter jejuni. Lancet ii:250-252, 1983.

327. Rush O, Sayed HI, Whitby JL, et al.: Cholangitis caused by Yersinia enterocolitica. Can Med Assoc J 123:1017-1021, 1980.

328. Rutala WA, Sarubbi Jr. FA, Finch CS, et al.: Oyster-associated outbreak of diarrhoeal disease possibly caused by Plesiomonas shigelloides. Lancet i:739, 1982.

329. Ryan JM, Riley HD Jr: Shigella keratitis: a case report. J Pediatr 74:294296, 1969.

330. Sack DA, Islam S, Rabbani $\mathrm{H}$, et al.: Single-dose doxycycline for cholera. Antimicrob Agents Chemother 14:462-464, 1978.

331. Saginur R, Fogel R, Begin L, et al.: Splenic abscess due to Clostridium difficile. J. Infect Dis 147:1105, 1983.

332. Saimot AG, Cremieux AC, Hay JM, et al.: Albendazole as a potential treatment for human hydatidosis. Lancet ii:652-656, 1983.

333. Salmi TT, Arstila P, Koivikko A: Central nervous system involvement in patients with rotavirus gastroenteritis. Scand J Infect Dis 10:29-31, 1978.

334. Samadi AR, Huq MI, Ahmed QS: Detection of rotavirus in handwashings of attendants of children with diarrhoea. $\mathrm{Br}$ Med J 286:188-1189, 1983.

335. San Joaquin VH, Marks MI: Gianotti disease or Gianotti-Crosti syndrome? J Pediatr 101:216-217, 1982. 
336. San Joaquin VH, Marks MI: New agents in diarrhea. Pediatr Infect Dis 1:53$56,1982$.

337. San Joaquin VH, Ward KE, Marks MI: Gianotti disease in a child and acute hepatitis B in mother. JAMA 246:2191-2192, 1981.

338. Santosham M, Sack RB, Foehlich J, et al.: Biweekly prophylactic doxycycline for travelers' diarrhea. J Infect Dis 143:598-602, 1981.

339. Santosham M, Yolken RH, Quiroz E, et al.: Detection of rotavirus in respiratry secretions of children with pneumonia. J Pediatr 103:583-585, 1983.

340. Sarr MG, Zuidema GD: Splenic abscess-presentation, diagnosis, and treatment. Surgery 92:480-485, 1982.

341. Saulsbury FT, Winkelstein JA, Yolken RH: Chronic rotavirus infection in immunodeficiency. J Pediatr 97:61-65, 1980.

342. Schatz JW, Wiener L, Gallagher HS, et al.: Salmonella pericarditis: an unusual complication of myocardial infarction. Chest 64:267-269, 1973.

343. Scott RM, Snitbhan R, Bancroft WH, et al.: Experimental transmission of hepatitis B virus by semen and saliva. J Infect Dis 142:67-71, 1980.

344. Scribner RK, Marks MI, Weber A, et al.: Yersinia enterocolitica: comparative in vitro activities of seven new $\beta$-lactam antibiotics. Antimicrob Agents Chemother 22:140-141, 1982.

345. Scullard GH, Pollard RB, Smith JL, et al.: Antiviral treatment of chronic hepatitis B virus infection. I. Changes in viral markers with interferon combined with adenine arabinoside. J Infect Dis 143:772-783, 1981.

346. Schwartz RH, Bryan C, Rodriguez WJ, et al.: Experience with the microbiologic diagnosis of Campylobacter enteritis in an office laboratory. Pediatr Infect Dis 2:298-301, 1983.

347. Sealy DP, Schuman SH: Endemic giardiasis and day care. Pediatrics 72:154$158,1983$.

348. Sears HF, Golden GT, Horsley III JS: Cholecystitis in childhood and adolescence. Arch Surg 106:651-653, 1973.

349. Sebes JI, Mabry Jr. EH, Rabinowitz JG: Lung abscess and osteomyelitis of rib due to Yersinia enterocolitica. Chest 69:546-548, 1976.

350. Sells CJ, Loesner JD: Peritonitis following perforation of the bowel: a rare complication of a ventriculoperitoneal shunt. J Pediatr 83:823-824, 1973.

351. Sewell CM, Clarridge J, Lacke C, et al.: Staphylococcal nasal carriage and subsequent infection in peritoneal dialysis patients. JAMA 248:1493-1495, 1982.

352. Sewell DL, Golper TA: Stability of antimicrobial agents in peritoneal dialysate. Antimicrob Agents Chemother 21:528-529, 1982.

353. Shaad UB: Reactive arthritis associated with Campylobacter enteritis. Pediatr Infect Dis 1:328-332, 1982.

354. Shafritz DA, Shouval D, Sherman HI, et al.: Integration of hepatitis B virus DNA into the genome of liver cells in chronic liver disease and hepatocellular carcinoma. N Engl J Med 305:1067-1073, 1981.

355. Shandera WX, Tacket CO, Blake PA: Food poisoning due to Clostridium perfringens in the United States. J Infect Dis 147:167-170, 1983.

356. Shapiro ED: Yersinia enterocolitica septicemia in normal infants. Am J Dis Child 135:477-478, 1981.

357. Shaul WL: Clues to the early diagnosis of neonatal appendicitis. J Pediatr 98:473-476, 1981. 
358. Sherman P, Liebman WM: Apparent protein-losing enteropathy associated with giardiasis. Am J Dis Child 134:893-894, 1980.

359. Shulman ST, Moel D: Campylobacter infection. Pediatrics 72:437, 1983.

360. Silva Jr. J, Batts DH, Fekety R, et al.: Treatment of Clostridium difficile colitis and diarrhea with vancomycin. Am J Med 71:815-822, 1981.

361. Silverstein MJ, Silverstein CR, Shulman S: Spontaneous gas peritonitis: a case report. Military Med 138:160-161, 1973.

362. Skidmore SJ, Boxall EH, Ala F: Short communication: a case report of posttransfusion hepatitis A. J Med Virol 10:223, 1982.

363. Snyder JD, Blake PA: Is cholera a problem for US travelers? JAMA 247:2268-2269, 1982.

364. Snyder JD, Christenson E, Feldman RA: Human Yersinia enterocolitica infections in Wisconsin. Am J Med 72:768-774, 1982.

365. South MA, Dolen J, Beach DK, et al.: Fetal adenovirus hepatic necrosis in severe combined immune deficiency. Pediatr Infect Dis 1:416-419, 1982.

366. Spratt HC, Marks MI, Gomersall M, et al.: Nosocomial infantile gastroenteritis associated with minirotavirus and calicivirus. J Pediatr 93:922-926, 1978.

367. Squires RH, Keating JP, Rosenblum JL, et al.: Splenic abscess and hepatic dysfunction caused by Shigella flexneri. J Pediatr 98:429-430, 1981.

368. Steinhoff MC: Rotavirus: the first five years. J Pediatr 96:611-622, 1980.

369. Stern MS, Gitnick GL: Shigella hepatitis. JAMA 235:2628, 1976.

370. St. John Sutton MB, Papadeas V, Pasquariello Jr. PS: Yersinia enterocolitica septicemia in a normal child. Am J Dis Child 137:305, 1983.

371. Strickland GT, Merritt W, El-Sahly A, et al.: Clinical characteristics and response to therapy in Egyptian children heavily infected with Schistosoma mansoni. J Infect Dis 146:20-29, 1982.

372. Sullivan WG, Koep LJ: Common bile duct obstruction and cholangiohepatitis in clonorchiasis. JAMA 243:2060-2061, 1980.

373. Swenson PD, Escobar MR, Carithers Jr. RL, et al.: Failure of preexisting antibody against hepatitis $B$ surface antigen to prevent subsequent hepatitis B infection. J Clin Microbiol 18:305-309, 1983.

374. Szilagyi A, Mendelson J, Portnoy J, et al.: Caseating granulomas in chronic osteomyelitis: salmonellosis, tuberculosis or both? Can Med Assoc J 120:963-965, 1979.

375. Tabor E, Krugman S, Weiss EC, et al.: Disappearance of hepatitis B surface antigen during an unusual case of fulminant hepatitis B. J Med Virol 8:277282, 1981.

376. Tabor E. Seeff LB, Gerety RJ : Chronic non-A, non-B hepatitis carrier state. N Engl J Med 303:140-143, 1980.

377. Tacket CO, Hickman F, Pierce GV, et al.: Diarrhea associated with Vibrio fluvialis in the United States. J Clin Microbiol 16:991-992, 1982.

378. Takekoshi Y, Shida N, Saheki Y, et al.: Strong association between membranous nephropathy and hepatitis-B surface antigenemia in Japanaese children. Lancet ii:1065-1068, 1978.

379. Taylor BG, Zafarzai MZ, Humphreys DW, et al.: Nodular pulmonary infiltrates and septic arthritis associated with Yersinia enterocolitica bacteremia. Am Rev Respir Dis 116:525-529, 1977. 
380. Taylor DN, Wachsmuth IK, Shangkuan YH, et al.: Salmonellosis associated with marijuana. N Engl J Med 306:1249-1253, 1982.

381. Taylor WR, Schell WL, Wells JG, et al.: A foodborne outbreak of enterotoxigenic Escherichia coli diarrhea. N Engl J Med 306:1093-1095, 1982.

382. Thompson Jr. CM, Gilligan PH, Fisher MC, et al.: Clostridium difficile cytotoxin in a pediatric population. Am J Dis Child 137:271-274, 1983.

383. Thoren A, Wolde-Mariam T, Stintzing G, et al.: Antibiotics in the treatment of gastroenteritis caused by enteropathogenic Escherichia coli. J Infect Dis 141:27-31, 1980.

384. Tiollais P, Charnay P, Vyas GN: Biology and hepatitis B virus. Science 213:406-411, 1981.

385. Tomkins A: Nutritional status and severity of diarrhoea among pre-school children in rural Nigeria. Lancet i:860-862, 1981.

386. Trevisan, Cadrobbi P, Crivellaro C, et al.: Virologic features of chronic hepatitis B virus infection in childhood. J Pediatr 100:366-372, 1982.

387. Vandepitte J, Lemmens P, De Swert L: Human edwardsiellosis traced to ornamental fish. J Clin Microbiol 17:165-167, 1983.

388. vanSonnerberg E, Ferrucci Jr. JT, Mueller PR, et al.: Percutaneous radiographically guided catheter drainage of abdominal abscesses. JAMA 247:190-192, 1982.

389. Vantrappen G, Ponette E, Geboes K, et al.: Yersinia enteritis and enterocolitis: gastroenterological aspects. Gastroenterology 72:220-227, 1977.

390. Vergani D, Masera G, Moroni G, et ail.: Histologic evidence of hepatitis-Bvirus infection with negative serology in children with acute leukemia who develop chronic liver disease. Lancet i:361-364, 1982.

391. Verlenden WL III, Frey CF: Management of liver abscess. Am J Surg 140:53$59,1980$.

392. Vernon AA, Schable C, Francis D: A large outbreak of hepatitis A in a daycare center. Am J Epidemiol 115:325-331, 1982.

393. Vesikari T, Isolauri E, Delem A, et al.: Immunogenicity and safety of live oral attenuated bovine rotavirus vaccine strain RIT 4237 in adults and young children. Lancet ii:807-811, 1983.

394. Viscidi RP, Bartlett JG: Antibiotic-associated pseudomembranous colitis in children. Pediatrics 67:381-386, 1981.

395. Wade JC, Newton B, McLaren C, et al.: Intravenous acyclovir to treat mucocutaneous herpes simplex virus infection after marrow transplantation. Ann Intern Med 96:265-269, 1982.

396. Ware AJ, Cuthbert JA, Shorey J, et al: A prospective trial of steroid therapy in severe viral hepatitis. Gastroenterology 80:219-224, 1981.

397. Warren KS: The pathology, pathobiology and pathogenesis of schistosomiasis. Nature 273:609-612, 1978.

398. Warren KS, Mahmoud AAF: Algorithms in the diagnosis and management of exotic diseases. XXII. Ascariasis and toxocariasis. J Infect Dis 135:868872, 1977.

399. Webb S, Fowler R: Giardiasis and ulcerative colitis in an infant. N Engl J Med 306:1551, 1982.

400. Weiland O, Berg JVR, Flehmig B, et al.: Acute viral hepatitis, types A, B and Non-A, Non-B: A prospective study of the epidemiological, laboratory 
and prognostic aspects in 280 consecutive cases. Scand J Infect Dis 13:247$255,1981$.

401. Weinstein JM, Elliott J, Tilford RH: Metastatic endophthalmitis due to Salmonella typhimurium. Arch Opthalmol 100:293-295, 1982.

402. Welch DF, Marks MI: Is Clostridum difficile pathogenic in infants? J Pediatr 100:393-395, 1982.

403. Welin SL, Grand RJ: Bloody diarrhea: complication of sulfasalazine. Mod Med Can 33:1712-1713, 1978.

404. Welsh JK, May JT: Anti-infective properties of breast milk. J Pediatr 94:19, 1979.

405. Williams C, Weber FT, Cullen J, et al: Hepatitis B transmission in school contacts of retarded $\mathrm{HB}_{\mathrm{s}} \mathrm{Ag}$ carrier students. J Pediatr 103:192-196, 1983.

406. Willson RA: Intercurrent hepatitis A in B viral hepatitis. JAMA 245, 2495, 1981.

407. Wilson R, Feldman RA, Davis J, et al.: Salmonellosis in infants: the importance of intrafamilial transmission. Pediatrics 69:436-438, 1982.

408. Wittman DH, Schassan H-H: Penetration of eight $\beta$-lactam antibiotics into the peritoneal fluid. Arch Surg 118:205-213, 1983.

409. Woelfel GF, Hansbrough JF: Spontaneous bacterial peritonitis and pneumoperitoneum. JAMA 249:921-922, 1983.

410. Wolfe MS: The treatment of intestinal protozoan infections. Med Clin North Am 66:707-720, 1982.

411. Wray D, Graykowski EA, Notkins AL: Role of mucosal injury in initiating recurrent aphthous stomatitis. Br Med J 283:1569-1570, 1981.

412. Wyler DJ, Wahl SM, Wahl LM: Hepatic fibrosis in schistosomiasis: egg granulomas secrete fibroblast stimulating factor in vitro. Science 202:438440, 1978.

413. Wyllie R, Fitzgerald JF: Bacterial cholangitis in a ten-week-old with fever of undetermined origin. Pediatrics 65:164-167, 1980.

414. Yolken RH, Bishop CA, Townsend TR, et al.: Infectious gastroenteritis in bone-marrow-transplant recipients. N Engl J Med 306:1009-1012, 1982.

415. Yolken RH, Lawrence F, Leister F, et al.: Gastroenteritis associated with enteric type adenovirus in hospitalized infants. J Pediatr 101:21-26, 1982.

416. Yolken R, Murphy M: Sudden infant death syndrome associated with rotavirus infection. J Med Virol 10:291-296, 1982.

417. Yolken RH, Whitcomb LS, Marien G, et al.: Enzyme immunoassay for the detection of Clostridium difficile antigen. J Infect Dis 144:378, 1981.

418. Zeldis JB, Dienstag JL, Gale RP: Aplastic anemia and non-A, non-B hepatitis. Am J Med 74:64-68, 1983. 